\title{
THE EVOLUTION OF \\ INTERNATIONAL POLICING IN THE PACIFIC: \\ A CRITICAL ANALYSIS
}

\author{
BY \\ BRONWIN M. BOSWELL
}

\begin{abstract}
A thesis
submitted to the

Victoria University of Wellington

in fulfilment of the requirements for the degree of Master of Arts in International Relations
\end{abstract}

School of History, Philosophy, Political Science and International Relations

Victoria University of Wellington

March 2010 
In Loving Memory of my Parents

Douglas Eric Boswell

(1923-1995)
Margaret Ethel May (neé Hooper)

(1923-2007) 
I have been involved in policing and crime prevention for many years. I was a sworn member of Victoria Police (Australia), a crime prevention coordinator in a New Zealand community, and am currently employed by New Zealand Police (NZP). My interest in international policing grew as I realised more and more police were serving in a number of roles overseas. At first, I thought this a nice departure from normal duties for those lucky enough to take up opportunities to contribute to policing in other countries. Deeper thought followed about the juxtaposition of western models of policing, international relations and the customs of developing countries. The more I tried to find out the more questions were raised. Soon it was evident that little had been written about international policing and even less about international policing in relation to the Pacific. The need for research that combines the study of cross-border policing of crime and criminality with international relations scholarship has been identified by Peter Andreas and Ethan Nadelmann in their 2006 co-authored book. ${ }^{1}$ A growing body of literature ${ }^{2}$ examines policing and development in the Pacific, but is mainly centred on conflicts in Melanesia with particular emphasis on the Regional Assistance Mission to Solomon Islands (RAMSI). Apparently, no single work discusses the needs of police services in the Pacific in relation to domestic policing and international cooperation. This work seeks to fill that gap.

\footnotetext{
1 Peter Andreas and Ethan Nadelmann, Policing the Globe: Criminalisation and Crime Control in International Relations (New York: Oxford University Press, 2006). This text provides a comparative study of international policing in the UK and US and as such does not discuss the Pacific region.

${ }^{2}$ M. Anne Brown, "Security and Development: Conflict and Resilience in the Pacific Islands Region," in Security and Development in the Pacific Islands, ed. M Anne Brown (Boulder, London: Lynne Rienner Publishers Inc, 2007), 1-32.; Andrew Goldsmith and J.W.E. Sheptycki, "Introduction," in Crafting Transnational Policing: Police Capacity-Building and Global Policing Reform, ed. Andrew Goldsmith and James Sheptycki, Onati International Series in Law and Society (Oxford, Portland: Hart Publishing, 2007), 1-28.; Abby McLeod, "Police Reform in Papua New Guinea," in Security and Development in the Pacific Islands: Social Resilience in Emerging States, ed. M Anne Brown (Boulder, London: Lynne Rienner Publishers Inc, 2007), 73-88.; Abby McLeod and Sinclair Dinnen, "Police Building in the Southwest Pacific - New Directions in Australian Regional Building," in Crafting International Policing: Police Capacity-Building and Global Policing Reform, ed. Andrew Goldsmith and James Sheptycki, Onati International Series in Law and Society (Oxford, Portland: Hart Publishing, 2007), 295-328.; Abby McLeod and Juani O'Reilly, "Pacific Policing," in The SAGE Dictionary of POLICING, ed. Alison Wakefield and Jenny Fleming (London, Thousand Oaks, New Dehli, Singapore: SAGE Publications Ltd, 2009), 213-215.; James Sheptycki, "Introduction," in Issues in Transnational Policing, ed. J.W.E. Sheptycki (London, New York: Routledge, 2000), 1-20.
} 


\section{ACKNOWLEDGEMENTS}

This thesis would not have seen the light of day without significant financial, intellectual and personal contributions and encouragement from five groups of people who touch my life in many ways and to all of whom I am forever grateful.

First, the New Zealand Police (NZP). The late Superintendent Steve Fitzgerald supported my application and proposal to New Zealand Police for full time study leave, his periodic offering of 'pearls of wisdom', and a lengthy informal conversation before his untimely tragic death in June 2008 provided moments of laughter, inspiration and hope. Superintendent Steve Christian also supported my application and offered frequent verbal support. The selection panel at the Royal New Zealand Police College accepted my application and granted one year's full time paid study leave to complete this degree, while Dr Steve Kay and Inspector Sean McManus acted as mentors and conduits to police knowledge. Without such support, this thesis would have taken a lot longer to complete.

Second, Victoria University of Wellington. Professor Elizabeth McLeay, coordinator for postgraduate studies in the Political Science and International Relations Programme accepted and helped structure my proposal. Dr Ray Goldstein, my principal academic supervisor provided wise counsel and challenged my reasoning when I needed it. I am thankful he agreed to furnish scholarly advice even after retirement and that Professor McLeay willingly took on this role after my unexpected health journey and her own retirement. I wonder what is it about me that forces my supervisors into retirement?

Third, the participants who agreed to answer my questions and be interviewed. Without their input this thesis would be mainly a regurgitation of previously published studies. I value the trust placed in me and I am privileged to have the opportunity of presenting their voices, and I only hope I have done so fairly and justly. My wish is that this research helps ensure their needs for policing in the Pacific are met.

Fourth, several friends who helped me through the dark days of doubting I would ever finish this thesis. Monica Lichti, offered coffees at the end of writing draft chapters and were a tasty carrot and her technical assistance was invaluable and de-stressing. Dr Lizzie Stanley always said I could do it and then scared me half to death with talk of a PhD. Dr Fiona Hutton helped fashion the 
methods, questions and limitations section. Nibor Sretep, Debra Lee and Louie Braae made themselves available for coffee, wine and conversation, often at short notice.

Fifth, my enduring saviours, family. Andrew cheerfully undertook the cooking, cleaning and household chores, lessening the burden of domestic duties. Douglas gave encouragement via Google Chat $^{\odot}$ while in Germany doing his own amazing work. Hannah contributed her treasured catch phrase 'Mum, now that you're not working...' and also assisted at home with encouragement and love. Morag and Graeme's encouragement spurred me on. Julie, Dianne and Carolyn deserve thanks for listening and trying to understand why I had to do this. 
ACKNOWLEDGEMENTS IV

TABLE OF CONTENTS VI

$\begin{array}{lll}\text { TABLE OF FIGURES } & \text { VIII }\end{array}$

ACRONYMS IX IX

KEY TERMS AND CONCEPTS XI

Metropolitan State $\quad x i$

Rule of Law $\quad x i$

Sovereignty $x i$

The Pacific Way xii

CHAPTER ONE: INTRODUCTION

$\begin{array}{ll}\text { Research Methods and Methodology } & 6\end{array}$

CHAPTER TWO: POLICING, COLONISATION AND GLOBALISATION, 11

Pacific Policing in the International Context 11

External Policies and Pacific Island Countries 16

Globalisation, Internationalisation \& Regionalisation 20

Conclusion 23

CHAPTER THREE: THE POLITICS OF POLICING PACIFIC ISLAND COUNTRIES 25

$\begin{array}{lr}\text { Mapping Pacific Policing } & 28\end{array}$

Issues in Pacific Policing $\quad 34$

Towards a New Approach $\quad 45$

Summary 46

$\begin{array}{ll}\text { Conclusion } & 48\end{array}$

CHAPTER FOUR: REGIONAL COOPERATION AND DYNAMICS

$\begin{array}{ll}\text { The Pacific Community } & 50\end{array}$

Pacific Islands Chiefs of Police (PICP) 55

Pacific Islands Forum (PIF) 59

Pacific Islands Law Officers' Network (PILON) 66

$\begin{array}{ll}\text { Oceania Customs Organisation (OCO) } & 67\end{array}$

Pacific Islands Association of Non-government Organisations (PIANGO) 68 
$\begin{array}{ll}\text { Pacific Immigration Directors' Conference (PIDC) } & 69\end{array}$

$\begin{array}{ll}\text { Pacific Regional Policing Initiative (PRPI) } & 70\end{array}$

Global Partnership for the Prevention of Armed Conflict (GPPAC), Pacific People

$\begin{array}{ll}\text { Building Peace (PPBP) } & 70\end{array}$

Pacific Transnational Crime Coordination Centre (PTCCC) 71

$\begin{array}{ll}\text { Others } & 71\end{array}$

Asia-Pacific Economic Cooperation (APEC) 71

Association of Southeast Asian Nations (ASEAN) and ASEAN Regional Forum

(ARF) 71

$\begin{array}{ll}\text { Sub-regional bodies } & 72\end{array}$

Cooperation and Collaboration $\quad 72$

$\begin{array}{ll}\text { Summary } & 77\end{array}$

CHAPTER FIVE: RECOMMENDATIONS AND CONCLUSIONS $\quad 79$

$\begin{array}{ll}\text { Consideration of Culture and Custom } & 79\end{array}$

$\begin{array}{ll}\text { The Balance of Power } & 80\end{array}$

Methods of Engagement $\quad 82$

AID $\quad 85$

$\begin{array}{ll}\text { Conclusions } & 86\end{array}$

$\begin{array}{ll}\text { REFERENCES } & \mathbf{8 7}\end{array}$

APPENDIX ONE: AN APPROACH to POLICING IN THE PACIFIC 95

APPENDIX TWO: POPULATIONS \& POLICE NUMBERS 97

APPENDIX THREE: EXTERNAL AID \& GDPPC 99

$\begin{array}{ll}\text { APPENDIX FOUR: INTERVIEW SCHEDULE } & 101\end{array}$

$\begin{array}{ll}\text { APPENDIX FIVE: CONSENT FORM } & 102\end{array}$ 
Figure 3 - Total Population and Police Numbers by PICP Member Country as at 2008 unless otherwise specified.

Figure 4 - External States by Country, Population, GDP, Government Type and Aid 


\begin{tabular}{|c|c|}
\hline ANZAC Pact & Australia, New Zealand Army Corp \\
\hline AFTA & ASEAN Free Trade Area \\
\hline ANZUS & Treaty between Australia, New Zealand and United States \\
\hline APEC & Asia-Pacific Economic Cooperation \\
\hline ARF & ASEAN Regional Forum \\
\hline ASEAN & Association of Southeast Asian Nations \\
\hline ASEAN + 3 & ASEAN plus China, Japan and South Korea \\
\hline ASEAN PMC & ASEAN Post Ministerial Conference \\
\hline ASEANPOL & Meeting of the Chiefs of National Police of ASEAN member countries \\
\hline ASPAC & Asian and Pacific Council \\
\hline AusAID & Australian Agency for International Development \\
\hline & Committee for Coordination of Joint Prospecting for Mineral Resources in \\
\hline CCOP/SOPAC & South Pacific Offshore Areas \\
\hline CROP & Council of Regional Organisations Pacific \\
\hline CSCAP & Council for Security Cooperation in the Asia Pacific \\
\hline DAC & Development Assistance Committee \\
\hline DFAT & Department of Foreign Affairs and Trade (Australia) \\
\hline EEZ & Exclusive Economic Zone \\
\hline EPG & Eminent Persons Group \\
\hline ESCAP & Economic and Social Commission for Asia and the Pacific \\
\hline EU & European Union \\
\hline GDPPC & Gross Domestic Profit Per Capita \\
\hline ILO & International labour Organisation \\
\hline IMF & International Monetary Fund \\
\hline MFAT & Ministry of Foreign Affairs (New Zealand) \\
\hline NGO & Non-governmental organisation \\
\hline NZAID & New Zealand Agency for International Development \\
\hline OCO & Oceania Customs Organisation \\
\hline ODA & Overseas Development Assistance \\
\hline OECD & Organisation for Economic Cooperation and Development \\
\hline OPTAD & Organisation of Pacific Trade, Aid and Development \\
\hline PFTA & Pacific Free Trade Area \\
\hline PIDC & Pacific Immigration Directors Conference \\
\hline PIDP & Pacific Islands Development Project \\
\hline PIF & Pacific Islands Forum \\
\hline PIFS & Pacific Islands Forum Secretariat \\
\hline PICP & Pacific Islands Chiefs of Police \\
\hline
\end{tabular}




$\begin{array}{ll}\text { PICP-S } & \text { Pacific Islands Chiefs of Police Secretariat } \\ \text { PIPA } & \text { Pacific Island Producers Association } \\ \text { PNG } & \text { Papua New Guinea } \\ \text { PRAN } & \text { Pacific Regional Assistance to Nauru } \\ \text { SPARTECA } & \text { South Pacific Regional Trade and Economic Cooperation Agreement } \\ \text { SPC } & \text { Secretariat of Pacific Community (Previously South Pacific Commission) } \\ \text { SPF } & \text { South Pacific Forum } \\ \text { SPREP } & \text { South Pacific Regional Environment Programme } \\ \text { UNDP } & \text { United Nations Development Programme } \\ \text { UNEP } & \text { United Nations Environment Programme } \\ \text { USAID } & \text { United States Agency for International Development } \\ \text { WTO } & \text { World Trade Organisation }\end{array}$




\section{METROPOLITAN STATE}

The term metropolitan state is used quite extensively throughout this thesis and means the countries that built empires through colonising smaller countries and nations across the globe over the centuries. In relation to the Pacific and particularly this thesis, the metropolitan states are Australia, New Zealand, France, the United Kingdom, the United States of America, Chile, and the Netherlands (Holland). All of these countries were or are still colonisers and have an impact on the developing countries of the Pacific Islands.

\section{RULE OF LAW}

"The Rule of Law, in it most basic form, is the principle that no one is above the law. The rule follows logically from the idea that truth, and therefore law, is based upon fundamental principles which can be discovered, but which cannot be created through an act of will.

The most important application of the rule of law is the principle that governmental authority is legitimately exercised only in accordance with established procedural steps that are referred to as due process. The principle is intended to be a safeguard against arbitrary governance, whether by a totalitarian leader or by mob rule. Thus, the rule of law is hostile both to dictatorship and to anarchy." ${ }^{3}$

\section{SOVEREIGNTY}

'Highly contested term - the highest law-making authority; or, the most effective law enforcement power. The recognition of an international frontier establishes two separate but interdependent notions of order. There is an internal order, which rests on the state and its relationship with its people, and there is an external order that is managed (or created) by the relations amongst states. ${ }^{4}$

\footnotetext{
3 "Rule of Law," LexisNexis, http://www.lexisnexis.co.nz/about-us/rule-of-law/default.aspx (accessed 3 March, 2009).

${ }^{4}$ Richard Herr, "The Concept of the 'Failed State': A Brobdingnagian View from Lilliput," in New Zealand in a Globalising World, ed. Ralph Pettman (Wellington: Victoria University Press, 2005), 99109.
} 


\section{THE PACIFIC WAY}

The term was coined by Fiji's then Prime Minister, Ratu Sir Kamisese Mara ${ }^{5}$ in 1972 as a way of explaining to ex-colonial rulers, and new partners in the South Pacific Forum how Pacific peoples went about doing things. Mara was keen to shy away from what is often seen as confrontational and contradictory Western political discourse and stressed dialogue, consensus and mutual understanding as three key factors of collective engagement in creating a common Pacific regional identity. ${ }^{6}$ These three key factors are further underpinned by moderation, respect, inclusiveness, negotiation, adaptation and compromise, ${ }^{7}$ all of which are necessary in facilitating the journey of regional and global development and growth. This said, there is criticism of Mara's Pacific Way by some who see it as an excuse to slow progress and stifle freedom of expression. ${ }^{8}$

\footnotetext{
${ }^{5}$ Steven Ratuva, "Mara's 'Pacific Way' Legacy: Remembering The Pacific's Dominant Leader," Pacific Magazine, 1 June 2004.

${ }^{6}$ Ibid.

7 Elise Huffer, "Regionalism and Cultural Identity: Putting the Pacific back into the plan," in Globalisation and Governance in the Pacific Islands, ed. Stewart Firth (Canberra: Australian National University (ANU) E Press, 2006).

${ }^{8}$ Ratuva, "Mara's 'Pacific Way' Legacy: Remembering The Pacific's Dominant Leader." Confidential interview, Respondent A:05, Apia, 2008. Confidential interview, Respondent B:01, Wellington 2008. Confidential interview, Respondent B:02, Wellington 2008. Confidential interview, Respondent B:03, Wellington 2008. Confidential interview, B:04, Wellington 2008.
} 


\section{CHAPTER ONE: INTRODUCTION}

The main objective of this thesis is to enhance our understanding of the phenomenon of international policing and the unique internal and external pressures on policing jurisdictions within the Pacific Region. Pressures arise from a complex of situational factors including: the isolated nature of the region; varying levels of development in its small island states; histories of colonisation and decolonisation and self-determination; United Nations Declarations on human rights; unprecedented amounts of donor funding; neighbouring states' national security concerns and increasing transnational organised crime. Such pressures are pitted against low populations, an area that contains twenty percent of the world's cultures and languages but only one percent of the population, ${ }^{9}$ a lack of technology and other resources, fiscally dependent economies, internal conflicts, emerging understandings of globalisation, regionalisation and internationalisation, and policing methods that are considered naïve by advanced western countries. Policing these complexities requires a deep understanding of the individual countries and cultures of the Pacific, their laws, and of policing.

Most countries in the Pacific carry the burden of colonial structures of governance that are expensive to maintain and follow western models that bear little, if any, resemblance to Pacific Islands' customary ways of living. For the strong familial cultures of the Pacific they are difficult to understand and seem odd and alien. On the other hand, more recently colonial standards have raised awareness of the rights of humans to be free from hunger, fear and pain and to be treated fairly and without violence. But, Westerners must understand the realities of life in developing small island countries, particularly those in the Pacific. Populations are small and scattered over thousands of islands. There is often only one urban centre where large percentages of populations have domiciled to take up or seek work. There is a huge difference in the way people live in urban centres compared to rural or outlying islands. There is an even bigger difference between the way urbanised Pacific Island peoples live and the way urbanised westerners live. Many outlying islands and villages do not have police at all, or access to clean fresh water, medical services or education. It

9 K.R. Howe, "The Last Frontier," in VAKA MOANA: Voyages of the Ancestors, ed. K.R. Howe (Auckland: David Bateman Ltd, 2006), 14-21. 
can take days on foot to get to the nearest medical centre or police post to report a medical or criminal event. Often, there are no telephones, roads or cars. People deal with emergencies or life's events the way they always have; mothers and babies die because of isolation from medical care and these deaths are not reported because of distance and effort, ${ }^{10}$ and crime, for the same reasons may be dealt with in traditional village manner. Tribal justice is often described by westerners as arbitrary and brutal and as such can also be regarded as a fundamental breach of human rights, but not always. In many cases tribal justice is a vast and successful improvement on the impractical, expensive and unsuccessful 'solution' imprisonment offers western countries...even, and perhaps especially, for serious crime such as murder. As one local observer commented:

It's working. Look at it this way. Some of these are first time offenders, they were just drunk, and they kill somebody. You lock them up, you and I don't get anything out of that. But through [tribal] process the guy who killed my son replaces my son. Then our family become one. So when I have work my son, the one who killed my son, is doing all my work like he is my son, your family come and help me. So he will fish for me, he will collect copra, clear the land, just like he was my real son. So in a way it's a win-win. And everybody's happy. We get used to it. That's our custom. When we apologise the whole clan apologises to my clan and we forgive you. We are small. We know each other. That's why it's effective. ${ }^{11}$

The question remains though, and the main question this thesis attempts to answer is, not whether breaches of human rights should be ignored, but how external aid providers can help Pacific Islands' police and other government agencies update traditional solutions to meet human rights conventions and the rule of law, within the confines of cultural appropriateness.

Embedded in these complexities is a very real desire for the police services of the region to take control of their issues and find solutions together. The Pacific Islands Chiefs of Police (PICP) has been working to these ends since 1970 and as this organisation has grown and its focus changed, the nature of crime has also changed. Globalisation and migration have introduced the dangerous and covert

10 Dame Carol Kidu, "Maternal health in PNG- reality, challenges and possible solutions," in Eliminating World Poverty: Global Goals and Regional Progress Symposium (Wellington: Institute of Policy Studies, 2009).

${ }^{11}$ Interview A3. 
world of transnational organised crime (TOC) and its co-existent response, criminal intelligence, to the waters and sands of the Pacific. These advanced crime issues demand sophisticated processes carried out by well trained analytical personnel supported with sufficient financial resources. The police services of the Pacific could easily be overwhelmed by the more experienced metropolitan countries intent on using policing as a tool of regional control. Therefore, while there is a vital role for the well established PICP, there are a number of issues that must be addressed to allow this to happen.

There are a number of prevalent beliefs about policing internationally. One is that Western styled political democracy coupled with democratic policing is the only solution to building and maintaining peace in the wake of internal conflict; a second is that the elements of modern domestic policing can be exported in their entirety to emerging or developing countries leading to the old adage 'policing is policing is policing'; and a third assumption is that capacity building can only be carried out by representatives of government. I challenge these assumptions by mapping international policing in the Pacific; documenting the voices of the Pacific in relation to issues and potential solutions raised in interviews; and offering a new approach to meet the policing needs of the emerging countries of the Pacific, and the security concerns of donor countries. However, I do not challenge the essential transferability of internationally agreed values and standards that are critical in ensuring the rights of all humans are honoured and upheld.

My first argument is based on an understanding of 'the rule of law'. The rule of law is simply described as the legislation set by a legitimate government and the belief that no-one is above the law. This means then, that it is the rule of law according to the laws of host countries, and not the laws of the countries contributing to peace building in those host countries, which must be honoured and upheld. The rule of law does not extend to dictatorships or other instruments of governance taken by force, but my own analysis of the concept is that it does extend to traditional or tribal models of governance because they have the legitimacy of the people. I argue that the duties and tasks of international policing in the Pacific should be carried out transparently, honestly and fairly without prejudice to the rule of law and take into account indigenous models of law.

My second argument is based on the processes of state and capacity building. Whilst a whole of government approach is desirable because it is inclusive of all parts of government, I argue that contributing countries assert their own values 
in this restructuring, which reflect their own legal concepts rather than the essence of the host's rule of law. I posit that such a situation is undesirable and that whole of government change and resultant stability can only properly be achieved by insisting that host countries lead and drive change while contributing countries offer advice and guidance.

My third argument is based on the changing political environment within the Pacific which challenges relationships based on colonial heritage. The increasing presence of China with an ever larger purse must cause some consternation within the foreign affairs departments of both Australia and New Zealand and also the US. China's donations come with conditions that are not always overt, but without expectations of how they will be used, whereas the significant investments made by Australia and New Zealand, in the area they both claim as within their neighbourhood, demand close monitoring and accountability. These are heavy demands on cultures with a past based on unwritten language and story telling. I argue that for transparency and accountability an administrative partnership that represents all donor countries is required to oversee and assess the needs of developing police jurisdictions, to distribute donations accordingly and to evaluate the results of such spending.

My fourth argument is based on the level of involvement of metropolitan countries in the Pacific. Heavy investment in the Pacific by Australia and New Zealand in particular has resulted in these two countries taking leadership and 'board' positions in a number of institutions throughout the Pacific, including the Pacific Islands Forum and the Pacific Islands Chiefs of Police. I argue that such positions result in a conflict of interest where countries take part in decision making and also donate funds; therefore, metropolitan representatives should take a consultancy role rather than a leadership one enabling decision makers of the Pacific to seek advice but independently to make their own decisions about matters that affect them.

For the purposes of this thesis, the Pacific Region is limited to the Pacific Island Countries (PICS) and territories lying in the Pacific Ocean from the Northern Mariana Islands and the US State of Hawaii in the north, to New Zealand in the South, and from the Republic of Palau and Papua New Guinea in the west, to Rapanui $^{12}$ in the east. Hawaii and Rapanui, while not independent states, are included for their geographical positioning in Polynesia and their shared

12 Rapanui is a province of Chile. 
settlement histories. ${ }^{13} \quad$ New Zealand is in the unique position of being both a metropolitan state and a Pacific Island country geographically sited in Polynesia. Australia is not treated here as a Pacific Island Country although it is usually included in Oceania, and Indonesia is omitted because it more naturally forms part of the Asian Region. Timor Leste has been included in the Pacific region by some commentators since it became independent from Indonesia in 2005 and although it is not considered as a PIC here, it does warrant examination, not only for similarities in its peace building operations, but also for kinship and a sense of where it belongs. In all, twenty-six PICs and territories are included in this study. ${ }^{14}$

Many commentators consider the island countries of the Pacific to be part of the Asia-Pacific Region, partly because they were originally settled by migrants from Asia. While Asia and the Pacific Islands regions display intraregional disparity in economic and technical development, ${ }^{15}$ and have a number of ongoing conflicts, ${ }^{16}$ the Pacific Islands region is sufficiently distinct from Asia through other factors; the PICs share their own significantly different histories, languages and religions, smaller populations than those of Asia, a lack of land borders ${ }^{17}$, and geographical isolation. Thus this thesis considers the Pacific Islands to constitute a region on its own. ${ }^{18}$ The Pacific Region is further grouped into three sub-regions: Micronesia, Melanesia and Polynesia, each unique but with overlapping histories and current needs. Interestingly, most of the ongoing tensions or conflicts occur in the most heavily populated sub-region, Melanesia. Being in close geographical proximity to Australia, Melanesian conflicts impact significantly on Australia's political discourse and foreign policy, particularly since

\footnotetext{
13 Each strives for indigenous self-determination putting them in the same situation as New Caledonia and Wallis and Futuna, and on that basis cannot be excluded even though neither is a member of any of the regional organisations highlighted later in this thesis. Grant McCall, "Rapanui (Easter Island)," Fiji Times Ltd, http:www2.hawaii.edu/ ogden/piir/pacific/Rapanui.html (accessed 30 December, 2008), "A Brief History," http://www.samoa.co.us/history.html (accessed 9 June, 2008). "Hawaii History," Hawaiian Roots Website, http://www.hawaiian-roots.com/hawaiihistory.htm (accessed 30 December, 2008).

${ }^{14}$ States and territories covered here are: American Samoa, Australia, Commonwealth of Northern Marianas, Cook Islands, Federated States of Micronesia, Fiji, French Polynesia, Guam, Hawaii (USA), Kingdom of Tonga, Kiribati, Nauru, Nouvelle Caledonie, New Zealand, Niue, Papua New Guinea, Pitcairn Island (UK), Rapanui (Chile), Republic of Marshall Islands, Republic of Palau, Solomon Islands, Samoa, Timor Leste, Tokelau, Tuvalu, and Vanuatu.

15 "The World Factbook," Central Intelligence Agency, https://www.cia.gov/library/publications/theworld-factbook/geos/zn.html (accessed 8 October, 2008).

${ }^{16}$ Benjamin Reilly and Kennedy Graham, "Conflict Through Asia and the Pacific: Causes and Trends," in Searching for Peace in Asia Pacific: An Overview of Conflict Preventions and Peacebuilding Activities, ed. Annelies Heijmans, Nicola Simmonds, and Hans van de Veen (Boulder, Covent Garden: Lynne Reinner Publishers, Inc, 2004), 9-22.

17 The exception is Papua New Guinea which shares its island with Irian Jaya.

18 It is acknowledged that regions overlap for a number of reasons, including for matters of convenience. However, this study simply considers the Pacific as described and studies only those included in footnote 8 .
} 
the September 2001 terrorist activity on US soil, and the October 2002 terrorist bombings in Bali, Indonesia.

Policing and justice models in many PICs reflect the Westminster system but with some local cultural flavour, while others reflect the French or USA systems, but all are heavily supported through the provision of personnel, resources and training either by Australia, New Zealand, France or the US or a combination of them, including the European Union. The Regional Assistance Mission to Solomon Islands (RAMSI) has been a feature of the Solomon Islands since July 2003 and currently has five hundred and seventy-two personnel involved as civilians, Participating Police Force (PPF), and military from fifteen PIF countries. ${ }^{19}$ Apart from RAMSI, personnel from Australia and New Zealand are involved in capacity building roles in the police services of Cook Islands, Nauru, Niue, Tonga and Timor Leste.

\section{ReseARCH METHOdS AND METHOdOLOGY}

I have chosen to approach the study through both external and internal lenses. These are my own terms. The former simply means the view seen by looking at what is considered a problem from those external to it but with the 'power' to change or solve it. Conversely, an internal lens means exploring issues or situations from the inside by those involved in them. These two views often overlap, but more specifically, the external lens is used to provide a political overview of metropolitan interests in the region while the internal lens offers a comprehensive overview of organisations within the Pacific. Utilising both views demonstrates the multiplicity of the region's challenges.

To gather an appreciation of the complexities of the Pacific Region I am reminded of Max Weber's verstehen - the deep understanding one is afforded from standing in another man's shoes, ${ }^{20}$ and which cannot be expressed in numbers. Therefore, the design of this research was based on a flexible qualitative approach seeking to find out what and why, rather than providing a quantitative assessment of how much and how many. In-depth interviews provided powerful and vibrant stories as well as data about the impacts of metropolitan states, regionalisation and policing. ${ }^{21}$

19 Administrator, "Contributing Nations," Regional Assistance Mission to Solomon Islands, http://www.ramsi.org/node/8 (accessed 09 January, 2009).

${ }^{20}$ Max Weber (1864-1920), one of the founding fathers of sociology.

21 Zina O'Leary, The Essential Guide to Doing Research (London, Thousand Oaks, New Delhi, Singapore: Sage Publications Ltd, 2004; reprint, 2007)., Fiona Hutton, 
The use of semi-structured one-on-one interviews with key informants was deemed appropriate to the complex nature of the region and the research questions, so an interview schedule was designed around six sections. ${ }^{22}$ The first section asked respondents about their roles and organisations; the second related to the Pacific Islands Chief of Police, ${ }^{23}$ its regional policing-focus, and opinions on its success; the third section focussed on country donations and contributions; the fourth asked questions about regional collaboration and cooperation; the fifth discussed perceptions of power across the region and the most important factors impacting on policing and the region; and the sixth and final section related to policing models that have been developed or left behind by colonisers, and the respondent's vision of the future of policing in the Pacific. The face-to-face semi-structured interviews offered the opportunity to probe for clarification or further information. Because respondents originated from a wide range of countries, consideration was given to the need for interpreters. However, this proved unnecessary as all respondents spoke English to a reasonable or high standard. Once the data was collected it was transcribed to word documents identified only by the alphanumeric code allotted and transferred to a qualitative analysis tool, NVivo8.

Interviews were carried out in two stages, in Apia, Samoa, in September 2008, and in Wellington, New Zealand, between October and December 2008. Written responses were obtained from some Australian contributors. Respondents were approached by mail and telephone with a request for an interview, provided with written information about the research, and given a consent form which they were asked to sign prior to the interview. ${ }^{24}$ All respondents requested a synopsis of the thesis after it was completed with one requesting a copy of the full thesis. Prior to the interview, respondents were given an opportunity to seek clarification about the research and to ask questions about it. All face-to-face interviews, with one exception, were digitally recorded. All respondents were offered and given confidentiality because of perceived or real sensitivities between metropolitan and small island state actors. Respondents are therefore only identified by alphanumeric code. Each interview took between thirty and ninety minutes. After the interview had been completed respondents were given a small gift to thank them for their time, such as a magnetic note pad, key ring or ornament depicting Maori imagery, which were received with surprise and

\footnotetext{
22 See Appendix Four.

${ }^{23}$ The Pacific Islands Chiefs of Police use the acronym PICP for their annual Conference and the PICP-S for the Chiefs Secretariat.

${ }^{24}$ See Appendix Five.
} 
appreciation. This entire procedure was approved by Victoria University of Wellington's Human Ethics Committee.

Because of the wide range of this study, attempts were made to recruit participants from police, foreign affairs and other regional organisations. It was important to speak to as many respondents from the Pacific Island Countries as possible and therefore I targeted the Pacific Islands Chiefs of Police and their Secretariat at Conference in Apia, Samoa. This strategy was successful and secured interviews from fourteen of the twenty-one members. In addition, nine interviews were conducted with personnel from donor countries and other regional organisations, including $\mathrm{PIFS}^{25}$ and PRPI, ${ }^{26}$ resulting in a total of twentythree interviews.

The interview data form much of the discussion throughout the thesis. Secondary data have been found in newspaper articles and other media reports.

Key stakeholders in the US, Japan, China and Taiwan were not interviewed for this study and therefore their views are absent. Given time and resource constraints such interviews were not feasible. However, an indication of the importance and impacts of these countries is gained from the respondents and secondary sources.

In the interests of time and word constraints, this thesis does not explore or examine five important areas which my research revealed as having an impact on the region and on building a deeper understanding of the issues. First, the history and current status of the relationship between New Zealand and Australia has a profound effect on the region. Historically bound through common origins the two countries formed a relationship of alliance and friendship, particularly when working in their common backyard, the Pacific. But this relationship has been continually tested during times of disagreement between the two where Australia has abandoned New Zealand in favour of the US. ${ }^{27}$ Although still seen as traditional partners, future academic study of the relationship, particularly as it relates to policing in the region would be useful. Second, a comparative study of the EU and PIFS would be beneficial, particularly considering governance through a regional parliament, a regional court and a regional police force. I do

\footnotetext{
25 The Pacific Islands Forum Secretariat.

26 The Pacific Regional Policing Initiative but is now know as the Pacific Policing Development Programme (PPDP).

${ }^{27}$ Especially during New Zealand's stand against nuclear ships entering her ports and harbours in the 1980 s, affecting the ANZUS Treaty.
} 
not advocate that an EU type model should be transferred to the Pacific ${ }^{28}$ since further study is warranted to provide a clearer picture of the complexities of the region and feasible ways of improving policing in the region. Third, African, Caribbean and Pacific (ACP) countries are designated developing countries by the United Nations, but as a group, have not been addressed in this thesis. A comparison of Caribbean and Pacific Countries could be of value particularly due to their geographical similarities. However, the complexities of each region need to be fully explored in relation to policing and regionalism. Fourth, although the judiciary is the beginning and end process of policing, there is no space in this thesis to conduct extensive analysis of the state of the judiciary in the Pacific. Fifth, the issue of aid was found to be significant. Many of the issues raised by respondents related to larger questions concerning international development assistance. As this was unanticipated, this thesis only examines this aspect very briefly, but it appears that my conclusions are in harmony with emerging critiques of the dominant approach and thus this interrelationship deserves future expanded analysis.

So far, in Chapter One I have introduced the topic and the region, drawn attention to key terms used throughout the thesis, presented the overall question and arguments, and identified the aims, methodology and limitations of the thesis. The remainder of this thesis is structured as follows.

Chapter Two provides a review of the literature relating to international policing methods and policy, globalisation and regionalisation, and foreign policies impacting on the Pacific.

Chapter Three presents respondents' visions of policing in the region and analyses the first set of questions through an 'external lens' concerning the impacts of metropolitan powers on Pacific Island Countries. ${ }^{29}$ The chapter maps current models of international policing in the region and introduces the metropolitan and other states involved in the region through their contributions of aid, thus contributing to my first argument concerning the understanding of 'the rule of law' and how aid providers contribute. The interviewees raised a number of issues including globalisation, colonisation, aid, personnel training and resources, and a lack of attention to their cultures and needs. These discussions relate to my second argument, the processes of state and capacity building. Chapter Three presents and analyses these issues and offers a new approach to

\footnotetext{
${ }^{28}$ Not to mention ongoing criticisms of the effectiveness and desirability of EU institutions.

${ }^{29}$ See p. 6 for an explanation of the terms 'external and internal lenses'.
} 
international policing in the region which meets the needs of the emerging countries of the Pacific, and the donor countries. This analysis enhances my third argument about the significance of the changing political environment and colonial relationships.

Chapter Four examines a second group of questions which arise from the view through an internal lens and studies the regional organisations in the Pacific, the dynamics caused by those organisations and how they impact on the development of regional architecture. An overview of the regional organisations is provided, followed by an assessment of the links of cooperation, collaboration and coordination of these efforts. The agencies analysed were selected on the basis of their links to political agendas, civil society and law enforcement. There is no other publication that explains or presents the organisations of the Pacific as comprehensively as this study and therefore it makes a valuable contribution to the current literature and understanding of the region. This chapter contributes to my fourth argument, which relates to a conflict of interest for fund providers who also take roles as decision makers within regional organisations; and supports the assessments made in Chapter Three.

Chapter Five draws together the main findings and proffers recommendations to inform future policy in relation to financial aid, policing, and ways of engaging with Pacific Island Countries. 


\section{CHAPTER TWO: POLICING, COLONISATION AND Globalisation,}

This chapter reviews the literature published up until the beginning of 2009 on policing in the Pacific. The works fall into three main areas: international policing methods and policy; globalisation and regionalisation, and the foreign policies of metropolitan and emerging powers with interests in the Pacific. ${ }^{30}$

\section{PACIFIC Policing In the INTERNATIONAl CONTEXT}

A common thread running through the development literature, both economic and political, is the acknowledgement that development cannot be progressed without law and order. Therefore, policing and police services are critical in making and keeping the peace and in maintaining social control. The Pacific Region offers a unique blend of policing needs ranging from traditional domestic policing carried out by local jurisdictions to international policing carried out under the guise of bilateral or multilateral agreements.

Transnational policing was transported by the British and French colonisers to many parts of the world. Today's open markets, increased communication and ease of transportation have forced police agencies to adapt their processes and build partnerships to allow them to keep up with the globalisation of crime, working across borders in the process. Transnational policing is based on highly technical surveillance and international information sharing about the movement of commodities by transnational criminals. But, state capacity-building is also a feature of transnational policing ${ }^{31}$ and scholarly research also includes paramilitary and counter-insurgency missions. ${ }^{32}$ Further discourse explores international responses to issues of transnational crime, ${ }^{33}$ terrorism, and peacekeeping efforts. ${ }^{34}$ Transnational law enforcement needs heightened cooperation between states to ensure justice is done outside the limited

\footnotetext{
30 Two important works have not been included here: Beth Greener, "The New International Policing" (Houndsmills: Palgrave Macmillan), and Miranda Forsyth's "A Bird That Flies with Two Wings" (ANU E-Press). They were both published after my research was completed but before my own work was submitted for grading in 2010.

31 Alison Wakefield and Eugene McLaughlin, "Transnational Policing," in The SAGE Dictionary of POLICING, ed. Alison Wakefield and Jenny Fleming (London, Thousand Oaks, New Dehli, Singapore: SAGE Publications Ltd, 2009), 308-310.

32 Andreas and Nadelmann, Policing the Globe.

33 Transnational crime types include piracy, slavery, trafficking in persons, drugs, exotic animals, firearms and other commodities, and people smuggling.

34 Goldsmith and Sheptycki, "Crafting Transnational Policing".
} 
jurisdictions of investigating officers involving cross-state cooperation as well as cross-agency cooperation. ${ }^{35}$ Much of the early literature finds transnational policing is mostly involved in covert surveillance combined with political liaison. ${ }^{36}$ That is, a high ranking member of a police service is deployed for a (usually) two year period to another country. This role generally sits in the high commission or embassy of the member's home country and is responsible for diplomatic and political liaison between the two countries, and also for intelligence matters.

The role of International Police Liaison officers is relatively new, involving only small numbers of police in postings all over the world. They are the physical and political interface between the police of the country of residence and their own domestic police service in matters of security, terrorism, transnational crime and immigration. ${ }^{37}$ However, liaison roles are taken up at a number of ranks depending on the originating police service, and their work can be carried out either from within the destination country's police service or the originating country's embassy. In Europe within the Schengen ${ }^{38}$ countries, liaison officers work side-by-side in offices at joint internal borders. In 2009, New Zealand Police had nine highly ranked personnel deployed in seven countries including Thailand, China, Australia, Indonesia, Fiji, England and the US. ${ }^{39}$ In 2007-2008 Australian Federal Police had eighty-three international liaison officers at various ranks deployed in twenty-seven countries. ${ }^{40}$ In 2008, China intended to improve its international policing relationships by sending anti-terrorism liaison officers to Australia and other countries concerned about the terrorist threat. This would add to the thirty liaison officers currently deployed by China in nineteen countries including the US, the UK, Russia, Thailand, Afghanistan, Pakistan, Turkey, Kyrgyzstan, Kazakhstan, and Uzbekistan. ${ }^{41}$

\footnotetext{
35 Sheptycki, "Introduction".

36 James W.E. Sheptycki, "Introduction," in Issues in Transnational Policing, ed. James W.E. Sheptycki (London, New York: Routledge, 2000), 1-20.

37 Didier Bigo, "Liaison Officers in Europe," in Issues in Transnational Policing, ed. J.W.E. Sheptycki (London, New York: Routledge, 2000), 67-99.

38 The agreement signed in Luxembourg by countries (France, Germany, Belgium, Luxembourg and the Netherlands - this number has increased as EU countries agree to the terms of free movement) allowing free movement of all travellers between signatory countries. The agreement ultimately removes the borders between these countries but also sets up the Schengen Information System and right of hot pursuit and surveillance within Schengen countries for the police services of member countries.

39 International Service Group, "International Service Group," New Zealand Police, http://www.police.govt.nz/service/overseas/faq.html (accessed 19 January, 2009).

40 Australian Federal Police, "International Liaison," Australian Federal Police (AFP), http://www.afp.gov.au/international/liaison.html (accessed 19 January, 2008).

${ }^{41}$ Zhu Zhe, "Police liaison officers to be sent to Australia," Chinadaily.com, http://www.chinadaily.com.cn/china/2008-12/03/content_7263529.htm (accessed 19 January, 2009).
} 
Theoretically, transnational policing is a natural progression of the globalisation of crime with the transnational law enforcement community enforcing the rules and laws made through relationships with trans-governmental networks. Applying international relations theory to international crime control, the need to control transnational crime requires greater cooperation through bilateral and multilateral agreements that eliminate obstacles to international crime control. Differing crime fighting systems, political tensions, or conflicting sovereignties are encouraged to cooperate in establishing generic criminal laws and guidelines and frameworks that smooth the progress of international law enforcement and justice. However, a different viewpoint emphasises the role of the state in facilitating bilateral and multilateral agreements that are weighted towards powerful states' interests and agendas. These often tend towards imposing, or retaining, colonial and imperialist models of law and justice. The dissolution of the British, French and other empires at the end of World War Two turned cooperation between the police jurisdictions within empires into international policing suggesting a simple exportation of western ideals and morals for political and economic gain. A third view is, that what is deemed criminal and in need of control, is changeable. Fear, suspicion and prejudice about religions such as Islam, moral indignation about human rights abuses occurring in other countries, and a renewed emphasis on what is deemed right and wrong, create a groundswell of action and reaction in the international order. These actions and reactions are encased in United Nations Declarations that create international criminal offences to protect the human rights of world citizens. ${ }^{42}$

In order to police breaches of human rights and particularly to bring peace and social control following internal conflicts, the United Nations is responsible for establishing peacekeeping missions. These are made up of personnel from a range of countries with the consent of conflicting parties which include the military as well as civilian police who help in securing short-term law and order and in long-term establishment of 'efficient, accountable national police forces which reinforce the rule of law'. ${ }^{43}$ According to the United Nations in December 2006 there were 8,482 police from ninety-one countries serving in thirteen UN Police missions. ${ }^{44}$ As of May 2007 there were 9,565 personnel from ninety-three

\footnotetext{
42 Andreas and Nadelmann, Policing the Globe; Goldsmith and Sheptycki (2007) also discuss this aspect of cooperation.

43 Jeremy Farrall, "Peacekeeping," in The SAGE Dictionary of POLICING, ed. Alison Wakefield and Jenny Fleming (London, Thousand Oaks, New Dehli, Singapore: SAGE Publications Ltd, 2009), 221223.

44 United Nations, "Summary of Contributors of UN Police Personnel: As of 5 December 2006," UN Police Magazine, December 2006.
} 
countries involved in thirteen missions. ${ }^{45}$ By December 2007 that number had risen to 11,077 personnel from one hundred and nineteen countries involved in eleven missions. ${ }^{46}$

An increase of internal conflicts over the last few years of the $20^{\text {th }}$ Century meant an increase in deployments of UN civilian police and this caused a drain on domestic policing instigating a recommendation for, among many other points, a pool of police ready for rapid deployment. ${ }^{47}$ The European Union responded with a rapid-reaction police force of one thousand four hundred personnel ready to deploy within thirty days and a further five thousand in reserve. In 2004 the Australian Federal Police (AFP) established the International Deployment Group (IDG) with a pool of two hundred police personnel ready for rapid-response deployment. ${ }^{48}$ New Zealand responded by establishing the International Services Group (ISG) in 2005 to manage overseas deployments and overseas liaison posts. ${ }^{49}$

The establishment of peacekeeping by the United Nations in 1948 as the first stage of democratising institutions around the world involved, in most cases, the civilian police from a number of countries. ${ }^{50}$ The role of peacekeepers has changed over time from monitoring and observing indigenous police to armed law enforcement from 1994, and the inclusion of programmes such as Support for human rights, Monitoring And Reporting, and Advising and Training (SMART) from 1995. These developments have meant the peacekeeper's role now is to establish democratic policing methods underpinned by a set of principles ${ }^{51}$ as

\footnotetext{
45 United Nations, "Summary of Contributors of UN Police Personnel: As of May 2007," UN Police Magazine, June 2007.

46 United Nations. "United Nations Peace Operations: A Year in Review 2007." Peace and Security Section of the United Nations Department of Public Information 2007. http://www.un.org/Depts/dpko/dpko/pubs.shtml (accessed 17 January 2009).; William J. Durch et al. "The Brahimi Report and the Future of UN Peace Operations." Washington DC: The Henry L. Stimson Center 2003.

47 David H Bayley, Changing the Guard: Developing Democratic Police Abroad (New York: Oxford University Press, 2005).; Durch et al. "The Brahimi Report and the Future of UN Peace Operations".

${ }^{48}$ Australian Federal Police, "International Deployment Group: Fact Sheet," ed. Australian Federal Police (Canberra: Australian Federal Police (AFP), 2006).

${ }^{49}$ International Service Group, "International Service Group".

50 Bayley, Changing the Guard: Developing Democratic Police Abroad.

${ }^{51}$ Ibid., United Nations, "Principles of Democratic Policing," UN Police Magazine, December 2006.

'The Principles of Democratic Policing are 1) Representative policing ensure that: Police personnel sufficiently represent the community they serve; Minority groups and women are adequately represented through fair and non-discriminatory recruitment policies in police services; and, the human rights of all people are protected, promoted and respected. 2) Responsive policing ensures that: Police are responsive to public needs and expectations, especially in preventing and detecting crime and maintaining public order; policing objectives are attained both lawfully and humanely; police understand the needs and expectations of the public they serve; and police actions are responsive to public opinion and wishes. 3) Accountable policing is achieved in three ways: Legally: police are accountable to the law, as are all individuals and institutions in States. Politically: police
} 
part of democracy building after conflict has ended. The principles of democratic policing then are: the inclusion of internationally agreed human rights, acting within lawful authority, accountability for actions, and an appropriately prioritised response in securing the safety of community members. ${ }^{52}$

Another facet of international policing is transitional policing, described as a state intervention following an abrupt change in the political environment of a country that is not intended as a long-term role. ${ }^{53}$ The Australian-led Regional Assistance Mission to Solomon Islands (RAMSI) is a type of transitional policing that followed the Solomon Islands government's plea for assistance in 2000 from Australia and New Zealand. ${ }^{54}$ However, RAMSI has brought much criticism which recognises and acknowledges unique issues for policing in the Pacific that are connected to strong and varied cultural identities and informal traditional systems combined with legacies of colonial legal systems. This brings challenges for Australia and New Zealand in their attempts to establish democracy and western models in a vast region of small island states, small populations and isolation from markets, factors which impact on states' economies. Western style policing models appear to be inappropriate, but the Pacific Islands Forum and the Pacific Islands Chiefs of Police have an important part to play in the development of policing models in the region. What is essential is that it must be the peoples of the Pacific, not external donors, who shape their own modern police models. ${ }^{55}$

The terrorist attacks in New York 2001, Bali 2002 and Jakarta 2003 changed the policy and strategy of both Australia and New Zealand, concerning the immediate region. The Australian Federal Police (AFP) now has a focus on peacekeeping and regional capacity-building in vulnerable states in the region. Their hands-on role includes direct intervention with the 'insertion' of police into key roles in offshore jurisdictions rather than purely advisory positions. Furthermore, the AFP has taken independent management of and responsibility for policing initiatives away from AusAID, to ensure that increasing police

\footnotetext{
are accountable to the public through the democratic and political institutions of government as well as through police and citizen liaison groups; and, Economically: police are accountable for the way they use resources allocated to them.'

52 David Bayley, "Democratic Policing," in The SAGE Dictionary of POLICING, ed. Alison Wakefield and Jenny Fleming (London, Thousand Oaks, New Dehli, Singapore: SAGE Publications Ltd, 2009), 80-82.

53 Andrew Goldsmith, "Transitional Policing," in The SAGE Dictionary of POLICING, ed. Alison Wakefield and Jenny Fleming (London, Thousand Oaks, New Dehli, Singapore: SAGE Publications Ltd, 2009), 305-307.

54 Ibid.

55 McLeod and O'Reilly, "Pacific Policing".
} 
capacity is part of a whole of government approach to aid in the region. The direct implantation of personnel in key roles and the invasive nature of Australia's assertiveness is seen by some Pacific leaders and communities as offensive and a risk to national sovereignty. Australia's insistence on immunity for their officers working in the region also caused friction and the dissolution of the Australian Enhanced Cooperation Programme in Papua New Guinea in less than twelve months. ${ }^{56}$

This type of approach lacks strategic vision and tactical skill. Success in building capacity in democratic police organisations requires seven 'must-do's'. According to Bayley these are: 'adapting reforms to local conditions'; 'persuading local stakeholder to support reform'; 'treating aid recipients as partners'; 'develop a comprehensive plan'; 'prepare for the long haul'; 'coordinate assistance efforts'; and 'sending the right people into the field'. ${ }^{57}$ Unpacking these 'to do's' creates some understanding of how capacity building and democratic policing can be harmoniously achieved. ${ }^{58}$

\section{EXTERNAL POLICIES AND PACIFIC ISLAND COUNTRIES}

Pacific Island Countries have undergone momentous upheavals through colonisation over the past few hundred years and decolonisation since the United Nations Declaration on the Granting of Independence to Colonial Countries and peoples in 1960. Decolonisation has resulted in the granting of independence and sovereignty to an increasing number of countries which become eligible for membership in the United Nations General Assembly. ${ }^{59}$ While those that have gained their independence grappled with rediscovering their identity and analysing their new place in the world, others in the Pacific are still struggling for self-determination and independence from colonisers.

During the mid-1980s New Caledonia was the scene of violent clashes between the indigenous Kanak population and the French colonising government. These clashes led to negotiations for independence, and the Matignon Accords provided for a vote on the future of New Caledonia to be held in 1998. But, in 1998 new negotiations for a fifteen year delay in the referendum on self-determination and

\footnotetext{
56 McLeod and Dinnen, "Police Building in the Southwest Pacific".

57 Bayley, Changing the Guard: Developing Democratic Police Abroad, pp.87, 88.

58 Ibid.

59 Paul Keal, "Indigenous Self-Determination and the Legitimacy of Sovereign States," International Politics. The Hague 44, no. Iss. 2/3 (2007). A seat at the UN General Assembly has become a negotiating point in the Pacific for funds from Taiwan and China.
} 
independence were stipulated in the Noumea Accord. ${ }^{60}$ The nature of the Noumea Accord with its creation of shared sovereignty with the Republic of France and abolition of 'overseas territory' status was ground-breaking. The Accord also replaces the Territorial Congress with new political institutions, makes moves to recognise Kanak culture and identity and transfers administrative power from France to New Caledonia. However, France's powers relating to justice, public order, defence, finance and currency will not be transferred to the new order until the results of the final referendum on selfdetermination have been counted at some time in the future; and, whether they will ever be transferred will depend on the referendum itself. ${ }^{61}$ These are not the only concerns over broader questions of independence and sovereignty.

New Zealand and Australia made speedy moves to hand over their Pacific Island territories to their original settlers, taking a hands-off approach. ${ }^{62}$ Whilst this approach appears on the surface as a supportive and independent stance, new sovereignties were left with models of governance that were strange to their customs and impossible to maintain. Indigenous peoples had been left out of the governance and running of their countries and had little knowledge of the workings of such institutions. Neither did they have the resources to maintain these structures. ${ }^{63}$ Globalisation expects and provides for development but Pacific Island Countries were in a position of survival and rediscovery and, by world standards, poverty. ${ }^{64} \mathrm{~A}$ hands-off approach may have been acceptable during the sixties but rich countries have since developed a new global conscience.

Two factors changed western foreign policy at the beginning of the new millennium, the United Nations Millennium Development Goals (MDGs) to end poverty, ${ }^{65}$ and the terrorist attacks on New York's World Trade Centre in 2001. The MDGs have resulted in significant changes to OECD countries' foreign policy

\footnotetext{
${ }^{60}$ Nic Maclellan, "The Noumea Accord and Decolonisation in New Caledonia," The Journal of Pacific History 34, no. 3 (1999).

61 Ibid.

62 United Nations, "Declaration on the granting of independence to colonial countries and peoples," (Official Records of the General Assembly, Fifteenth Session, Supplement No. 2 (A/4494). 1960).

63 Brown, "Security and Development"; Research participants.

64 The International Bank for Reconstruction and Development/The World Bank, Atlas of Global Development (Glasgow: Collins, 2007).

65 One hundred and eighty-nine countries present at the Millennium Summit in 2000 undertook to free humans from the effects of abject and extreme poverty by 2015 . Eight goals towards this aim are known as the Millennium Development Goals (MDGs). They are: Eradicate extreme poverty and hunger; Achieve universal primary education; Promote gender equality and empower women; Reduce child mortality; Improve maternal health; Combat HIV/AIDS, malaria and other diseases; Ensure environmental sustainability; and Develop a global partnership for development.
} 
as a response to the burden of responsibility in providing aid to developing countries. The World Bank defines all of the islands in the Pacific as developing nations ${ }^{66}$ with the exception of Guam, French Polynesia and New Caledonia and although the MDGs have caused unprecedented commitment to development, recent studies challenge the degree of real change in the Pacific. ${ }^{67}$

The terrorist attacks on American soil were the catalyst of an abrupt change in the language and strategies of the US, Britain and Australia. ${ }^{68}$ Australia's Prime Minister of the time, John Howard, pledged unconditional military support to the US the day following the bombings of the World Trade Centre and the Pentagon, which resulted in some critical commentary in Australia. Prior to 9/11, terrorism was relegated to the same low priority as other security risks including the environment, human rights, people smuggling and HIV/AIDS. ${ }^{69}$ But, the Jemaah Islamiyah bombings of Bali in 2002 were the turning point in the dramatic change in the flavour and language used in policy for constructing defence of Australian borders and regional security. ${ }^{70}$ Pacific Island nations, previously considered a benign security threat, were suddenly described as failing or rogue states within an arc of instability from Papua New Guinea, Solomon Islands, Vanuatu, and New Caledonia to Fiji, and providing safe haven and recruitment centres for terrorists. ${ }^{71}$ This language of fear stimulated public support for direct intervention by the Australian government in others' affairs and lands regardless of sovereignty 'if it considers its security interests are threatened' ${ }^{72}$

There is robust debate over the terms 'failed state' and 'arc of instability' and the practical uses of the terms. The concept of a failed state conjures images of well developed and firmly established state institutions that have been unable to stem a break-down in social order. Pacific Island Countries are in the forming

\footnotetext{
${ }^{66}$ Average income per capita equals less than US $\$ 10,726$. Most PICs have an average income of less than US $\$ 3,465$ putting them in the low income bracket.

${ }^{67}$ Commonwealth of Australia. "Pacific 2020: Challenges and Opportunities for Growth." Canberra: Australian Agency for International Development (AusAID) 2006, New Zealand Government, "Pacific Strategy 2007-2015," ed. NZAID (Wellington: NZAID, n.d.); Malcolm Cook. "The Pacific: Beyond Post-colonialism and the Pacific Way, A New Era?" Sydney: Lowy Institute for International Policy, 2005.

${ }^{68}$ Goldsmith and Sheptycki, "Crafting Transnational Policing".

${ }^{69}$ Carl Ungerer, "Introduction," in Australian Foreign Policy in the Age of Terror, ed. Carl Ungerer (Sydney: University of New South Wales Press Ltd, 2008), 1-20.

${ }^{70}$ Ibid. John Henderson, "Security in Oceania in the Post 9/11 and Bali Era," in New Zealand in a Globalising World, ed. Ralph Pettman (Wellington: Victoria University Press, 2005), 73-82. Elsina Wainwright et al. "Our Failing Neighbour: Australia and the Future of Solomon Islands." Barton: Australian Strategic Policy Institute (ASPI), 2003.

${ }^{71}$ Wainwright et al. "Our Failing Neighbour." , Henderson, "Security in Oceania in the Post 9/11 and Bali Era."

72 Henderson, "Security in Oceania in the Post 9/11 and Bali Era", p.74; Herr, "The Concept of the 'Failed State'".
} 
phase of becoming 'modern states', necessary in a globalising world, and most are still developing an understanding of centralised governance. However, such an understanding may never be fully realised in communities that traditionally seek governance through clan and cultural norms. Accordingly, there is a mismatch between emerging states and the foreign policy and expectations of long established modern states seeking to secure their national borders, and OECD countries charged with new responsibilities in providing development aid to developing and emerging countries. ${ }^{73}$

Apart from Australia, New Zealand, the US and France, the Pacific game is also played by China, Taiwan and Japan, and strategy, diplomacy, aid and natural resources are elements in the game. Recognition that China has become a major player in the Pacific, is tempered by claims that China is not sufficiently endowed with either soft or hard power to cause concern for the US and Australia and that China's weight is felt in its 'no-strings-attached' development funding and increasing trade deals. ${ }^{74}$ Another view centres on Taiwan's push for recognition at the United Nations and subsequent competition with China in securing formal diplomatic agreements with strategic sovereignties. Although Taiwan has partnerships only with a few developing small and microstates, it has achieved a democratic government and met global human rights standards, strengthening the case for separatism from China. ${ }^{75}$ Another analyst argues the rise of China as a power in the region has occurred by default through small investments economically, diplomatically and strategically, as the US and Britain have withdrawn their interest from the area. Thus, rather than a cause for concern over regional competition for power, China provides endless opportunities for collegial development partnerships. ${ }^{76}$ The debate about whether China is seen as a political threat or looming hegemon is set to continue especially because China is seen by some observers as the only world power with the blue water capability of plying the vast Pacific Ocean without any real supervision from Australia, whose interests lie in the seas and oceans to their west, or New Zealand, who has little to offer in the way of blue water surveillance. The effects of China's investment in the region are already obvious in the mining, logging and fishing industries and an increasing Chinese Diaspora

\footnotetext{
73 Brown, "Security and Development".

74 Jian Yang, "China in the South Pacific: A Strategic Threat?" (www.asianz.org.nz, 2008).

75 Anthony van Fossen, "The Struggle for Recognition: Diplomatic Competition Between China and Taiwan in Oceania," Journal of Chinese Political Science 12, no. 2 (2007).

76 Yongjin Zhang, "China and the emerging regional order in the South Pacific," Australian Journal of International Affairs 61, no. 3 (2007).
} 
community said to be responsible for an increase in organised crime and corruption within government institutions. ${ }^{77}$

The Pacific region is the receiver of some of the highest levels of development funds from all corners of the earth but performs worse than most other developing regions. ${ }^{78}$ Australia and New Zealand are significant donors to the Pacific Region, with Australia focussed on its own security issues, while arguably New Zealand is more concerned with identification with the Pacific and its peoples. Nevertheless, both countries recognise the need for speedy action to address the challenges to the Pacific region in areas of governance, economic growth and environmental change. ${ }^{79}$ The 'whole of government' approach applied in the Pacific integrates cross departmental policy instruments to alleviate poverty, increase accountability and capability in governance and assists in stabilising emerging states. ${ }^{80}$ All commentators agree that development cannot occur in a climate of poverty or civil unrest and that policing is central to maintaining societal order and safety.

\section{GLOBALISATION, INTERNATIONALISATION \& REGIONALISATION}

Globalisation, as defined by rich people like us, is a very nice thing...you are talking about the Internet, you are talking about cell phones, you are talking about computers. This doesn't affect twothirds of the people in the world (President Jimmy Carter). ${ }^{81}$

Although this thesis focuses on one particular region, the larger forces of globalisation need also to be understood in order to provide a fuller context for the analysis of policing.

Arguably, globalisation has had the biggest impact on developing countries since industrialisation, as borders open up and international standards such as human rights are imposed. Globalisation is designed to remove barriers to the movement of goods, services, people and information in order to grow national economies. It links people on one side of the world with markets on the other and has opened up new opportunities for trade with non-traditional partners.

\footnotetext{
77 Paul G. Buchanan, "China Steps into Pacific Power Vacuum," Samoa Observer, 17 September 2009.

78 Cook. "The Pacific: Beyond Post-colonialism and the Pacific Way, A New Era?"

79 Ibid.

80 Terje Rød-Larsen, "Foreword," in Greater than the Sum of its Parts? Assessing "Whole of Government" Approaches to Fragile States (New York: International Peace Academy, 2007), vii-viii.

${ }^{81}$ As cited in Eugene D. Jaffe, Globalisation and Development, The New Global Society (Philadelphia: Chelsea House Publishers, 2006), p.1.
} 
The advent of technology has sped up this capability so that exchanges all over the world can take place instantly in real time, without leaving the office or living room. ${ }^{82}$ Imagine having the capability of reaching almost four-fifths of the world's six billion people at one time. This occurred during the 2008 Beijing Olympics with the use of about sixty outside broadcast vans, one thousand cameras, four thousand staff and two hundred broadcasters who made four thousand hours of live viewing available to a cumulative audience of over forty billion. ${ }^{83}$ While this example conveys the omnipresence of globalisation, as pointed out so poignantly by President Jimmy Carter, the benefits of globalisation are not always realised by the poorest countries and peoples. Even though computers and televisions are now much more readily available in developing or emerging countries, and in the Pacific, and tourism is a national income, the new awakening brings pressures on customary ways of life and new expectations of lifestyle.

Three forces have contributed to globalisation. First, technology has reduced the cost of doing business; second, the decrease in the cost of communication and of doing business, has resulted in increased trade and tourism; and third, the growth of regional economic integration has resulted in the clustering of smaller groups. ${ }^{84}$ These forces resulted in a new division of labour, with transnational corporations driving the bulk of global production, which has taken over from trade in servicing international markets. ${ }^{85}$ Corporations have been the main actors in the growth of globalisation as they have taken their business offshore for bigger financial gain. ${ }^{86}$ This has also often resulted in the exploitation of disadvantaged peoples in developing countries and therefore the benefits of globalisation most often accrue to the wealthy, impinging on the human rights of the poor. ${ }^{87}$ Furthermore, an increase in tourism also alters the dynamics of developing societies with an increase in crime generally targeted against tourists

\footnotetext{
82 Ibid. Peter J. Katzenstein, A World of Regions: Asia and Europe in the American Imperium (Cornell: Cornell University Press, 2005), p.15.

83 Beijing Organising Committee, "Beijing Olympic Broadcasting," The Beijing Organising Committee for the Games of the XXIX Olympiad (BOCOG),

http://en.beijing2008.cn/53/66/column211716653.shtml (accessed 31 December, 2008). Note: forty billion viewers is a cumulative figure which relates to the total number of viewings over the life of the games. AC Neilson, the researcher, was approached for an explanation of this figure but did not respond.

84 Jaffe, Globalisation and Development.

${ }^{85}$ Anthony McGrew, "Introduction," in Globalisation, Development and Human Security, ed. Anthony McGrew and Nana K. Poku (Cambridge, Malden: Polity Press, 2007), 1-21. Katzenstein, A World of Regions: Asia and Europe in the American Imperium. p.15

86 Jaffe, Globalisation and Development.

${ }^{87}$ Naomi Klein, No Logo: no space, no choice, no jobs (London: Flamingo, 2000); Jaffe, Globalisation and Development.
} 
whose lifestyle is inconsistent with the populace they visit. Even so, increased industrialisation and tourism in developing countries contributes to economic growth. ${ }^{88}$ As the economies of more and more nations become increasingly entwined, secondary actors, national and international government organisations, have joined the 'game' with the role of regulating global trade, which may or may not be successful in levelling the playing field. The World Trade Organisation (WTO) takes on this role dealing with rules of trade between countries and is the only global organisation with this mandate. Perhaps the most important actor, and the third to be raised here, is civil society in the form of non-governmental agencies (NGOs) which, as part of the community itself, have a unique advantage in hands-on knowledge, can act in the interests of human rights, and are essential partners for government agencies in sustainable development. ${ }^{89}$

Region building can occur much more informally and for non-economic purposes. Some regions are formed geographically, or in response to crises which need a coordinated response such as a state collapse as seen in West Africa, ${ }^{90}$ or ethnic conflicts which threaten state stability such as those seen in the South Pacific. ${ }^{91}$ This 'new regionalism' is not bound by economic arrangements for free trade but goes beyond it to include political, security, social and cultural issues and reflects political ambition, by some, in creating identity and coherence regionally. ${ }^{92}$ Although for others, the nature of regionalisation suggests disintegration of territorial boundaries and to some extent the dissolving of sovereignty, or the use of sovereignty as a bargaining chip in political processes involving aid where asymmetric flows create one-sided dependence and vulnerabilities. ${ }^{93}$ A changing focus on issues other than economic means a change in the architecture of regions.

This change is recognised in discourse about the Pacific's regional architecture which suggests that a new regional security organisation should be convened with China, Japan, Korea, the US, Russia, the ASEAN states, Australia, New

\footnotetext{
88 McGrew, "Introduction".

89 Jaffe, Globalisation and Development.

${ }^{90}$ Bjorn Hettne, "Globalism, Regionalism and Interregionalism," in Globalisation, Development and Human Security, ed. Anthony McGrew and Nana K Poku (Cambridge, Malden: Polity Press, 2007), 25-46.

91 Jon Fraenkel, The Manipulation of Custom: From Uprising to Intervention in the Solomon Islands (Wellington: Victoria University Press, 2004). Jon Fraenkel, "South-West Pacific: Arc of Instability or Matrix of Discontent?," in New Zealand in Globalising World, ed. Ralph Pettman (Wellington: Victoria University Press, 2005), 119-140.

92 Hettne, "Globalism, Regionalism and Interregionalism".

93 Katzenstein, A World of Regions: Asia and Europe in the American Imperium.
} 
Zealand and India as members, and a regular meeting of heads of states should be established where multilateral issues could be discussed and bi-lateral contacts made. Such a structure should not be too diverse and key heads of government would need to be carefully identified. This arrangement provides an opportunity for the APEC heads of government meeting to revert to its original status as a heads of finance meeting as the high point of APEC. ${ }^{94}$ Whilst an important part of the Pacific regional architecture, the only Pacific Islands member of APEC is Papua New Guinea, therefore it is important for a purely Pacific regional structure to represent those voices at APEC.

The Pacific Islands Forum should fill this role. However, New Zealand's Prime Minister of the time, Helen Clark, instigated a significant review of the Forum's role and Secretariat in 2003 resulting in the writing of a Pacific Plan designed to develop the small Pacific Island Countries. An Eminent Persons Group (EPG) ${ }^{95}$ was given one month to review, consult and report on their findings, meaning that there was little time to consult widely and in depth. ${ }^{96}$ Pacific peoples and their culture are at the forefront of Pacific life and although the EPG's report agreed that 'cultural identity' required 'immediate attention', the 2005 Plan did not reflect this point. ${ }^{97}$ While subsequently the Plan was rewritten in an attempt to address this, it is an issue which is a continuing reflection of the region's background. I discuss these points more fully in Chapter Three.

\section{CONCLUSION}

Over the past few years there has been an increase in international policing that impacts on developing countries, including those in the Pacific region. There are a number of factors that help explain this. The first is globalisation and the second is regionalisation. Globalisation affects even the smallest countries through economic trade and technological advances. For a country to progress and prosper it must be encouraged to trade with other countries within its own region and across the globe. Technology has reached most corners of the world decreasing the cost of communication and transport and accelerating to the

\footnotetext{
94 Allan Gyngell. "Design Faults: The Asia Pacific's Regional Architecture." Sydney: Lowy Institute for International Policy, 2007.

95 The group charged with carrying out the review consisted of Kiribati President Teburoro Tito, former PNG Prime Minister Sire Julius Chan, Samoan Onbudsman, Maiava Iulai Toma, University of the South Pacific pro-Chancellor, Dr Langi Kavaliku and retired Australian diplomat Bob Cotton.

96 "Eminent Person Group has a month to review Pacific Islands Forum Secretariat," Pacific Islands Broadcasting Association, http://www.accessmylibrary.com/coms2/summary_0286-2312121_ITM (accessed 8 January, 2009).

97 Huffer, "Regionalism and Cultural Identity".
} 
speed of light the ability to communicate with others everywhere. These forces have also extended to crime and law enforcement.

The end of colonialism and the beginning of self-determination and selfgovernance has placed the economies and societies of small and newly independent countries in an emergent or developing state. In many places this and lines drawn on maps by past colonisers have caused conflict between ethnicities. Countries in conflict have been labelled weak, failing or failed states by metropolitan states, but that label assumes that something already established had failed or broken. Commentators argue that this is not the case as these newly independent states have not had the benefit of a hundred years to build and establish their models of government and economy. They have been left a legacy of Westphalia structures but no instruction booklet on how to ensure their sustainability or efficacy.

Interests in matters of security following the end of the Cold War and terrorist events in the US and Indonesia, as well as United Nations interests in the rule of law and human rights have been the causes of abrupt changes in the foreign policies of metropolitan states. In the Pacific this is evident in an about-turn from a hands-off approach in the interests of sovereignty, to direct intervention with whole-of-government strategies by Australia through the Australian Federal Police (AFP) in the interests of regional and national security. Although much of the literature refers to Australia and the AFP as being the instigators of regional missions there is less in the literature about the roles of New Zealand in particular, and other Pacific countries, which are also heavily involved in policing across borders.

In sum, there remain large gaps in the literature about the effects of decolonisation and the continuing impacts of metropolitan states on the small island countries of the Pacific. There is little in the literature that explains the relationships of regional organisations and how they affect dynamics in the region and although there is a growing body of work on policing in the region, it mostly concentrates on Australia's efforts in RAMSI and post-conflict peacekeeping missions. While there are volumes of information about policing as a profession, evidently, there is a dearth of information about what the police jurisdictions of the Pacific actually need and want in the way of building modern domestic policing models that provide local social control as well as international security. The remaining chapters in this thesis attempt to correct this deficiency. 


\section{CHAPTER THREE: THE POLITICS OF POLICING PACIFIC ISLAND COUNTRIES}

Policing is a core feature of national security, economic growth, community safety and security, crime prevention and community reassurance, road safety and emergency management. Successfully executing this role in a regional setting requires honest and open collaboration between police services and jurisdictions by professionals who value high standards of integrity and accountability and who lead and develop their organisations to these standards. Policing in the Pacific is complex and forms the crossroads for a number of global, regional and domestic strategies involving various stakeholders including Interpol, the Australian Federal Police (AFP) and Australian government, the New Zealand Police (NZP) and the New Zealand government, and the police services of Pacific Island Countries. Decisions about policing that affect the region as a whole have been discussed and made by the Pacific Islands Chiefs of Police (PICP) since 1970, a body of twenty-one member countries.

The smallness and isolation of many of the PICP police services and their island countries means cooperation is essential. The development of protocols to facilitate the movement of criminals and investigators across borders and sharing information to ensure justice is done is ongoing. But, this smallness also creates challenges for external players who need to listen and creatively assist in developing in-country law and justice processes in partnership with those who live in these small states. Just as their differences are to be celebrated, the rule of law and human rights must also form part of the vision of policing in the Pacific. However, the ultimate goal of overseas involvement in policing must be the independence of the individual police forces, alongside cooperation amongst them. This goal was voiced by the respondents to this study during interviews when asked about their vision of future policing in their homeland and region. Nearly all discussed sustainable police services that no longer needed to rely on donors, and a safe Pacific region where all of the police services in the region work together to achieve this. A typical response was:

In the long term, each country is able to control its own and effective law enforcement organisation and environment for communities that accords with the spirit and principles of the rule of law - at the same time respecting local indigenous cultures and identities. They should have good governance and support access to justice and protection and 
promotion of human rights of Pacific Community members and the rule of law. ${ }^{98}$

This vision seems practical and achievable but there are a number of difficulties that stand in the way. The Pacific Islands and the ocean in which they rest are highly important to the large and influential metropolitan countries on the Pacific Rim including the United States, Japan, China, Taiwan, Australia and New Zealand. The Commonwealth of Nations, France and the European Union also have a vested interest in the area through their history in the region. European Empire building in the $18^{\text {th }}$ Century and two World Wars and decolonisation in the $20^{\text {th }}$ Century have all shaped and continue to influence the domestic policy and models of government of Pacific Island nations and territories. Many PIC governments mirror those of colonial rulers which, in the contemporary world, appear culturally inappropriate and, for countries with low populations and emerging economies, are costly to maintain. ${ }^{99}$ This means then a reliance on external funds which sets the stage for a clash of values and agendas between external players focused on national security, diplomacy battles, and retention of territory claimed through colonisation, and societies seeking to re-establish their own identities and values in a changed world. Included in this mix is the bounty offered up by the vast Pacific Ocean and its island countries in the way of fishing rights, minerals and metals, exotic timbers and black pearls.

The twenty-six PICs are pawns in a battle for influence on the international stage between the rising power of China, the Pacific's self-appointed hegemon, Australia, in reluctant and pesky partnership with NZ, the USA as a declining superpower, and the increasingly powerful EU. And in the background, Taiwan has built and maintains strong economic and trade relationships with almost all PICs as well as Australia and New Zealand, but only holds formal democratic relationships with six PICs. ${ }^{100}$ All of these countries invest heavily in the Pacific through aid payments related to national security, peace and capacity building, improvements to health and welfare, and economic development. In reality, money speaks volumes and small populations, along with a high risk of environmental damage and little hope of significant independent economic growth, place the governments of these developing nations between the proverbial rock and a hard place. One participant was eloquent in explaining this problem:

\footnotetext{
98 Interview B5.

99 McLeod and Dinnen, "Police Building in the Southwest Pacific".

100 Graeme Dobell. "China and Taiwan in the South Pacific: Diplomatic Chess versus Pacific Political Rugby." Sydney: Lowy Institute for International Policy 2007. [See Table 3.]
} 
In many respects it all boils down to the fact that he who has the dollars calls the tune, and to the extent that a Chinese, Japanese, Australian, New Zealand, [or] EU supply of funds is made available the recipients acknowledge the power of that. They have to weigh up [...] how much of their national sovereignty they want to surrender in consideration for the supply of this aid. And they're making those judgements all the time. ${ }^{101}$

It has been noted in the literature that Western models of policing are incompatible with Pacific Islands' culture ${ }^{102}$ so it is appropriate to explore how the international community can add compatible value to the developing nations of the Pacific. It is also appropriate to visit the idea of the rule of law, its connections to interventions and other policing advances in the Pacific, and the policing needs of Pacific Island Countries.

The most discussed and written about of policing interventions in the Pacific is the Regional Assistance Mission to Solomon Islands (RAMSI), followed by the mission to Timor Leste. Both of these post-conflict missions, the first a regional mission and the second a United Nations (UN) mission, resulted from a break down in civil order and have been highly profiled in the media. In 2010, both were in a transitional policing phase although the Solomon Islands situation was more advanced. Another UN intervention resulting from conflict during 19891999, the Bougainville Community Policing Project (BCPP), continues in 2009, in a capacity building mode with just seven NZP personnel.

There have also been other notable initiatives. In 2004 the Pacific Regional Policing Initiative (PRPI) ${ }^{103}$ was established to strengthen policing in the Pacific by AusAID with A $\$ 14.5$ million and NZAID NZ\$2.5 million over five years, with in-kind contributions from Fiji, until the latter's suspension from the PICP after the 2006 coup d'etat. The PRPI provided training to police in Forum member countries but its contract ended at the end of 2008 and was replaced by the Pacific Policing Development Programme (PPDP). ${ }^{104}$ In 2007, collaborative planning involving NZP, NZAID and the PICP resulted in the Pacific Prevention of Domestic Violence Programme (PPDVP) which is being implemented in an increasing number of PICs. Australia's Transnational Crime Units (TCUs) have

\footnotetext{
101 Interview A5.

102 McLeod and O'Reilly, "Pacific Policing".

103 The PRPI is now known as the Pacific Policing Development Programme (PPDP).

104 Pacific Regional Policing Initiative (PRPI), "Programme Profile," PRPI Website, http://www. pacificrpi.com/ (accessed 19 January, 2009).
} 
been established in a number of PICs ${ }^{105}$ to gather intelligence that is coordinated and disseminated by the Pacific Transnational Crime Coordination Centre (PTCCC). The AFP and NZP provide direct assistance and capacity building to police in a number of PICs, with personnel placed in strategic leadership roles. Furthermore, a growing number of countries are placing police liaison officers in their embassies and high commissions right across the world.

The next section of this chapter explores the complexities of the different elements of international policing in the Pacific and uses examples to explain them. The chapter then identifies and discusses the big issues of globalisation, climate change, personnel training, and foreign aid and their impacts on policing in the Pacific from research participants' points of view. Based on the research findings I offer a new approach to international policing in the Pacific.

\section{Mapping Pacific Policing}

Since 1970, the chiefs of police services of Pacific Island Countries have met and discussed policing issues and potential solutions to problems. The numbers of countries engaged in these deliberations grew to twenty-eight in 1993, but was reduced to twenty-one with the resignation of Australia's state police services in 2000. Over the years the chiefs have witnessed big changes in crime and the way they deal with it. They have also noted an increase in the numbers of external influences in the region which have resulted in a loss of voice and power over their own direction. Unfortunately, too frequently metropolitan 'experts' impose their standards and methods when asked for advice or intervention, but this is not always appropriate for the cultures and societies that ask for help.

James W.E. Sheptycki's typology overview developed at the beginning of the new millennium identifying private and public, and high and low policing was aimed at securing territory and securing populations. ${ }^{106}$ This typology no longer adequately explains international policing in view of the enormous changes to international politics over the first three years of the new millennium. I consider that international policing in $\mathbf{2 0 1 0}$ has four key elements: intelligence, that which is gathered, collated, analysed, and disseminated in relation to transnational organised crime, terrorism and national security; peacemaking as a rapid response to internal conflict and the restoration of order, which includes criminal

\footnotetext{
105 "Pacific Transnational Crime Network (PTCN)".

www.aic.gov.au/Trafficking_Persons_Presentations/Pacific_Transnational_Crime_Network.pdf -

(accessed 7 March, 2009). TCU's have been established in Papua New Guinea, Vanuatu, Fiji, Samoa and Tonga. They are fully funded by the Australian Federal Police (AFP).

106 Sheptycki, "Introduction".
} 
investigation of the instigators of the conflict; state building, establishing democracy and democratic policing involving whole of government solutions; and capacity building by strategic positioning of international personnel in key positions. These four elements are independent of each other although rapid response is usually followed by state building, and the establishment of democracy and democratic policing. There are a further three elements of international policing in the current understanding of it: training and targeted programmes designed and delivered by bi-lateral or multi-lateral partners; emergency management; and liaison and collaboration by individuals in political posts across the globe. ${ }^{107}$ Examples of current practice in the Pacific help explain each of the elements and provide the basis for my own approach presented in Appendix One.

\section{Rapid Response}

This generally refers to the response of the international community to conflict within states. Such a response is usually generated by the United Nations on receipt of a call for assistance from a country such as occurred for East Timor, ${ }^{108}$ but can also, albeit rarely, occur regionally as when Solomon Islands appealed to Australia and New Zealand for assistance, first in 2000 and again in 2003. The United Nations was unable provide a mission at the request of PIF or authorise the regional response, RAMSI, because of the relationship between Solomon Islands and Taiwan. ${ }^{109}$

\section{Criminal Investigations}

These are the responsibilities of the police within post-conflict peacekeeping missions including the investigation of high level crimes involving deception and corruption and violent crime. Many elites are investigated for their part in civil conflict and often convicted and imprisoned, making it more appropriate for these investigations to be the responsibility of an impartial international community. For instance, in Solomon Islands large numbers of weapons were stolen from police armouries and distributed to rebel fighters, often with the assistance of members of the Solomon Islands Police Force who were also

\footnotetext{
107 Liaison roles are described as political posts because they are the connector between government ministers and police management in the host and origin countries.

108 Renamed Timor-Lesté after independence.

109 Dobell. "China and Taiwan in the South Pacific: Diplomatic Chess versus Pacific Political Rugby".
} 
members of rebellion forces. ${ }^{110}$ Many of these were put before the courts after lengthy but thorough investigations.

Criminal investigations into high level criminal activity closely follow initial interventions and are required to ensure offenders are brought to justice before their communities, contributing to public trust and confidence. By 2005, RAMSI had seized almost 3,600 weapons and made 4,000 arrests. ${ }^{111}$

\section{State Building and Establishing Democracy}

Once order has been established following conflict, a mission or intervention is designed at the invitation of the country involved in conflict and agreed on by all parties. Long term solutions include whole of government reform designed to stimulate economic growth, democratic government, and fair and peaceful policing and justice. These aims are based on international human rights standards and education. An example of this type of state-building in the Pacific neighbourhood is the Regional Assistance Mission to Solomon Islands (RAMSI), now in its sixth year and involving fifteen countries, all members of the Pacific Islands Forum (PIF). RAMSI has been criticised as an aggressive invasion with little if any consultation with the Solomon Islands Government, and even recolonisation by Australia and New Zealand. ${ }^{112}$ However, it has also attracted favourable discourse. State-building and establishing democracy in the developing countries of the Pacific must be based on transparent dialogue and agreement between the interveners and the host country which must take central stage and lead planning for design and implementation.

Another initiative resulting from rapid response is the Bougainville Community Policing Project that is unique in its evolution. An Australian, Fijian, New Zealand and Vanuatuan intervention followed years of struggle for independence from Papua New Guinea in 1999, to attempt capacity building from about 2001. When Bougainville won autonomy from PNG, the BCPP was established to embed a community policing model there. The Community Auxiliary Police (CAP) was successfully established with the support of AusAID and AFP, NZAID and NZP, in 2001 and so NZP withdrew from the project. But in 2005, Bougainville police became disenchanted with the AFP's higher rates of pay and insistence on

\footnotetext{
${ }^{110}$ Fraenkel, The Manipulation of Custom.

${ }^{111}$ Elsina Wainwright. "How is RAMSI faring? Progress, challenges, and lessons learned." Australian Strategic Policy Institute (ASPI) 2005; RAMSI, "RAMSI's Work," Regional Assistance Mission to Solomon Islands Website, http://www.ramsi.org/node/2 (accessed 9 January, 2009).

112 Jon Fraenkel. "The Manipulation of Custom: From Uprising to Intervention in the Solomon Islands." Victoria University Press, 2005.
} 
immunity for their in-country representatives. Immunity was withdrawn in the Supreme Court and more than one hundred and fifty Australian police and officials left the country. ${ }^{113}$ In the vacuum left behind, the government of Papua New Guinea approached New Zealand for help. ${ }^{114}$ In April 2005, New Zealand Police returned to Bougainville in partnership at village level to re-establish the BCPP and implement a restorative justice system. ${ }^{115}$

\section{Capacity Building}

While state building is based on building capacity through the total reform of government structures and instruments, capacity building by strategic positioning has a different philosophy and is less visible to the communities it serves. It is manifested in policing by the strategic appointment of personnel to the position of Chief of Police. In six Pacific countries ${ }^{116}$ either New Zealand or Australian nationals fill the top police position. A seventh position held by Australian national, Andrew Hughes, as Commissioner of Fiji's police service followed Speight's 2000 coup; ${ }^{117}$ but what was a warm relationship between the military leader, Frank Bainimarama, and Hughes deteriorated from October to November 2006 over a shipment of ammunition, ${ }^{118}$ which may have been a factor in the December 2006 military coup d'etat. ${ }^{119}$

Cook Islands appointed a New Zealand national to the top police job in $2007^{120}$ following a 2006 review which identified poor leadership and management as factors in an inefficient police service. ${ }^{121}$ Nauru appointed its first Australian to the Office of Commissioner following a Memorandum of Understanding between Australia and Nauru in 2004 which saw Australia taking over responsibility for

\footnotetext{
113 Ian McPhedran, "Aussie cops to get out of PNG," The Mercury, 14 May 2005.

114 "Govt asks NZ for help on Island," Post-Courier, 20 May 2005.

115 New Zealand Police, "Bougainville Community Policing Project," New Zealand Police Website, http://www.police.govt.nz/service/overseas/bougainville.html (accessed 15 December, 2008).

${ }^{116}$ Cook Islands (NZ), Nauru (Aust), Niue (NZ), Solomon Islands (NZ), Tonga (NZ) and Pitcairn Islands (NZ).

117 Joel Gibson, "Fiji's police chief reads riot act as military rift grows," The Sydney Morning Herald Website, http://www.smh.com.au/news/world/fijis-police-chief-reads-riot-act-as-military-riftgrows/2006/11/02/1162339989045.html (accessed 15 March, 2009).

118 Radio New Zealand International, "Fiji Police refuse to release shipment of ammunition to army," Radio New Zealand International Website, http://www.rnzi.com/pages/news.php?op=read\&id=27872 (accessed 15 March, 2009).

119 Gibson, "Fiji's police chief reads riot act as military rift grows".

120 Online Editor, "Cook Islands Police Chief Tasker won't renew contract," Pacific Islands News Association, http://www.pina.com.fj/?p=pacnews\&m =read\&o=195285357849a743ae6e732d85dc70 (accessed 15 March, 2009).

121 Winston Peters, "Cook Islands Police Service Review," NZ Government Website, http://beehive.govt.nz/release/cook+islands+police+service+review (accessed 15 March, 2009).
} 
the offices of finance and police; ${ }^{122}$ New Zealand Police has provided a person for the top Niue police job for most years since 1974. A localisation policy was adopted for some years until a long search with little interest offered up a new Commissioner from New Zealand's ranks mid-year 2005. ${ }^{123}$ That Commissioner completed almost four years service with a responsibility for a total of fifteen staff. Solomon Islands' appointment of key government roles including the police commissioner occurred as a part of RAMSI and a number of Australian and a New Zealand nationals have filled the top role and deputy roles. ${ }^{124}$ In July 2008, Tonga announced the Tonga Police Development Programme, a tripartite result of a collaborative assessment carried out the previous year to identify any need for change. This followed riots in the capital, Nuku'alofa that saw much of the central business district destroyed. The agreement involves funding from NZAID and AusAID, and support from New Zealand Police (NZP). A small number of staff from New Zealand Police has been deployed including the appointment to Commander of a New Zealand national provided by NZP. ${ }^{125}$ In Tonga, the agreement is built on alignment to the needs of Tongan people with ownership by Tonga and building local leadership qualities and skills for the future of Tonga Police. ${ }^{126}$ The sole police position in the Pitcairn Islands, a British overseas territory, has also been filled by a New Zealand national ${ }^{127}$ since a request from the British Government in 2007 opened the way for selection and appointment of that post. ${ }^{128}$ The establishment of the Pitcairn Islands position followed investigations of historical sexual offences and the New Zealand officer replaced military personnel who had previously acted in the police role. Each deployment, with the exception of Pitcairn Islands, involves an internal top-down change model from local models of policing to western democratic domestic

\footnotetext{
122 Jake Skeers, "Nauru deal cements Australia's Pacific incarceration policy," World Institute for Asian Studies, http://www.asiantribune.com/oldsite/show_article.php?id=1378 (accessed 15 March, 2009).

123 Weekly Niue News, "Search Continues for Top Cop," Weekly Niue News, http://www.mailarchive.com/weekly-niue-news@lists.electric.gen.nz/msg00107.html (accessed 15 March, 2009).

124 RAMSI, "RAMSI's Work".

125 Administrator, "Tonga Police Development Programme launched," Government of Tonga, http://www.minfo.gov.to/index.php?option=com_content\&view=article\&id=197: tonga-police-

development-programme-launched (accessed 15 March, 2009).; It should be noted that the appointments of New Zealand Police members to Commissioners roles in Cook Islands and Tonga are made by the police service they serve, not New Zealand Police. The Commissioners of Cook Islands and Tonga are on leave without pay, and retired respectively. [see New Zealand Police. "Briefing to the Incoming Minister." Wellington: New Zealand Police 2008] The Commissioners to Niue and Solomon Islands do not enjoy the immunity afforded to AFP members and as such are accountable under the laws of the country in which they serve.

${ }^{126}$ Administrator, "Tonga Police Development Programme launched".

127 Richard Edmondson, "Island Paradise Like Returning to the 1950s," stuff.co.nz, http://www.stuff.co.nz/print/4817147a6015.html (accessed 15 January, 2009).

128 John Andrews, "Wanted: New Zealand police officer looking for an overseas adventure," nzherald.co.nz, http://www.nzherald.co.nz/pitcairn-

islands/news/article.cfm?!_id=433\&objectid=10482163 (accessed 27 March, 2009).
} 
policing and has resulted from a plea for help from those countries' governments as a solution to a break down in trust and confidence. ${ }^{129}$

\section{Training and Targeted Programmes}

The capability of police services cannot be increased without training, and training as an issue has been an enduring agenda item of the PICP since its first conference in 1970, with bilateral training arrangements being a feature of the area. ${ }^{130}$ Historically, training of Pacific police members was carried out by the British in Britain which did not meet the needs of Pacific cultures. While much of the later training provided has been well received, some of it, such as forensics, is too advanced and unsustainable for police services that do not have the basics, such as pens and notebooks, let alone a laboratory to carry out forensics testing. ${ }^{131}$

\section{Transnational Criminal Intelligence}

Because transnational crime and terrorism pose a real and significant risk to regional, national and community safety it is necessary to track the movements of known and suspected transnational criminals and commodities. Interpol has been the international face of cooperation between countries on crime and criminals since $1923 .^{132}$ However, it is likely that a Pacific focus has not been a top priority at Interpol's headquarters. In June 2004 the Pacific Transnational Crime Coordination Centre (PTCCC) was established in Fiji to coordinate intelligence about transnational crime and criminals in the region. A number of Pacific Island Countries host Transnational Crime Units (TCU) which feed information back to the PTCCC.

\section{Liaison}

Australia has liaison officers in thirty-six posts in more than twenty-seven countries, New Zealand has eight in six countries, and China is increasing its numbers into western countries. These are political appointments that provide a conduit for dialogue between the governments of host and origin countries, the governments and police services of host and origin countries, and a point of first

\footnotetext{
129 Ibid.

130 B.M. Boswell, "Policing the Pacific: The Pacific Islands Chiefs of Police 1970-2008," (Wellington: Victoria University of Wellington, 2008).

131 Ibid.

132 Interpol, "About Interpol," Interpol Website, http://www.interpol.int/public/icpo/default.asp (accessed 28 February, 2009).
} 
contact for international cooperation. Liaison officers are often in a position to anticipate support, as occurred at the very beginning of the 2004 Boxing Day Tsunami in Indonesia and Thailand, where more than 100,000 people perished.

Having established the range of policing initiatives by external countries, I now turn to analysing the participants' views on what has happened in the Pacific Island states. ${ }^{133}$

\section{ISSUES IN PACIFIC POLICING}

Research participants were asked to identify a factor which, for them, had the single biggest impact on policing in the Pacific. They presented a range of views with many identifying a number of inter-related factors such as training and resources. But others identified the big issues of globalisation, westernisation and climate change as their single biggest impact as verbalised by this interviewee:

It's globalisation. Globalisation is both changing people's expectations of their quality of life and it's also, it's shifting people, product, and ideas that more rapidly around the world. In my belief the flow-on effect of that, I mean if you could summarise it it's just progress really, but it's accelerated to some extent and enabled by so many different features of the modern world that it is creating huge tensions in the ability of police agencies to do what they've traditionally done. ${ }^{134}$

Globalisation, and tourism as an offshoot of this, has also exposed the isolated communities of the Pacific to new tastes in food and goods. This exposure has caused a massive decline in heart and diabetic health in the Pacific as pointed out by many respondents:

People get sick because of the kind of food they eat. They no longer get the food we grew and planted [...]. We have got kids eating ice cream or anything salty or sweet. And then you look at the older generation, they are all having problems with diabetes. ${ }^{135}$

These changes in health and expectations increase financial pressure where a move away from traditions has meant a reliance on imported foods and costly medical care and medication. People who do not have the means to buy these

\footnotetext{
133 Police are also involved internationally in disaster and emergency management however, this element is not included in this study.

134 Interview A5.

135 Interview A11.
} 
necessities are more likely to turn to crime to ease their family's pain and disease.

Globalisation is an interesting concept to explore and its qualities shimmer and fade depending from which view it is explored. Globalisation has shifted the economy from the traditional barter system to a cash economy and with this, expectations change and a better quality of life is part of that expectation. Exposure to globalisation leads to pressure, discontent and unequal shares in the global economy. Personal expectations of an expanded lifestyle can lead to disappointment, anger, and amoral or criminal behaviour when luxury items are unaffordable but desirable, creating a further drain on society and policing resources:

The people are moving away from their traditional way of life and because of that they found that money is the main source of living rather than their own resources. So, we have emerging crime resulting from globalisation. Like gang members, youth members, mainly we have an increasing problem resulting from alcohol. Women in most of the region know that sex is a good way to satisfy themselves financially. ${ }^{136}$

Even if expectations of a new and luxurious life do not lead to crime, the lure of a more exciting and better paid lifestyle in the US, Australia or New Zealand is powerful, meaning that young men and women are lost as an island resource. But, many return later in life rich in experience and eagerness to contribute to traditional island life again. For many Pacific Island cultures where elder respect is part and parcel of life, an older police service with 'mana' may help secure community trust and confidence. However, it is not only the lure of a perceived better life that draws the populace to metropolitan countries. Global warming also creates a need to relocate:

Global warming is basically the same [as globalisation]. Some of our officers are trying to relocate themselves. They are very good, experienced, but we have no choice but to let them go because they have to, you know, look after their family, and being from a remote island it's very difficult for them to make a living on a small salary so they either have to go where they can get a better paying job and look after their family much better than back home. So we have a high turnover in

${ }^{136}$ Interview A13. 
personnel because this global warming has affected everyone, especially if you're from a remote small island. ${ }^{137}$

Climate change and sinking islands were discussed by a number of interviewees and identified by many as a looming cause of increased crime as the world food shortage and high fuel costs result in decreased numbers of deliveries and product, turning people towards crime to make a living. This is particularly evident where the isolation of small islands also causes an increase in transportation costs and the cost of goods. Some respondents suggested that people will need to return to traditional ways of sustaining life, but that it would take a long time to adapt to a life without rice, and canned and fast foods. I surmise that an expectation to revert to a life of traditional self-sufficiency after being subjected to a life of instant gratification would also play a part in an increased crime problem.

Respondents also discussed smaller, but still significant, issues that were within the power of people to address in a shorter time frame. Specific training and resource issues were uppermost in people's minds, but exploration of these issues raised more complex factors. Training has been an enduring agenda item since the police chiefs of the South Pacific first met in 1970. A number of potential solutions have been discussed and some have been delivered. In 2002, PIF acknowledged the importance of policing as a stabiliser of political climate and economic growth and in 2003, the Australian and New Zealand prime ministers committed to a joint police training programme that would provide standardised police training for Forum Island Countries (FIC) in the Pacific. Implemented in 2004, the Pacific Regional Policing Initiative (PRPI) met Australia and New Zealand's goals for regional and national security and was offered in six components. ${ }^{138}$ The initiative was reviewed towards the end of 2008, being the end of the five-year commitment. This coincided with the AFP being allocated $A \$ 80.1$ million during 2008 for policing initiatives in the region, and the renaming of the PRPI in December 2008 to the Pacific Policing Development Programme (PPDP). ${ }^{139}$ The new arrangement sheds its previous

\footnotetext{
137 Interview A3.

138 The six components are: Strategic Policing; Executive Development Programme; Police Technical Skills; Training Capacity Development; Forensic Technical Skills; and Programme Management.; AusAID Australian Government, "Strengthening the Pacific's Crime Fighting Capabilities," Commonwealth of Australia,

http://www.ausaid.gov.au/media/release.cfm?BC=Media\&Id=2925_2989_8265_171_3189 (accessed 15 March, 2009); Pacific Regional Policing Initiative (PRPI), "Programme Profile".

139 Interview B3.
} 
partnership and dialogue with key regional stakeholder, New Zealand Police, and causes some consternation in the region over AFP's agenda in the Pacific: ${ }^{140}$

I find sometimes there is diplomatic problem with Australia and New Zealand; they do have cheque-book diplomacy. We like to criticise China and Taiwan for that, but I think it would be remiss to say New Zealand and Australia don't have the same approach. And I think they need to be careful, you know, there is disquiet within the Pacific countries about that type of approach. ${ }^{141}$

The sentiment raised by this interviewee was echoed by most others and extended to discuss the reality of metropolitan states providing training to their own understanding of policing needs in their own countries without real or proper understanding of the receiving country's culture and needs. While many acknowledged the value of some of the training given, they also asserted that PICs were often not in the situation to sustain or continue the results of it. This was considered essential to ensure that money spent is not simply wasted. Some saw that some training in expert areas, like forensics testing, while excellent, was also useless to them because they did not have the facilities or financial resources to carry out such testing. Another criticism of training was that while there was copious training provided, there was no measurement of learning from the training. Therefore, there was no accountability expected from people going on courses and it was almost impossible for managers to gauge what had been learnt or how to further develop their people. Successful and appropriate training is reliant on dialogue, two-way communication, needs assessments and evaluation of the course itself and of participant learning, appropriate design, and recognising that core ownership and focus lies with the receiving country not the donor:

Whatever comes into the Pacific it has to be moulded to fit the Pacific. If it doesn't we don't want it. That's my strong belief. ${ }^{142}$

From the evidence of the interviews, it was plain that training and resources need to be designed to fit the policing model that blends cultural needs with the rule of law specific to the country receiving the training, not the needs assumed by donor aspirations and plans.

\footnotetext{
140 Interview B2.

141 Interview B1.

142 Interview A10.
} 
Developing ways of working with new partners is a long process that requires patience and a real willingness to understand the other. This can be a difficult process in the Pacific where globalisation meets development particularly when Pacific peoples appear acquiescent to the demands of more globalised societies:

Because of the Pacific persona they are very reluctant to criticise, so it's very difficult and they certainly won't do it in a way that looks like it's going to embarrass or cause any country or agency to lose face. [...] The big thing that people from Australia and New Zealand have to realise is that they tend to think of their countries as more politically astute because they have this power of the economic thing, and that is the biggest mistake they can make. ${ }^{143}$

Much was made of the differences in learning methods between the Pacific cultures where politics and the ways of the world are passed from elder to infant throughout the course of their life in full immersion; ${ }^{144}$ and western cultures which rely on the written word and schooling to teach:

The people learn politics at their mother's knee. It's an immersion education in the Pacific where these people are acutely conscious of what's on offer and what they are expected to deliver up for it. ${ }^{145}$

The interviewees also discussed the different ways in which Australia and New Zealand work, with many recognising different points of value between Australia and New Zealand. A number of interviewees noticed some tension between the two countries in who was doing what, who was responsible for providing the most funds or who had the better reputation in the Pacific. Mostly, respondents just wanted both countries to get on with the work and not to bicker about who was doing what and whose approach was better:

And this competition of the AFP that seems to be pre-occupying some people. For me I couldn't care less about it. I've got no problems with the AFP. I've got no problems with the New Zealand Police. I've got no problems with any of them. But I have got a problem with the competition. ${ }^{146}$

The bickering aside, there are noticeable differences in the types of policing offered by the AFP and NZP, and in the language used in documentation

\footnotetext{
143 Interview A5.

144 Ibid.

145 Ibid.

146 Interview A7.
} 
describing their work. For example, Australia and the AFP insist on advertising their 'lead' role in interventions without acknowledging their partners. One interviewee commented:

I believe that the Australians believe that how they go about doing business is the right way to go about doing business. You and I might look, from the outside looking in and say well, New Zealand is slightly different than that. But I don't know that they [AFP] want to beat the chiefs into submission and say this is how it's going to be. But that might end up being the view. I don't know that's actually what they intend at all. But look, everybody knows the Australians and New Zealanders work together, they always have in the Pacific. New Zealanders have a great deal of respect, I think, for other Pacific Island countries, and Australia has given a lot of aid and assistance, but they work differently. ${ }^{147}$

Respondents also noted that the AFP was strictly involved in and appeared to be only interested in transnational crime and intelligence gathering, and that NZP was more involved in building capacity through a community policing model. While the AFP has established a number of Transnational Crime Units across Pacific Islands Forum countries employing local staff, who are supported and mentored by AFP representatives in those countries, ${ }^{148}$ New Zealand has implemented, among other things, the Pacific Prevention of Domestic Violence Programme (PPDVP), a tripartite agreement and fully collaborative arrangement between New Zealand Aid (NZAID) New Zealand Police (NZP) and the Pacific Islands Chiefs of Police (PICP). The programme is not limited to Forum Island countries but is available to all PICP member countries. While the PPDVP programme is welcomed as a complete partnership, the spread of the TCUs has caused some tension between Australia and New Zealand, and also some PICs:

While the TCUs have been supported, we know that New Zealand police aren't part of the TCU, so obviously there's some underground tension there as to why they're not, and they're likely seeing what the ultimate objective of having these TCUs is, so I guess in a nutshell I'd say that I think it's good that they're there, but I think there needs to be some more transparency about, you know, what their final objective is. Because I don't believe it's all about just providing for the Pacific Islands,

\footnotetext{
147 Interview A6.

${ }^{148}$ Australian Federal Police, "Pacific Transnational Crime Coordination Centre Opens in Suva," Commonwealth of Australia,

http://www.afp.gov.au/media_releases/national/2004/pacific_transnational_crime_coordination_cent re_opens_in_suva.html (accessed 14 January, 2009).
} 
you know, Australia and New Zealand actually don't have that approach. There's obviously a requirement for something to be given back and, it is yet to be seen what that actually is. ${ }^{149}$

These differences stimulated discussion during the interviews about how well each of the metropolitan countries mandates fitted the needs of building police capacity in the Pacific. Many respondents thought that the AFP 'wanted to put their footprint over everything', only brought its own international and intelligence mandate to the PICP table, and did not fairly represent the value offered in domestic and community policing by Australia's other police services. When discussing the PICP and the AFP the majority of respondents thought that the views of the Australian state and territory police, rather than the AFP, were valuable because they better reflected the type of policing that was carried out in PICs. But even though this was so, most respondents felt that the inclusion of all the Chiefs of Australia's state and territory services as members of the PICP, would result in the drowning of their own voices; therefore, this was not an option. There was also some acknowledgement that the AFP was making some improvements by swearing in selected members from state and territory police as AFP members, for specific field tenures and this was changing the flavour, to some degree, of the AFP in Pacific postings. Some participants suggested one or two state representatives could accompany the AFP delegate to the PICP conference, such as occurs from the Federated States of Micronesia which also has state and federal policing. Another suggestion was that a meeting of AFP and all Australian state and territory police to discuss issues and representation could be held just prior to the PICP conference, although there was concern that contributions from the states and territories may not be put forward at conference. Even though there was lively discussion about Australia and New Zealand, it was generally agreed that both countries were important to the future of policing in the Pacific, but perhaps with a little more 'distance' than they currently enjoy.

The vigorous discussions about Australia and New Zealand overshadowed, to a degree, interviewees' views on the other important influences on the region. However, the discussions identified perhaps the biggest factor impacting on the region. This was the problem of aid. The region has one of the lowest GDPPC in the world, creating an attractive vessel into which OECD countries eager to parade their responsible international citizen's badge can flood copious amounts of dollars, pounds, euros, yen and Chinese yuan.

149 Interview B3. 
There is an enormous amount of aid specifically targeted to the Pacific. Much of it is earmarked for social and economic development and some of it finds its way to the police services within the region. Research participants were asked a series of questions about donor funding, any perceived power imbalances between donor and receiver, and the differing expectations between donors who are members of Pacific regional organisations including France, Australia and New Zealand, and those of countries from outside this framework such as China, Taiwan, the United States and the European Union. Many agreed there were demands of accountability in relation to the use of funds particularly from Australia and New Zealand because of their own interests in regional and national security, whereas the EU was fairly benign and China and Taiwan were different again. ${ }^{150}$

Some interviewees observed that it was easy to get money from China and Taiwan and the arrangements about its use were fairly flexible. Additionally, there was no monitoring of expenditure, which was different from Australia and New Zealand who wanted to know a great deal about how the money was used and how much was needed. These two countries also wanted to evaluate the success or otherwise of its use, ${ }^{151}$ enabling donors to assess the usefulness and success of specific programmes and projects. Particular problems can arise when projects are partially funded by more than one country as occurred when Australia refused to allow some staff to attend an opening ceremony and put in writing to the host country to "reconsider receiving funding from the source of this country". ${ }^{152}$

Many participants described the receipt of funds as a necessity without which they could not provide services of a high standard to their citizens or keep their societies safe. ${ }^{153}$ Others saw the amount of funding as a disadvantage that caused a 'benefit mentality' in many parts of the Pacific. ${ }^{154}$ One participant had this to say:

There has to be a change of mindset from the Pacific Island nations [...] the first thing they say is "how can we get aid on this? How can we get it?" The first thing I say is, "how can we do it ourselves? What do we

\footnotetext{
${ }^{150}$ Interviews $\mathrm{A} 2 ; \mathrm{A} 5 ; \mathrm{A} 11 ; \mathrm{A} 13 ; \mathrm{B} 3$.

${ }^{151}$ Interview $\mathrm{A} 13$.

152 Interview A11.

153 Interviews A1; A2; A6.

154 Interview A7.
} 
need help with?" In my [country] it is chronic. And if everything collapses they know that somebody will come to their rescue. ${ }^{155}$

Another theme arising from discussion about donations and funding was that on many occasions the criteria set by donors did not match the needs of the receiver. For example, some of those interviewed discussed the millions of dollars being spent on new police buildings which would boost morale among the staff, but they still needed funds for basic personnel development and resources which were more difficult to come by. ${ }^{156}$ There were also comments on the need to ensure the results of donations were sustainable. For example, one participant spoke of receiving motor vehicles from Taiwan only to discover that spare parts were at additional cost and had to be sourced from Taiwan, and once vehicles were no longer usable there would be no replacements. ${ }^{157}$ Many agreed that whatever funding was provided it had to be done in a way that the outcomes from it could be sustained and would provide benefits for the country. ${ }^{158}$ It was claimed that many of the services carried out in country were provided by personnel contracted by the aid donor and that perhaps only thirty percent of the aid money stayed in country whilst the other seventy percent returned to the country of origin. ${ }^{159}$ Not only does this practice belie the messages of aid by donor countries, it also hampers the development of skills in the receiving country and contributes to crime, as discussed earlier. In addition to this, donor countries benefit from increased power through the ability to force decisions which benefit their own agenda, and this has not gone unnoticed by Pacific populations as pointed out by this interviewee:

Those with a higher population, the wealthier, the wealthiest countries are taking more powers in the decision-making, in my personal view, because they are providing us with resource. ${ }^{160}$

Unequal power breeds resentment and that, in turn, frustrates western ideas of progress which typically want to 'sprint things along'.

New Zealand and Australia broadly agree on the type of assistance meted out to police services in the Pacific. Overall, they both see the implantation of democracy and western styled democratic policing as the solution. This involves

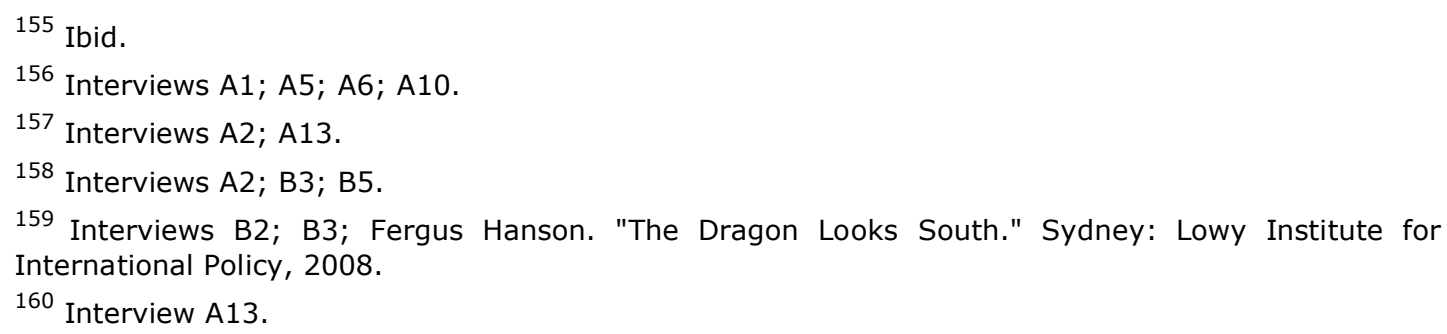


a 'whole-of-government' reform strategy as seen in the aggressive Regional Assistance Mission to Solomon Islands (RAMSI). Although RAMSI was planned at the regional level utilising the Pacific Islands Forum (PIF), a tactic designed to deflect accusations of neo-colonialism by Australia, there was no partnership in developing solutions, with the Solomon Islands government. ${ }^{161}$ The intervention involved two thousand two hundred and twenty-five military and police personnel from six countries. ${ }^{162}$ The RAMSI example, the demands for accountability and monitoring, and the numbers of expatriate New Zealand and Australian personnel placed in strategic police positions contribute to the perception of a power imbalance across the region. But such a perception can be eliminated through the willingness of metropolitan and donor minds to meet and actively listen to Pacific voices and to alter policies and practices accordingly.

Along with the perception of a power imbalance there was discussion by a number of respondents about a mismatch between colonial models of governance and traditional leadership, particularly in the area of knowledge and expertise in colonial models of public service. Attempts have been made in some countries to decentralise government, giving the power of governance back to tribal leaders but the complications faced were explained by this participant:

After de-colonisation, Britain pulled out and we became independent, but we still had all the British structures [...] which are centralised here with the government, but the new government decentralised governance substantially to some local leaders. We faced a lot of problems in that transition. It is good in a way because the traditional leaders are given power, but most often they work outside those powers simply because they don't understand, they don't have that knowledge [of British models of government]. Government officials have tried to explain but the leaders are changed from time to time and so they always lack the knowledge and understanding of how to work together with the central government. The police are caught in the middle of it. ${ }^{163}$

This discussion clearly demonstrates issues connected with advancing models of governance suitable and appropriate for recently independent societies. Some recognised advantages of colonisation, Christianity and government agencies

\footnotetext{
${ }^{161}$ Fraenkel, The Manipulation of Custom.

162 Australia, Fiji, New Zealand, Papua New Guinea, Samoa and Tonga.

163 Interview A9.
} 
that had provided a shift away from a more customary way of life. Although it was universally agreed that there was no going back, many participants strongly stated there was much work to be done in aligning western models with traditional ones and that metropolitan powers must listen more to the needs and voices of the Pacific:

It depends on those big countries. To improve this they have to work on dialogues and have not only a meeting but they have to expose themselves to our local environments, to see how well we go about with the people, what the customs are all about, whether there's political and social [customs]. [In] my personal view, I prefer a meeting [...] in that local environment, because they expose themselves to the heart of the country. ${ }^{164}$

Exposing donors to the heart of the country, its culture and resources seems like a simple solution, but along with exposure must also come understanding. There is no point in exposing donors to a situation if they consider the host's culture inferior or in need of meeting unrealistic western standards; or, if they don't understand it well enough to form real partnerships that will develop meaningful and collegial progress.

In addition to observations about a lack of attention to cultural matters and a willingness for both parties to meet somewhere in the middle, the AFP and NZP as members of the PICP as well as being donors and training providers, have a conflict of interest and a vested interest in the future of policing in the Pacific. A number of respondents saw a solution to this through a more assertive role for the Pacific Islands Chiefs of Police, a more involved role for their Secretariat and advisory roles only for AFP and NZP, rather than membership. An interviewee explained:

Ownership of policing standards and aid initiatives need to be seized by Pacific Islands' members of PICP to develop their own process, not to be dictated to by donor countries. This requires good practice and ownership which requires strong leadership - it is crucial for the Pacific Islands members to take control of their own processes. The Pacific Islands' chiefs need to lead while other members should sit outside as

${ }^{164}$ Interview A13. 
supporters. PICP-S has a crucial role to play, to be an action body in taking objective coordination of this process. ${ }^{165}$

Building on the seven key types of involvement in international policing, I now go on to propose a new approach to international policing in the Pacific which makes use of the insights gained from the interviews. This approach is designed to meet the needs of the developing countries of the Pacific region and, also of the donor countries.

\section{TOWARDS A NEW APPROACH}

State building and capacity building are two important and encompassing points where international policing meets domestic policing and it is essential that intervening personnel understand their host's needs and customs. I emphasise these meeting point this is where I think the greatest improvements can be made to communication, understanding and models of policing which will ensure interventions are appropriate to culture and country while also meeting the security and human rights needs of the international community.

My approach is based on the idea of community safety and defines community as those people socially and or politically bound by common interests; it can be as small as the smallest rural district or village within a country, or the wider community of a group of nations such as found in Polynesia, Melanesia, Micronesia, the Pacific, or within a group like the PICP. Likewise the approach is based on the idea that safety and security are interchangeable and therefore encompass personal, national and international security. In comparison to Sheptyicki's earlier typology, I suggest that if territory is not secure then it is plausible to assume that the territory's population is likewise not safe. This argument then, finds the concept of policing for community safety a solid and encompassing base that guides our understanding of policing in the international and domestic realms. Furthermore, the basis of community safety must be supported by a range of values and principles that ensure all police staff, national and international, are transparent and accountable in their work. The approach also offers a brief overview of nine basic individual elements that make up modern western policing systems. The principles of each of the elements are transferable in whole to any police jurisdiction, whether singly, in pairs or in total - but it is the content and methods of each element that must be appropriately designed to suit the rule of law and customs of the country adopting the model.

${ }^{165}$ Interview B5. 
If genuine attention is paid to this task the vision of the research participants is achievable:

The Pacific can sustain itself, it won't rely on outside people, each country will have its own style if you like. So each country has its own style and culture, but there is actually a regional awareness of the need to share information, to have similar sorts of protocols, so you can extradite people, and interview criminals in other countries, to have a bit of cooperation, because the countries are too small on their own to do that. So there needs to be more cooperation, and Pacific Islands' police would get more reliant on each other rather than turning to the bigger players every time. ${ }^{166}$

However, this vision can only become a reality if all sectors of government work together collegially, taking into account the effects of one sector on the others and designing solutions that balance policing, justice, health and education.

\section{SUMMARY}

Policing forms a crucial national security role in the Pacific not only for the Pacific Island Countries lying within it, but also for a growing number of large metropolitan countries who not only consider national security among their interests, but also the rich bounty of resources in the region and various diplomatic benefits. The Pacific Islands Chiefs of Police have met as a group since 1970 to discuss issues such as training, resources and terrorism. Research participants identified a vision for policing in the region that included self-control of their police services in accord with the spirit and principles of the rule of law, good governance and access to justice, while respecting local indigenous cultures and identities, and human rights.

A number of issues need to be addressed before this vision can succeed: an overwhelming interest in the region from a number of metropolitan and large countries with a range of agendas; a hangover of colonial models of governance that are culturally inappropriate and cumbersome, and expensive to maintain; globalised wealthy western states clashing with the emerging economies of unique once self-sufficient societies; and an inflow of billions of dollars, euros, yen and yuan accompanied by varying levels of accountability.

166 Interview B3. 
According to interviewees, globalisation has had the biggest influence on the region through changes in expectations of self-improvement, resulting in an explosion of heart disease and diabetes, one factor in an increasing crime problem, an increase in amoral behaviour and or crime, and migration. Tourism as an offshoot of globalisation exposes populations to western disposable incomes and this also causes crime against tourists through desire for unaffordable consumer goods. Climate change is also a factor in forcing migration and increased crime. Smaller solvable issues include training, but this point raised further complexities including a spat between Australia and New Zealand about who did things better in the Pacific; cheque-book diplomacy of China Taiwan, Australia and New Zealand; and, a perception of a power imbalance across the region which related to the power of those holding the funds over those who needed them. The power imbalance resulted in training programmes for Pacific policing that were decided by the providing body but often did not match what was actually needed or were not sustainable.

Assumptions about the peoples, cultures and politics of the Pacific made by outsiders are often out of touch with reality. The cultures of the Pacific teach their young through spoken language and story-telling from birth. They are very astute in the ways of the world and what they have to give up, but outsiders tended to think that because Pacific peoples do not complain or loudly argue, that they acquiesce to the demands of the wealthy; but a reluctance of Pacific peoples to criticise or embarrass often leads to exploitation.

Aid to the region raises even more complex issues and differing expectations from each of the states and bodies providing funds. Funds often do not meet the needs of the receiving country. The day-to-day resources needed to carry out their work are overlooked for more flamboyant testaments to assistance. Others require very high levels of accountability and transparency in the use of funds. Interviewees were almost unanimous in voicing that external funding organisations needed to be exposed to the 'heart of the country' before coming to them to discuss and dialogue what was needed, and that those funding organisations need to listen and help in designing interventions that fit with the customs of the country.

It was noted that the AFP and New Zealand have a conflict of interest in being members of the PICP as well as major funding providers of policing. A solution offered was to transition to advisory positions to the PICP rather than act as decision makers and members. This is in harmony with good development 
theory that encourages handing over the 'stick' of power to the less powerful, empowering them to make their own decisions. ${ }^{167}$

An understanding of Pacific Policing has been provided by an overview of the various types and examples of policing currently undertaken in the Pacific. These include intelligence such as that offered by Interpol, the PTCCC and TCUs; peace-making missions either by the UN or the regional mission RAMSI which include the investigation of high level criminal offences; state building; capacity building; training; emergency management; and liaison.

State-building and capacity-building are two areas where international policing meets domestic policing and it is these areas that provide a number of opportunities to satisfy cultural needs as well as the security needs of external providers. A new approach to pacific policing is offered that concentrates on collaborative processes.

\section{CONCLUSION}

This chapter has revealed a number of complex problems involved in international policing in the Pacific. It seems clear that Australia and New Zealand are committed to continuing their work in policing in the Pacific; however, they must be mindful that the peoples of the Pacific do not have the benefit of more than a hundred years experience in independence or sovereignty. This disadvantage places Pacific Islands' cultures and peoples in a vulnerable position therefore, although Pacific leaders acknowledge the need for assistance from external providers, the way forward must heed the voices of the Pacific. This will occur if Australia and New Zealand cease their bickering about who has the most money or who works better, recognise each other's strengths, and focus on working side-by-side. They should both step back from their active board roles and take on consultative ones instead, joining with other fund providers to assess and plan for sustainable policing practices in the Pacific. There are a number of well established organisations in the Pacific which have relevant expertise, knowledge and local respect and are featured in Chapter 4. These organisations should be at the forefront of future planning.

It is also apparent that Pacific leaders and decision makers need to change the Pacific Way from one of acquiescence to that of assertive leadership to ensure ownership of the way forward.

\footnotetext{
167 INTRAC, "Improving aid effectiveness: A review of recent initiatives for civil society organisations," n.d. International NGO Training \& Research Centre.
} 


\section{CHAPTER FOUR: REGIONAL COOPERATION AND DYNAMICS}

Policing in the Pacific has been regionalised since the Chiefs of Police from seven South Pacific police jurisdictions met in 1970 to discuss issues facing them. This offered an opportunity for all of the isolated jurisdictions of the Pacific to discuss common problems and plan solutions together, to learn and glean knowledge from the more experienced. At the first meeting it was important for the chair, His Excellency the Governor General of Fiji, Sir Robert Foster, to state that attendance and discussion should not be, in any way, limited by the constitutional status of any of the Pacific island nations. The importance of this qualification became more obvious in later years when some annoyance was displayed by the Pacific Islands Forum Secretariat (PIFS) in dismissing the importance of the larger membership of the PICP. However, the question of membership is also linked to regional kinship as can be seen in the trust and acceptability afforded the Pacific Community, which has the largest membership of all Pacific organisations. This is important in a region which values its culture and fights to retain it while progressing towards globalisation.

The main focus of this chapter as viewed through the internal lens is the collaboration and cooperation between organisations within the Pacific region with a special emphasis on law enforcement, encompassing police, customs and immigration. A number of organisations are examined, in order of their age, beginning with the South Pacific Community (SPC), which was established in 1947 and is now known simply as the Pacific Community, ${ }^{168}$ and ending with a brief overview of sub-regional policing bodies. The bulk of those in the middle have been included for their links to law enforcement (including police, customs and immigration), regional politics (through the Pacific Islands Forum, APEC, ASEAN and ARF), and civil society. In this section I focus on the backgrounds, functions, corporate plans, governance and funding of each organisation. This discussion is followed by analysis based on interview data about cooperation and collaboration, vertically and horizontally, among organisations. Particular questions raised involve communication and coordination, the tyranny of distance, language, the Pacific Way, and perceptions of power. The discussion also identifies areas of contention which have been more closely analysed in

168 The Secretariat of the Pacific Community now uses the acronym SPC. 
Chapter Three. A summary of the discussion and analysis completes the chapter.

\section{THE PACIFIC COMMUNITY}

The South Pacific Commission (SPC) ${ }^{169}$ was formed in 1947 by the six governments with territorial interests in the Pacific - Australia, New Zealand, the United Kingdom, France, the United States of America, and the Netherlands through the Canberra Agreement (1947). ${ }^{170}$ The SPC was a direct outcome of the ANZAC Pact, an agreement between Australia and New Zealand made in Canberra and brought into force 1 February 1944, to ensure post-war Australian security interests were regionally focussed and driven in concert by Australia and New Zealand. ${ }^{171}$

Article 30 of the ANZAC Pact referred to the establishment of a regional organisation which would have advisory powers and a suggested name of the South Seas Regional Commission. The possibility of including 'accredited representatives' from the United Kingdom, the United States of America and France were raised in Article 30, but only as a possibility, not as a foregone conclusion. ${ }^{172}$ The agreed broad function of the future organisation was to develop and establish common social, economic, and political development policy targeted at improving and advancing the well-being of the native peoples themselves'. ${ }^{173}$ At the forefront of the detailed functions of the organisation as set out in Article 31 (a) was a recommendation that indigenous peoples be increasingly introduced to administrative roles in preparation for self-government of a form most suited to those indigenous populations. ${ }^{174}$ Article 31 (b) to (e) expected the regional organisation to recommend arrangements for material development, coordination of health and medical services and education, maintenance and improvement of labour conditions and social services, as well as collaboration in economic, social, medical and anthropological research.

\footnotetext{
169 Now known as the Pacific Community.

170 Secretariat of the Pacific Community (SPC), "History," Secretariat of the Pacific Community, http://www.spc.int/corp/index2.php?option=com_content\&task=view\&id=24\&pop=1... (accessed 29 September, 2008).

${ }^{171}$ Richard Herr, "Australia, Security and the Pacific Islands: From Empire to Commonwealth," The Round Table 95, no. 187 (2006).

172 "The ANZAC Pact ", www.dfat.gov.au/GEO/new_zealand/01-ANZAC.pdf (accessed 29 September, 2008).

173 Ibid.,

174 Ibid.,
} 
Article 31 (f) suggested the organisation would make and publish periodical reviews of progress in relation to the previous five functions. ${ }^{175}$

Three years later on 6 February 1947, six metropolitan states ${ }^{176}$ convened, again in Canberra, to agree on and bring into force the Establishment of the South Pacific Commission. ${ }^{177}$ Territorial scope is contained in Article II, which limits representation to only non-self-governing territories and clearly sets geographical boundaries to include all territories administered by the participating governments which lie (wholly or in part) in the Pacific Ocean but south of the Equator and east from and including Netherlands New Guinea. ${ }^{178}$ This scope was amended in November 1951, to include Guam and the Trust Territories of Pacific Islands which lie north of the Equator. ${ }^{179}$ The territorial scope was further amended in 1964 to include representation of the first independent state, Western Samoa, and the potential inclusion of an increasing number of independent states. ${ }^{180}$ An additional amendment in 1964 involved the withdrawal of the Netherlands ${ }^{181}$ as a result of handing over Netherlands New Guinea to Indonesia in 1962, effecting the removal of almost three quarters of a million people from the Pacific region and placing them within Indonesia. ${ }^{182}$ The United Kingdom withdrew in 1996 and rejoined in 1998, but then withdrew again in $2005 .{ }^{183}$

Further amendments to the founding document occurred in 1974, 1976, 1983, 1996 and in 1997 the name of the South Pacific Commission was changed to the Pacific Community. In 1999 the Declaration de Tahiti Nui was written to eliminate the cumbersome processes required to make changes to the Canberra Agreement (1947) and embodies the operational policies of the Pacific

\footnotetext{
175 Ibid.,

${ }^{176}$ Australia, the French Republic, the Kingdom of Netherlands, New Zealand, the United Kingdom of Great Britain and Northern Ireland, and the United States of America.

177 Australian Treaty Series 1948 No. 15, "Agreement Establishing the South Pacific Commission," Australian Government Publishing Service,

http://www.austlii.edu.au/au/other/dfat/treaties/1948/15.html (accessed 20 November, 2008).

;Secretariat of the Pacific Community (SPC), "History".

178 Australian Treaty Series 1948 No. 15, "Agreement Establishing the South Pacific Commission".

179 Christopher Hedley, "Amendments to the Agreement Establishing the South Pacific Commission," Internet Guide to International Fisheries Law, http://www.intfish.net/igifl/treaties/related/spc.htm (accessed 20 November, 2008).

180 Ibid.

181 Ibid.

182 Secretariat of the Pacific Community (SPC), "History," , Richard Herr, "The Region and the World: Regional Cooperation and Initiatives, Pacific Community (South Pacific Commission), South Pacific Forum," in The Pacific Islands: an encyclopedia, ed. Brij V. Lal and Kate Fortune (Honolulu: University of Hawai'i Press, 2000).

183 Secretariat of the Pacific Community (SPC), "History".
} 
Community. This living document is updated as required by the governing body, the South Pacific Conference. ${ }^{184}$

The founding document and subsequent amendments established the SPC as a 'consultative and advisory body to the participating Governments' with a strong research focus. It was also to make recommendations and provide coordination of services to develop economics, social rights and welfare of the people in the region, particularly in 'agriculture, communications, transport, fisheries, forestry, industry, labour, marketing, production, trade and finance, public works, education, health, housing and social welfare'. ${ }^{185}$

Noticeably absent from the agreement was any reference to political development and the advancement of indigenous self-governance, having been ruled out by conservative European governments particularly against Australia, who argued strongly in favour of self-governance, and New Zealand. ${ }^{186}$ The significance of this omission was highlighted during the 1970s when members of the Pacific Islands Producers Association (PIPA) became disenchanted with SPC's refusal to act in relation to the issues of nuclear testing at Mururoa Atoll and Kanak suppression in New Caledonia. ${ }^{187}$ This disenchantment became a successful push for the establishment of a politically assertive regional organisation, the future South Pacific Forum. ${ }^{188}$

As a result of pressure to reform by member countries and the South Pacific Forum's initiative in establishing a regional coordination body, the SPC instigated independent external reviews in 1996, 2001 and 2005. The draft Declaration de Tahiti Nui (1999), ${ }^{189}$ reaffirms SPC's apolitical nature and its mandate to 'undertake research, technical assistance and training in support of the economic and social development of the region's twenty-two Pacific Island Countries and Territories'. The Declaration recognises and emphasises that the work of the SPC should complement that of other regional organisations and avoid overlap or infringement of other agencies' roles in the region. Section 43 clearly states a

\footnotetext{
184 Secretariat of the Pacific Community (SPC). "The Declaration de Tahiti Nui being The Operational Policies of the Pacific Community." Pacific Community 2000.

185 Australian Treaty Series 1948 No. 15, "Agreement Establishing the South Pacific Commission,"

186 Herr, "Australia, security and the Pacific Islands".

187 See Pacific Islands Forum for further discussion about this point, p.12.

188 Discussed further in the section 'Pacific Islands Forum (PIF).

189 The Declaration resulted from the 1996 review.
} 
necessary and desired inter-organisational relationship-building and cooperation stance at a regional and international level. ${ }^{190}$

The functions of the SPC remain true to the original document, but an external review of the organisation in 2005 is reflected in the Corporate Plan to 2012. Whilst recognising the three major focus areas of the SPC, the current Corporate Plan has new emphases on an increased focus on member priorities, strategic engagement at national, regional and international levels, and enhancing SPC's public profile and strategic positioning. ${ }^{191}$ The SPC's challenge is to become more proactive in monitoring and analysing developments relevant to its member countries and territories. It will develop individual country strategies across the region and devolve its staff to position itself as a hands-on, on-thespot organisation capable of responding to in-country needs promptly and proactively. It will ensure its programmes, currently based in Land, Marine and Social resources, complement other national and regional programmes to a greater extent than in the past. ${ }^{192}$

A constant theme running through the Declaration de Tahiti Nui (2000) and Corporate Plan 2007-2012, is that of collegial working partnerships with open and frequent communication to ensure the development of economies, health and social aspects of the peoples of the Pacific Islands. ${ }^{193}$

The SPC is governed by the Conference of the Pacific Community. ${ }^{194}$ This body, comprising Ministers of Foreign Affairs or equivalent, meets every two years and delegates its authority to make decisions to the Committee of Representatives of Governments and Administrations (CRGA) to provide a mechanism to advance issues between Conference years. ${ }^{195}$ Each of the twenty-six member countries and territories has one vote although decisions are only put to a vote where the Pacific Way of Consensus cannot be reached through a concerted effort of conversation and discussion. ${ }^{196}$

\footnotetext{
190 Secretariat of the Pacific Community (SPC). "The Declaration de Tahiti Nui".

191 Secretariat of the Pacific Community (SPC), Corporate Plan (2007-2012) (Noumea: Secretariat of the Pacific Community (SPC), 2008).

192 Ibid.

193 Secretariat of the Pacific Community (SPC). "The Declaration de Tahiti Nui." , Secretariat of the Pacific Community (SPC), Corporate Plan (2007-2012).

194 Members are representatives of the governments and administrations of the twenty-six countries and territories and are usually the Minister of Foreign Affairs or equivalent.

195 Secretariat of the Pacific Community (SPC), Corporate Plan (2007-2012).

196 Secretariat of the Pacific Community (SPC). "The Declaration de Tahiti Nui".
} 
The Conference of the Pacific Community and CRGA are supported by the Secretariat of the Pacific Community (SPC) which has its head office in Noumea, New Caledonia, one in Suva, Fiji and another recently opened office in Pohnpei, Federated States of Micronesia. The SPC is legally an international organisation managed by an Executive Director who in 2007 was responsible for approximately 350 staff. ${ }^{197}$

Figure 1 - SPC Donors ${ }^{198}$

\section{Donor Countries}

\begin{tabular}{|c|c|c|c|}
\hline Australia & France & European Union & Germany \\
\hline Japan & New Zealand & Taiwan & United States \\
\hline \multicolumn{4}{|c|}{ Land Programmes } \\
\hline $\begin{array}{l}\text { Australian Centre } \\
\text { for International } \\
\text { Agricultural } \\
\text { Research (ACIAR) }\end{array}$ & $\begin{array}{l}\text { Food and } \\
\text { Agriculture } \\
\text { Organisation } \\
\text { (FAO) }\end{array}$ & $\begin{array}{l}\text { International } \\
\text { Plant Genetic } \\
\text { Resources } \\
\text { Institute (IPGRI) }\end{array}$ & $\begin{array}{l}\text { United Nations } \\
\text { Development } \\
\text { Programme } \\
\text { (UNDP) }\end{array}$ \\
\hline \multicolumn{3}{|c|}{ Marine Programmes } & $\begin{array}{l}\text { Asian } \\
\text { Development } \\
\text { Bank (ADB) }\end{array}$ \\
\hline $\begin{array}{l}\text { Global } \\
\text { Environment } \\
\text { Facility (GEF) }\end{array}$ & $\begin{array}{l}\text { International } \\
\text { Maritime } \\
\text { Organisation } \\
\text { (IMO) }\end{array}$ & $\begin{array}{l}\text { MacArthur } \\
\text { Foundation }\end{array}$ & $\begin{array}{l}\text { Packard } \\
\text { Foundation }\end{array}$ \\
\hline \multicolumn{3}{|c|}{ Social Programmes } & $\begin{array}{l}\text { Commonwealth } \\
\text { Secretariat }\end{array}$ \\
\hline $\begin{array}{l}\text { Centres for } \\
\text { Disease Control } \\
\text { and Prevention } \\
\text { (Atlanta) (CDC) }\end{array}$ & $\begin{array}{l}\text { United Nations } \\
\text { Educational, } \\
\text { Scientific and } \\
\text { Cultural } \\
\text { Organisation } \\
\text { (UNESCO) }\end{array}$ & $\begin{array}{l}\text { United Nations } \\
\text { Population Fund } \\
\text { (UNFPA) }\end{array}$ & $\begin{array}{l}\text { World Health } \\
\text { Organisation } \\
\text { (WHO) }\end{array}$ \\
\hline
\end{tabular}

In 2007 the SPC had an annual budget of approximately US $\$ 48$ million that is split between core (US $\$ 35$ million) and non-core (US $\$ 8.5$ million) functions. ${ }^{199}$ New challenges for human resources, corporate services and programme support

\footnotetext{
197 Secretariat of the Pacific Community (SPC), Corporate Plan (2007-2012).

198 Secretariat of the Pacific Community (SPC), "Donors," Secretariat of the Pacific Community (SPC), http://www.spc.int/corp/index2.php?option=com_content\&task=view\&id=23\&pop=1... (accessed 29 September, 2008).

199 The evident disparity between the total budget and the split between core and non-core funds is taken from the SPC's Corporate Plan 2007, pp.16,38.
} 
services require a concerted effort to attract new funds realisation to relieve pressure on what is described as a static fund. ${ }^{200}$ [See Figure 1]

\section{PACIFIC IsLANDS CHIEFS OF POLICE (PICP)}

The Pacific Islands Chiefs of Police (PICP) was established in 1970 as the South Pacific Chiefs of Police Conference (SPCPC). The seven founding members ${ }^{201}$ met to discuss policing issues and ways of collaborating to ensure the best use of limited financial resources allocated to policing by governments. ${ }^{202}$ Membership grew to twenty-eight members by $1993^{203}$ and included all Pacific Island Countries and territories with the exception of Wallis and Futuna, Tokelau, Pitcairn Islands, Norfolk Island, Rapanui and Hawaii, but including New Zealand and Australia. A clear comment made at the first conference by Sir Robert Foster, Fiji's Governor, was that the constitutional arrangements of South Pacific Island nations would not limit discussions between members of the policing fraternity of the South Pacific. ${ }^{204}$ This philosophy set the political boundaries of the SPCPC and was in keeping with the South Pacific Commission but not with the South Pacific Forum which followed a year later. ${ }^{205}$

The SPCPC grew exponentially however, and by 2000 countries represented by more than one police service were required to relinquish seats of individual state services in favour of their Federal police services which would represent all police jurisdictions in their country. This brought the membership back to the current twenty-one members. ${ }^{206}$ The name of the organisation was changed in March 2005 to reflect that membership had outgrown the South Pacific with member countries from both Micronesia and Melanesia.

The PICP represents approximately 85,750 serving police staff and it also holds a seat on the International Association of Police Chiefs (IACP). [See Appendix Two, Table 1]

\footnotetext{
200 Secretariat of the Pacific Community (SPC), Corporate Plan (2007-2012).

${ }^{201}$ Fiji, Tonga, New Hebrides (Vanuatu), Gilbert (Kiribati), Ellice (Tuvalu), British Solomon Islands (Solomon Islands), and Nauru.

202 Conference Secretary "Minutes of the 1st South Pacific Chiefs of Police Conference," (Suva, Fiji Islands: SPCPC, 1970).

${ }^{203}$ Conference Secretary, "Minutes of the 22nd South Pacific Chiefs of Police Conference," (Papua New Guinea: SPCPC, 1993).

204 Conference Secretary "Minutes of the 1st Conference".

205 See overviews of each organisation in this chapter.

206 Conference Secretary, "Minutes of the 29th South Pacific Chiefs of Police Conference," (New Zealand: SPCPC, 2000).
} 
One of the functions of the PICP has been to discuss issues as they related to police jurisdictions across the Pacific. Many of the agenda items generated collaboration in training and the provision of equipment, but many of the items returned for discussion in successive agendas. As the political climate changed over the years, many of the agenda items increased in seriousness, particularly in the areas of terrorism, drugs and transnational crime, and offences relating to fishing. The nature of the Pacific and its reliance on its fishing industry indicates that the latter offences would be exceedingly important to the economy of the region. The terrorist events in New York and Washington DC in September 2001 and in Bali in October 2002 increased the emphasis on transnational crime and terrorism. Around this time the UN also sharpened its focus on human rights, placing additional pressure on developing countries to address issues such as HIV/AIDS and poverty. These growing issues and concerns stimulated the PICP Secretariat to increase staff numbers to address them.

New Zealand Police (NZP) provided a high-ranking member of NZP who acted as a secretariat, organising matters relating to the annual conference from 1976. This role was carried out as part of his day-to-day duties. Over the years the Chiefs regularly questioned the role of the organisation itself and that of its secretariat. A number of formal internal reviews confirmed that the role of the secretariat was to complete tasks as set by the Chiefs at the annual Conference and to ensure the conference was organised. However, in 2004/2005 another internal review of the PICP and Secretariat resulted in an expansion of the secretariat's role and increase in staff to run a growing number of projects around HIV/AIDS, Use of Force, Patrol Boats and Peace Keeping. A further internal review of the Secretariat in 2007/2008 was conducted by AFP, NZP and Palau Police to assess the capabilities and the capacity of the PICP Secretariat to develop and deliver the "Future Directions in Pacific Policing" programme of work. $^{207}$

The Future Directions in Pacific Policing paper of 2007 highlights the three pillars of Ethics and Integrity, Regional Policing Capacity Development and Regional Cooperation. ${ }^{208}$ The overall objective of the strategy is to place police in a central role in the region which is respected for its governance, democratic values and human rights. The overarching goal of the strategy is:

\footnotetext{
207 Boswell, "Policing the Pacific".

208 Pacific Islands Chiefs of Police Secretariat, "Future Directions of Pacific Policing,"2007 Wellington: Pacific Islands Chiefs of Police Secretariat http://www.picp.org/index.php/Publications/2007Communique (accessed 30 November 2008).
} 
To improve the value of policing in the Pacific and shift the focus from a cost to government to an investment in the safety and security of community, country and region. ${ }^{209}$

The strategy requires country by country dialogue to assess needs and develop specific plans for implementation which will include significant investment in staff training and development, new buildings and equipment in a number of locations, and improvements to governance and administration frameworks. The Chiefs' wishes and intentions to raise the profile and professionalism of policing in the Pacific are reflected in the FDIPP paper which will critically inform the PICP strategy to $2014 .^{210}$

The PICP is governed by a Constitution that was last revised and consolidated at the Annual Meeting of 2005. The Constitution encapsulates the name, mission statement and rules about how the organisation and its secretariat is organised and run. Article II contains information about the territorial borders of membership which are very broadly described as 'in the region of the Pacific Islands', meaning that any island country within the Pacific Ocean could apply for membership. ${ }^{211}$ Article II, S.3 allocated one vote per member country for any matter or issue with decisions carried on a two-thirds majority vote. ${ }^{212}$ This process departs from the usual decision making method for Pacific regional organisations of the "Pacific Way of Consensus". Meetings follow the general "Robert's Rules of Order". ${ }^{213}$ Although the Secretariat is mentioned in passing within various parts of the document, it does not specify any rules or purpose for it apart from those pertaining to the responsibilities of the Executive Director in heading the secretariat, reporting on its regular business at the annual meeting, and the responsibilities of a custodial and caring nature regarding the PICP funds.

The PICP and its Secretariat have been reviewed constantly over the life of the organisation. Some of these reviews have been formally carried out by an internal review team whilst others have been ad hoc. Most have been generated by the AFP who also form part of the review team along with NZP and another Pacific Island country representative. Whilst the generosity of time and

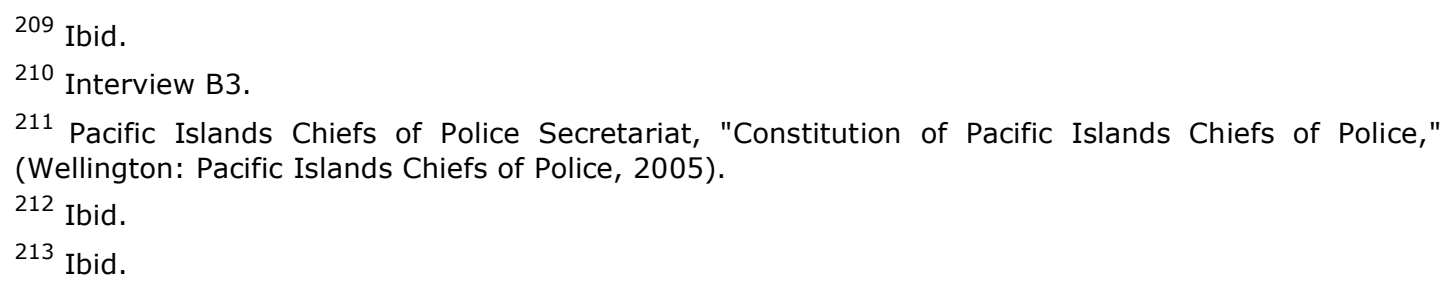


resources from the metropolitan states is commendable, this process of internal review is biased and weighted towards the powerful, with questionable transparency.

The PICP is serviced by a Secretariat which is housed in New Zealand at Police National Headquarters. Funds to administer the secretariat and provide salaries and project funding, including development funds for women in policing, and the travel fund are provided by New Zealand Police (NZP), Australian Federal Police (AFP), NZAID, AusAID, UNAID and France. AFP makes provision for two to three short term project officers to be sourced from the Pacific, and a Project Manager with the additional role of AFP liaison in New Zealand. This combination of roles also raises questions about a conflict of interest for the AFP, and transparency. The annual PICP budget is in the region of NZ\$1.6 million. ${ }^{214}$

The SPCPC established the South Pacific Islands Criminal Intelligence Network (SPICIN) in 1987 during its Conference in response to a need for police jurisdictions to share information about criminals and criminal movements throughout the region. The terms of reference for this arrangement were captured in a Memorandum of Understanding (MOU). The purpose of the network was to provide a central repository, analytical expertise, coordination of cross country investigations, and training in related matters. ${ }^{215}$

Although the PICP no longer claims any formal tie with SPICIN, SPICIN still implies links to the SPCPC through its website. ${ }^{216}$ In 2003 the PICP resolved to transfer governance of SPICIN to the government of American Samoa and the SPICIN Policy Board which had previously governed the organisation was dissolved. At this point the PICP pledged unanimous support for the newly established PTCCC which is discussed in more depth later in this chapter.

The first conference of the PICP - Women's Advisory Network (PICP-WAN) was held in 2004 in Fiji. The purpose of the group is to discuss issues facing women in police across the region and to report these to the Chiefs at their annual Conference. $^{217}$ This initiative follows a focus on human rights and the inclusion

\footnotetext{
214 Confidential source.

215 Conference Secretary, "Minutes of the 16th South Pacific Chiefs of Police Conference," (American Samoa: SPCPC, 1987).

216 "Policy Board," n.d. Pago Pago: SPICIN Website http://spicin.com/policy (accessed 1 December 2008).

217 Pacific Islands Chiefs of Police Secretariat, "5th PICP Women's Advisory Network Conference: Future Directions of Women in Pacific Policing," 1-2 July 2008 Wellington, New Zealand: PICP.
} 
of gender equality in a number of strategic plans in the region and is administered by the PICP. ${ }^{218}$

The PICP-WAN meets annually and actively endeavours to increase the knowledge base of women in policing by welcoming a delegation of two women from each PICP member country, one who has attended the conference in a previous year, and the other being a new initiate. The following year the new initiate becomes the experienced delegate and a new delegate is selected to accompany the experienced one. The 2008 Conference also identified a model to ensure impetus gained through the Conference was maintained throughout the year 'in-country'. ${ }^{219}$

\section{PACIFIC ISLANDS FORUM (PIF)}

The Pacific Islands Forum grew from the establishment of a group of newly independent ex British Commonwealth Pacific Island Countries in the 1960s to actively build trading markets in New Zealand for their produce. The group, Pacific Islands Producers Association (PIPA), had previously approached the SPC with two agenda items in 1970 . The first was to stop France testing nuclear bombs at Mururoa Atoll, ${ }^{220}$ and the second was to develop a regional political programme. Both of these items were firmly rejected by France and the US. ${ }^{221}$ The PIPA member states turned their attention to New Zealand in 1971 in a bid for her to host a meeting of the heads of independent and self-governing Pacific Island Countries and Australia. This meeting was hailed a success, however the increased political and wider regional focus was not reflected in PIPA as a name, and at the Australian hosted meeting in February 1972 the South Pacific Forum (SPF) was established as a regional political entity. ${ }^{222}$

The SPF actively opposed France's stand on nuclear testing at Mururoa Atoll and was responsible for establishing the South Pacific Nuclear Free Zone (SPNFZ) through the Treaty of Rarotonga of 1985. It also opposed France's denial of selfdetermination for the Kanak population in New Caledonia, resulting in New

\footnotetext{
218 Secretariat of the Pacific Community (SPC), Corporate Plan (2007-2012); Pacific Islands Forum Secretariat, "The Pacific Plan: For Strengthening Regional Cooperation and Integration," November 2007 Suva: Fiji Islands: Pacific Islands Forum http://www.forumsec.org.fj/UserFiles/File/Pacific_Plan_Nov_2007_version.pdf (accessed 18 August 2008).

219 Pacific Islands Chiefs of Police Secretariat, "5th PICP Women's Advisory Network Conference: Future Directions of Women in Pacific Policing".

220 Herr, "Australia, security and the Pacific Islands," 705-716. Derek McDougall, "Insecurity in Oceania: An Australian Perspective," The Round Table 96, no. 391 (2007): 415-427.

221 Herr, "Australia, security and the Pacific Islands".

222 Ibid.
} 
Caledonia's inclusion on the United Nations list of non-self-governing territories. ${ }^{223}$ This pressure led to the Matignon (1988) and Noumea (1998) Accords, which may eventually lead to New Caledonia's independence. ${ }^{224}$

The establishment and success of the South Pacific Forum gave its members the impetus to lobby for a single regional organisation (SRO) to replace the SPC with a more forward looking organisation after efforts in 1970 to force reform on the SPC failed. The South Pacific Bureau for Economic Cooperation (SPEC), an intergovernmental arm of the SPF, was reasonably successful for about ten years, but eventually the all inclusiveness of the SPC was more favourable to the shared background of all twenty-two Pacific Island nations than the partly shared history of British colonisation. ${ }^{225}$ To increase its attractiveness and regional 'clout', the SPF increased its scope to include all independent and self-governing countries as members. Perhaps a single regional organisation based only on British Commonwealth Pacific Island Countries could have existed alongside the SPC, but not one based on a membership that would include all Pacific Islands Countries as they became independent at some time in the future, as this would simply duplicate the SPC. ${ }^{226}$ However, recognition of overlaps and opportunities for the region did result in the Forum's successful establishment of the South Pacific Organisations Coordinating Committee (SPOCC) later known as the Council of Regional Organisations in the Pacific (CROP), in 1988 to manage relationships between the two, eliminating the need for a third organisation. ${ }^{227}$

The issue of a single regional organisation was first discussed at the Forum in Canberra in 1972. It was the same year the idea was floated to establish a Bureau in Fiji to organise matters of trade in the region. ${ }^{228}$ The Bureau became the South Pacific Economic Committee (SPEC) and eventually in 1988 became

\footnotetext{
223 McDougall, "Insecurity in Oceania".

224 Herr, "The Region and the World: Regional Cooperation and Initiatives, Pacific Community (South Pacific Commission), South Pacific Forum."; Maclellan, "The Noumea Accord and Decolonisation in New Caledonia."; David Q.A. Chappell, "The Noumea Accord: Decolonisation without independence in New Caledonia?," Pacific Affairs 72, no. 3 (1999).

225 Herr, "Australia, security and the Pacific Islands".

226 Two of the many factors influencing the outcome include Australia's fears over security stemming from the Cold War, and its interest in keeping the US involved in the Pacific. Other factors include the legal status of the SPC. (See Herr, "Australia, Security and the Pacific Islands." p.713.)

227 Herr, "Australia, security and the Pacific Islands.", SPC Publications Section, Regional Organisations of the Pacific: Working Together (Noumea: Secretariat of the Pacific Community, 2002).

228 Pacific Islands Forum Secretariat, "South Pacific Forum," 23-25 February 1972 Canberra: Pacific Islands Forum http://www.forumsec.org.fj/_resources/article/files/1972\%20Communique2.pdf (accessed 27 February 2008).
} 
known as the Forum Secretariat. ${ }^{229}$ In 1999 the members agreed to change the name to the Pacific Islands Forum (PIF) which came into effect in 2000. ${ }^{230}$ At Tarawa on 30 October 2000 the Agreement Establishing the Pacific Islands Forum Secretariat was opened for signature ${ }^{231}$ and is still currently in force although it was reviewed in 2004 and a new agreement opened for signature in 2005. This agreement has been signed by all parties but at the time of writing was not ratified. ${ }^{232}$

In 2005, PIFS contracted a review of the architecture for regional cooperation in the Pacific, again raising the desire of the Forum to instigate changes to established institutions in the region in pursuit of one single regional organisation. $^{233}$ The resulting fifty-four page report makes a total of nine recommendations, the final two of which would culminate in the merging of most regional institutions into one organisation, known as the Pacific Commission, under the joint supervision of PIFS and SPC. ${ }^{234}$ In 2006, the Forum agreed to establish a Taskforce to explore the issues and recommendations found in Hughes' 2005 report. ${ }^{235}$ The six-member Taskforce included individuals with backgrounds in economics, diplomatic postings, consultancy, and past directors of both the Pacific Islands Forum Secretariat and the Secretariat of the Pacific Community. ${ }^{236}$ This Taskforce analysed the previous report, consulted with all Pacific Island Countries and made a total of twenty recommendations. The main recommendation concerned a change in regional institutional framework, and

\footnotetext{
229 Pacific Islands Forum Secretariat, "Nineteenth South Pacific Forum," 20-21 September 1988 Nuku'alofa, Tonga: Pacific Islands Forum

http://www.forumsec.org.fj/_resources/article/files/1983\%20Communique2.pdf (accessed 27 November 2008).

230 McDougall, "Insecurity in oceania."; Pacific Islands Forum Secretariat, "Thirtieth Pacific Islands Forum," 3-5 October 1999 Koror, Republic of Palau: Pacific Islands Forum http://www.forumsec.org.fj/_resources/article/files/1999\%20Communique.pdf (accessed 26 November 2008).

231 This is the first formalisation of the organisation and it appears to have occurred in response to the Forum's inability to overthrow the SPC.

232 Pacific Islands Forum Secretariat, "Political \& Security," Pacific Islands Forum, http://www.forumsec.org/pages.cfm/security/law-enforcement/?printerfriendly=true (accessed 25 November, 2008).

233 Herr, "Australia, security and the Pacific Islands.", A.V. Hughes. "Consultative Draft, Strengthening Regional Management: A Review of the Architecture of Regional Co-operation in the Pacific." Suva: Pacific Islands Forum 2005.

http://www.forumsec.org.fj/pages.cfm/documents/other?PageIndex=1 (accessed 26 November 2008).

234 Hughes. "Strengthening Regional Management".

235 Pacific Islands Forum Secretariat, "Thirty-seventh Pacific Islands Forum," 24-25 October 2006 Nadi, Fiji Islands: Pacific Islands Forum

http://www.forumsec.org/_resources/article/files/2006\%20Communique.pdf (accessed 27 November 2008).

${ }^{236}$ Kaliopate Tavola et al. "Reforming the Pacific Regional Institutional Framework." Suva: Pacific Islands Forum 2006. http://www.forumsec.org.fj/_resources/article/files/RIF\%20Study\%20Final.pdf (accessed 26 November 2008).
} 
instead of accepting Hughes' 2005 recommendation of one regional organisation under the supervision of PIF and SPC, it proposed a three pillar structure of a political pillar (PIF), a non political but technical pillar (Pacific Community and others), and an educational pillar (Fiji School of Medicine (FSch), Pacific Islands Development Program, East-West Center (PIDP) and University of the South Pacific (USP)). ${ }^{237}$ This model may suit the "Pacific Way" more appropriately than a single all-powerful organisation ${ }^{238}$, although a superficial glance at history suggests that the Metropolitan powers in the region have not given up their push for hegemony. The failure of persistent efforts by PIF to replace the SPC ${ }^{239}$ sends a clear message that legitimacy is not forthcoming.

Once the new regional framework of the three pillars is implemented in 2010, if all parties come to agreement, organisations across the breadth of the Pacific Ocean will be in a position to concentrate on their core business. The framework will provide a solid network for sharing information and knowledge across the spectrum of activities occurring in the region if the PIF and PIFS are able to relinquish their desire to actively manage and control the Pacific's architecture.

The original functions of the Pacific Islands Forum were to focus on trade and related topics such as developing free trade arrangements, investigating the development plans of member countries, and exploring opportunities to develop transport in the region. Ultimately, the Forum would gather all information and knowledge available on trade, production and economic development in and out of the region, to foster and develop the region's economy. Other agenda items included Law of the Sea, Immigration, Civil Aviation, Telecommunications, Oceanic Resources, Shipping, Regional Cooperation and Education. ${ }^{240}$ At the 1972 forum a Regional Disaster Fund was approved and over twelve years would be built up to a total of $\$ 500,000^{241}$ with equal shares contributed by Australia, New Zealand and the Pacific Island members collectively. ${ }^{242}$

The modern functions of the Forum and its secretariat reflect, to a degree, the original issues raised in the first agendas and appear in the 2007 revised Pacific Plan and the Corporate Plan 2005-2007. However, the Forum has increased its

\footnotetext{
237 Ibid.

238 A Pacific Union modelled on the EU?

239 Pacific Islands Forum Secretariat, "Nineteenth South Pacific Forum,"; Herr, "Australia, security and the Pacific Islands".

240 Pacific Islands Forum Secretariat, "South Pacific Forum".

${ }^{241}$ As the meeting was held in Canberra and prior to the existence of the Secretariat I assume that the amount was expressed in Australian dollars.

242 Pacific Islands Forum Secretariat, "South Pacific Forum".
} 
areas of interest significantly which are now contained within four pillars economic growth, sustainable development, good governance, and security encompassing a total of nine programmes. The work generated by the programmes and priority areas seeks to meet the vision agreed by the Forum in April 2004. The vision's overall philosophy is one of a region of 'peace, harmony, security and economic prosperity, so that all its people can lead free and worthwhile lives'. It also acknowledges the cultural diversity of the region and seeks respect through the way the Forum endeavours to meet its goals, and recognises the need for wide-reaching partnerships to attain its vision. ${ }^{243}$

The Forum has identified areas for regional cooperation and ensured mechanisms such as the Honiara Declaration (1992), the Aitutaki Declaration (1997), the Biketawa Declaration (2000) and the Nasonini Declaration (2002) are in place to facilitate such collaboration between regional organisations. These particular declarations give priority to law enforcement and regional security issues, identifying major risk areas and interconnecting elements for specialist dialogue. Key regional stakeholders in the areas of law, policing, customs and immigration are identified and a model for communicating risks and solutions to the Forum is documented. ${ }^{244}$ From 2008 PILON, PICP, OCO and PIDC meet at the Forum Secretariat offices every two months and the results of these meetings are reported to the Forum Regional Security Committee (FRSC).

The Pacific Plan originated in 2005 and was revised in 2007. It is the result of a number of issues being identified that impact on the Pacific peoples' wealth and way of life. The Pacific Plan is arranged around the same four pillars as appear in the Corporate Plan but covers a ten-year period although it is described as a living document, giving it flexibility to prioritise or include emerging situations that require attention. The initiatives are further prioritised for action, that is, implementation, agreement in principle, or, further analysis required. ${ }^{245}$

The Pacific Islands Forum does not have any formal rules which regulate the way its meetings are held or conducted. Consensus, otherwise known as the Pacific Way, is the method of agreement for decisions on issues raised on the agenda.

\footnotetext{
243 Pacific Islands Forum Secretariat, "Corporate Plan 2005-2007: Excelling Together for the People of the Pacific,"2005 Suva, Fiji Islands: Pacific Islands Forum http://www.forumsec.org.fj/_resources/article/files/2005\%20-2007\%20Corporate\%20Plan.pdf (accessed 29 November 2008).

244 South Pacific Forum Secretariat, "Declaration by the South Pacific Forum on Law Enforcement Cooperation (Honiara Declaration),"1992 Honiara, Papua New Guinea: South Pacific Forum http://www.cbsi.com.sb/fileadmin/PDF/SIFIU/Honiara-Declaration.pdf (accessed 1 December 2008).

245 Pacific Islands Forum Secretariat, "The Pacific Plan".
} 
The agenda is the mechanism for the secretariat and other regional reports to the Forum. Other agenda items can be raised by members as they wish. Representatives of each of the Forum member governments make up the Forum Officials Committee (FOC) and this body is responsible for the governance and oversight of the PIFS. ${ }^{246}$

Collaboration and dialogue with partners external to the Forum takes place at ministerial level following the annual Forum. ${ }^{247}$ In 2006 this arrangement was reviewed to ensure that all members kept appropriate relationships with their external partners. ${ }^{248}$

The Secretary-General of PIFS permanently chairs the Council of Regional Organisations in the Pacific (CROP) ${ }^{249}$ which again implies that PIFS controls the consultative power in the region and particularly over the Pacific Community and its Secretariat.

The Secretariat acted for Pacific Island Countries Trade Agreement (PICTA) ${ }^{250}$ Rules of Origin Committee $(\mathrm{ROC})^{251}$ and as a partner to New Zealand and Australian Customs organisations in developing South Pacific Regional Trade and Economic Co-operation Agreement (SPARTECA) Rules of Origin. ${ }^{252}$

The Forum also established the Forum Fisheries Agency to deal with all fishing matters; the Forum Regional Security Council (FRSC) to deal with all security matters; and the Law Enforcement Unit (LEU) to coordinate efforts by police, customs and immigration institutions in the region.

\footnotetext{
246 Pacific Islands Forum Secretariat, "The Pacific Islands Forum and its Secretariat," Pacific Islands Forum Secretariat, http://www.forumsec.org/pages.cfm/about-us/ (accessed 18 August, 2008). 247 Ibid.

248 Pacific Islands Forum Secretariat, "Thirty-seventh Pacific Islands Forum".

249 CROP is made up of eleven regional bodies including: Fiji School of Medicine (FSchM); Pacific Islands Forum Fisheries Agency; Pacific Islands Development Program (PIDC); Secretariat for Pacific Community (SPC); Pacific Islands Applied Geoscience Commission (SOPAC), South Pacific Board for Educational Assessment (SPBEA); Pacific Islands Forum Secretariat (PIFS); Secretariat of the Pacific Regional Environment Programme (SPREP); South Pacific Tourism Organisation (SPTO); University of the South Pacific (USP); and, Pacific Power Association (PPA).

250 Members as at 30 September 2004 were Cook Islands, Fiji, Kiribati, Niue, Nauru, Papua New Guinea, Samoa, Solomon Islands and Tonga.

${ }^{251}$ Pacific Islands Forum Secretariat, "Pacific Island Countries Trade Agreement: Rules of Origin Manual,"2004 Suva, Fiji: Pacific Islands Forum Secretariat

http://www.forumsec.org.fj/_resources/article/files/PICTA\%20RoO\%20Manual2.pdf (accessed 29 November 2008).

252 "South Pacific Regional Trade and Economic Co-operation Agreement: A Reference Handbook for Forum Island Country Exporters," 4th Edition 1996 Suva, Fiji:

http://www.customs.gov.au/webdata/resources/files/origin4.pdf (accessed 29 November 2008); Members as at 1996 included Cook Islands, Federated States of Micronesia, Fiji, Kiribati, Marshall Islands, Nauru, Nauru, Niue, Papua new Guinea, Solomon Islands, Tonga, Tuvalu, Vanuatu and Samoa.
} 
The PIFS annual budget for 2008 was split between three funds: the general fund for contributions from members, the trust fund for donations, and the reserve fund, which is generated from interest earned. The overall budget of FJ $\$ 24,984,642$ is split between these accounts. Member and donor contributions are set out in a table expressing the amounts paid to the general and trust funds. As the reserve fund of $F J \$ 5,225$ is generated from interest earned, it is not included in the table. [See Figure 2]

Figure 2 - PIF Contributors and Donors ${ }^{253}$

\begin{tabular}{|c|c|c|}
\hline Contributors and Donors & General Fund in FJ\$ & Trust Fund in FJ\$ \\
\hline Australia & $1,302,809$ & $4,798,770$ \\
\hline Cook Islands & 35,403 & \\
\hline FSM & 69,536 & \\
\hline Fiji & 78,519 & \\
\hline French Polynesia (Assoc) & 15,500 & \\
\hline Kiribati & 35,403 & \\
\hline Nauru & 35,403 & \\
\hline New Caledonia (Assoc) & 15,500 & \\
\hline New Zealand & $1,302,809$ & $4,205,147$ \\
\hline Niue & 35,403 & \\
\hline Papua New Guinea & 192,341 & \\
\hline Palau & 35,403 & \\
\hline Republic of Marshall Islands & 35,403 & \\
\hline Samoa & 69,536 & \\
\hline Solomon Islands & 69,536 & \\
\hline Tonga & 69,536 & \\
\hline Tuvalu & 35,403 & \\
\hline Vanuatu & 69,536 & \\
\hline Japan & & 348,068 \\
\hline Japan DCF 254 & & 696,403 \\
\hline European Union & & $4,283,387$ \\
\hline United States of America & & -255 \\
\hline
\end{tabular}

253 Pacific Islands Forum Secretariat, "Pacific Islands Forum Secretariat Financial Statements for the Year Ended 31 December 2007," 31 December 2007 Suva, Fiji Islands: Pacific Islands Forum Secretariat http://www.forumsec.org.fj/UserFiles/File/PIFS_Audited_Report_2007.pdf (accessed 1 December 2008).

254 Japan Development Corporation Fund. 


\begin{tabular}{|l|r|r|}
\hline Contributors and Donors & General Fund in FJ\$ & Trust Fund in FJ\$ \\
\hline UNDP/ESCAP/UNODC & & 446,641 \\
\hline Asian Development Bank & & 114,776 \\
\hline Great Britain & 30,000 \\
\hline Taiwan & & 649,169 \\
\hline Commonwealth Secretariat & 263,644 \\
\hline Korea & & 640,127 \\
\hline People's Republic of China & 924,110 \\
\hline World Trade Organisation & & 262,473 \\
\hline Others & & 549,936 \\
\hline
\end{tabular}

\section{PACIFIC IsLANDS LAW OFFICERS' NETWORK (PILON)}

The Pacific Islands Law Officers' Network was previously known as the Pacific Islands Law Officers' Meeting (PILOM). It was first established in 1980 and provided a forum for law officers to discuss legal and justice matters as they related to the region. ${ }^{256}$ However, in 2005 it was noted by the Attorney-General of Samoa that the annual meetings did not go any further than discussion between members, and that there was no communication between members from one meeting to the next. It was also pointed out that there was no coordination of the information that came from PILOM or the Pacific Islands Chiefs of Police (PICP). ${ }^{257}$ Each organisation was similarly concerned about the effects of transnational crime and terrorism, creating a natural partnership in progressing legal, judicial and policing processes. The $25^{\text {th }}$ PILOM agreed that PIFS would be an appropriate agency to carry out a review of their organisation. ${ }^{258}$

The review made several recommendations including a commitment to table a report at the Forum Regional Security Committee Meeting and to change its meeting structure to focus on key regional legal issues rather than presenting country papers, on producing an outcomes paper from meetings, and to consider the possibility of a Pacific Law Ministers Meeting from 2008. Recommendations

\footnotetext{
255 The United States of America did not donate any funds in 2008 however in 2007 they donated $\$ 1,867,995$.

256 Brenda Heather-Latu, "Mending the Nets,"2005 Vanuatu: Pacific Islands Law Officers Network http://www.pilonsec.org/www/pilon/rwpattach.nsf/PublicbySrc/Mending+the+Nets.pdf/\$file/Mending +the+Nets.pdf (accessed 30 November 2008).

257 Ibid.

258 Ibid.
} 
were also made for the establishment of a secretariat to carry workloads and coordinate events between and for annual meetings. ${ }^{259}$

Many of the recommendations were accepted by PILOM, which also went a step further in changing its name to better reflect their focus on sharing information. ${ }^{260}$ The organisation also works closely with PIFS on various elements of the Pacific Plan. Its secretariat is currently housed in Fiji, funded by the Australian Government's Attorney-General's Office and continued as such until at least the 2008 PILON meeting ${ }^{261}$ at an annual cost of approximately FJ $\$ 160,000.262$

\section{OCEANIA CUSTOMS ORGANISATION (OCO)}

The Oceania Customs Organisation (OCO) was originally established as Customs Heads of Administration Regional Meeting (CHARM) in 1986 to improve communication between customs organisations throughout the region by communicating more effectively and also to simplify and harmonise procedures. ${ }^{263}$ Key focus areas for OCO to action at 2006 were: trade facilitation and revenue collection, law enforcement and security, human resource development in relation to modernisation and capacity building, and communication and representation. The Secretariat is now co-located in the Pacific Community's Fiji office compound in Suva, albeit as a stand-alone organisation. ${ }^{264}$

The OCO has representation of customs administrations from twenty-three member countries within an area defined by the territorial boundaries of Melanesia, Micronesia, Polynesia and Australasia. They meet at Conference annually. All members fund an operational budget which ensures representation

\footnotetext{
259 Pacific Islands Forum Secretariat, "Pacific Islands law Officers Meeting (PILOM) Review," January 2007 PILON Secretariat Website: Pacific Islands Law Officers Network (PILON) http://www. pilonsec.org/www/pilon/rwpattach.nsf/PublicbySrc/Pacific+Islands+Law+Officers+Meetin $\mathrm{g}+($ PILOM) +Review.pdf/\$file/Pacific+Islands+Law+Officers+Meeting+(PILOM)+Review.pdf (accessed 16 July 2008).

260 Pacific Islands Law Officers Network, "Home,"2007 PILON Website: PILON http://www.pilonsec.org/www/pilon/pilon.nsf/Page/Home (accessed 30 November 2008).

261 PILON Secretariat, "Pacific Islands law Officers' Network Meeting Outcomes," 6-10 December 2007 Cook Islands: PILON Secretariat

http://www.pilonsec.org/www/pilon/rwpattach.nsf/VAP/(756EDFD270AD704EF00C15CF396D6111) 26 th+PILON+Meeting+Outcomes.pdf/\$file/26th+PILON+Meeting+Outcomes.pdf (accessed 30 November 2008).

262 Pacific Islands Forum Secretariat, "Pacific Islands law Officers Meeting (PILOM) Review".

263 Oceania Customs Organisation (OCO), "Oceania Customs Organisation: Fact Sheet," http://www.ocosec.org/assets/oco\%20fact\%20sheet/PDF-Fact\%20Sheet\%20June\%202006-1.pdf (accessed 8 August, 2008). Note: that the annual report in respect of the financial statements of the OCO were unable to be located for this study. 264 Ibid.
} 
by members at conference. A tier structure for payment has been introduced in acknowledgement of the disparity in economies across the region. The OCO has an annual budget provided by the New Zealand government to run the secretariat and pay salaries, and New Zealand Customs provides a salary for the Head of the Secretariat. ${ }^{265}$

\section{PACIFIC ISLANDS ASSOCIATION OF NON-GOVERNMENT ORGANISATIONS (PIANGO)}

PIANGO as its name suggests is a civil society network of National Liaison Units (NLUs) in twenty-one Pacific Island Countries and territories. Established in 1991, its primary role is to act as a channel for NGOs and to strengthen their influence and impact in the Pacific. Its four key focus areas are Sharing Information, Building Capacity, Strengthening Key Relationships and Ensuring Quality Performance. ${ }^{266}$ It has attained formal recognition by PIFS which gives it access to some PIFS meetings, and is striving for accreditation of PIFS, the United Nations and the European Union. ${ }^{267}$

PIFS attends PIANGO's planning, implementation, monitoring, evaluation and reporting (PIMER) meeting, along with resource personnel from NZAID, the International Centre for Not-for-Profit Law (ICNL), AUSAID Pacific Leadership Programme and the European Union (EU), to 'guide and mainstream the direction of the year's review and appraisal process'. This process demonstrates a high level of transparency and accountability for PIANGO and collaboration at a number of levels for strategies involving the region. ${ }^{268}$

PIANGO is supported by NZAID, Commonwealth Foundation, AusAID, UNDP Pacific Centre, Canadian International Development Agency, PIFS, the Development Resource Centre ${ }^{269}$, Australian Volunteers International and CCFD. The organisation has a budget of approximately FJ $\$ 260,000.270$

\footnotetext{
265 Ibid.

266 PIANGO Secretariat, "Pacific Islands Association of Non-government Organisations Annual Report," 31 December 2006 Suva: PIANGO Secretariat

http://www.piango.org/docs/Publications/PIANGO_Annual_Report_2006.pdf (accessed 26 November 2008).

267 PIANGO Secretariat, "PIFS Accreditation,"2007 PIANGO Website: PIANGO Secretariat http://www.piango.org/pifs-accreditation.html (accessed 26 November 2008).

268 PIANGO Secretariat, "Pacific Islands Association of Non-government Organisations Annual Report".

269 Now constituted as Global Focus Aotearoa (GFA).

270 PIANGO Secretariat, "Pacific Islands Association of Non-government Organisations Annual Report".
} 


\section{PACIFIC IMMIGRATION DIRECTORS' CONFERENCE (PIDC)}

The first Conference of the Immigration Directors was sponsored by and held at the Forum Secretariat in Suva, Fiji Islands in 1996. Directors from across the region agreed on the importance of meeting together to share information and discuss issues that affect the lives of citizens through the policies and actions of immigration departments. They saw the importance of collaboration with other organisations where overlaps in interests occur, specifically the PICP, OCO, PILON, Interpol and others. The PIDC has been supported by a permanent secretariat since 2002 and for most of that year was co-located with the OCO in Brisbane offices. However, the OCO moved its secretariat to Noumea in November of the same year, creating a dilemma for the PIDC Secretariat. This was solved by negotiating with the Forum Secretariat, and from December 2002 the PIDC Secretariat has been co-located at the Forum Secretariat offices in Suva, Fiji. 271

In 2005, the PIDC recognised the changing landscape and reviewed its structure, direction and membership. The review resulted in new strategic and work plans, to facilitate continuing action between conferences, and establish a Policy Advisory Group. ${ }^{272}$

Activities of the group include comparative analysis of legislation covering immigration in member countries, work on secure information communication systems, integrity, institutional strengthening and a range of specific issues relating to immigration and the movement of people and commodities. ${ }^{273} \mathrm{Key}$ focus areas cover cooperation, implementation of regional policies, the exchange of technical assistance, and collaboration with other regional and international bodies. Membership is open to twenty-three Pacific Island Countries and territories including Australia and New Zealand. ${ }^{274}$

The PIDC and PIDC Secretariat receive funds from New Zealand and Australia to cover administration running costs and salaries of the Head of the Secretariat, an administration assistant, a research officer and a seconded analyst.

\footnotetext{
271 Matthew Gibbs, "Fact Sheet," April 2007 Suva, Fiji Islands: PIDC Secretariat http://www.pidcsec.org/files/Toolkit/PIDC\%20Fact\%20Sheet\%20April\%202007.pdf (accessed 10 November 2008).

272 Ibid.

273 Ibid.

274 Pacific Immigration Directors' Conference Secretariat, "Charter," 30 August 1 September 2005 Fiji Islands: PIDC Secretariat

http://www.pidcsec.org/files/Toolkit/PIDC\%20Charter\%20April\%202007.pdf (accessed 30 November 2008).
} 


\section{PACIFIC REgIONAL POLICING INITIATIVE (PRPI)}

The establishment of the PRPI was announced in 2002 as a five-year collaborative response by Australia, New Zealand and Fiji following the terrorist attack on New York's World Trade Centre Towers in 2001 and a growing concern about transnational crime. Because policing in the region was considered by some 275 as naïve, the purpose of the PRPI was to build the domestic policing capacity of individual police services which would increase the ability of local jurisdictions to recognise the more sophisticated offending peculiar to transnational crime. The PRPI developed training packages targeted at raising the competency of basic policing methods and delivered them to PIF countries. At the end of 2008, the PRPI was reviewed resulting in a change of name to the Pacific Policing Development Programme (PPDP) and the project shedding its previous partners with the AFP taking control of the new initiative as well as providing all funds for its programmes. ${ }^{276}$

\section{Global PARTNERship for the PREVENTION OF ARMEd CONFLICT (GPPAC), Pacific People Building PeAce (PPBP)}

Included in this section is the Global Partnership for the Prevention of Armed Conflict (GPPAC) or as they are better known in the Pacific, Pacific People Building Peace (PPBP). This, like PIANGO, is a non-government organisation working across the Pacific including Bougainville, the Cook Islands, Fiji, Kiribati, Samoa, the Solomon Islands, Papua New Guinea, West Papua, Tonga, Tuvalu, Australia and New Zealand. ${ }^{277}$ The organisation was established in 2003 and aims to 'build a new international consensus on peace building and the prevention of violent conflict'. Fifteen regions around the world have set their own action agenda which contribute to the global action agenda based on tasks targeted to national, regional and international levels. ${ }^{278}$ Listed as GPPAC partners in the Pacific are: the Pacific Islands Forum Secretariat (PIFS), and the United Nations Development programme Pacific-Centre (UNDP-PC). ${ }^{279}$ This

\footnotetext{
275 Confidential source.

276 Interview B6.

277 "The Regional Process," GPPAC Website, http://www.gppac.net/page.php?id=1650 (accessed 18 November, 2008).

278 "Pacific Regional Consultation on the GPPAC Programme", (Recommendations resulting from the Conference: "From Reaction to Prevention: Civil Society Forging Partnerships to prevent Violent Conflicts and Build Peace", Pacific Harbour, Fiji Islands, 17-22 April 2005) http://www.gppac.net/uploads/File/Regions/Pacific/Pacific\%20Regional\%20Action\%20Agenda.pdf (accessed 18 November 2008).

279 "The Regional Process".
} 
organisation forms an important link between civil society, security and law enforcement in the region.

\section{Pacific Transnational Crime Coordination Centre (PTCCC)}

Since 2003 the PICP has unanimously supported the establishment of the Pacific Transnational Crime Coordination Centre (PTCCC) to manage matters of intelligence in relation to transnational crime. Provided by the Australian Federal Police (AFP) the PTCCC opened its first office in Suva, Fiji on 15 June 2004 and moved to Apia, Samoa in June 2008 to avoid deteriorating relationships resulting from the 2006 military coup. ${ }^{280}$

\section{OTHERS}

There are two other main international and regional organisations working in the Pacific with which security and law enforcement agencies have a peripheral relationship; as such, they need to be identified.

\section{ASIA-PACIFIC ECONOMIC COOPERATION (APEC)}

The first is Asia-Pacific Economic Cooperation (APEC), which includes Australia and New Zealand as members but none of Pacific Island Countries. The group is primarily a forum to reduce barriers to economic and trade activities between its members. It is given space in this thesis simply for the reason that prosperous economies rely on societies that are peaceful and lawful and APEC is a potentially beneficial relationship for the emerging and developing economies throughout the region.

\section{ASSOCIATION OF SOUTHEAST ASIAN NATIONS (ASEAN) AND ASEAN REGIONAL FORUM (ARF)}

The second is Association of Southeast Asian Nations (ASEAN) and ASEAN Regional Forum (ARF). The dialogue partners of ASEAN include Australia, Japan, New Zealand, Canada, the European Union, the United States, the People's Republic of China, India, the Republic of Korea, Russia and the United Nations Development Programme. These partners almost mirror the Pacific Islands Forum's Dialogue partners and it seems Pacific Islands Forum ministers attend this round of discussions annually immediately following the PIF.

280 Nautilus Institute at RMIT, "Pacific Transnational Crime Coordination Centre (PTCCC)," http://gc.nautilus.org/Nautilus/australia/australia-in-pacific/pacific-transnational-crime-coordinationcentre (accessed 14 November, 2008). 
ARF is the regional security arm of ASEAN and was created by ASEAN and its dialogue partners in 1992 as a 'move towards a higher plane of political and economic cooperation to secure regional peace and prosperity'. ${ }^{281}$ The two major goals of ARF place expectations and responsibility on participants to encourage useful and beneficial communication about matters of security and matters of concern, and to be active in building confidence and preventative diplomacy in the region. Whilst only one of the Pacific Islands Countries (PNG) has direct input into this forum, about two-thirds of them have collective representation through the Pacific Islands Forum. ${ }^{282}$

\section{SUB-REGIONAL BODIES}

In addition to the regional organisations, Chiefs of Police meet sub-regionally in Micronesia, Melanesia and Australasia. The Australasian conference in 2006 had representation from Hong Kong, New Zealand, Singapore, Papua New Guinea, Tonga, and all the Australian state, territorial and federal police. Discussion topics focused on community safety, common police arrangements, crime, mental health, security, and integrity. ${ }^{283}$

\section{COOPERATION AND COLLABORATION}

\section{COMMUNICATION}

As can be seen by the Pacific Islands regional organisations highlighted in the first part of this chapter, there is a good deal of cooperation going on in the Pacific. All of these groups have formed a cooperative liaison because their interests bind them together and common threads run through their constitutions and corporate plans. Many describe their key focus areas as pillars, implying structures of support. Evident in most plans is particular reference to the need for communication within their own agencies in addition to communicating with other agencies and organisations. These groups are working well within their own spheres but a need to coordinate efforts has been identified to ensure that overlaps in programmes and services do not occur. Coordination could be achieved by one group assuming the mantle of overarching coordinator, or it could be achieved by taking the task to a topic specific level as presented in the three pillar structure, spreading the

\footnotetext{
281 "Overview," ASEAN Website, http://www.asean.org/328.htm (accessed 29 November, 2008).

282 Ibid.,

283 Victoria Police, "Commissioner's Conference Concludes," 25 May 2006 Melbourne: Victoria Police Website http://www.police.vic.gov.au/content.asp?Document_ID $=6314$ (accessed 10 December 2008).
} 
responsibility over a number of personnel or organisations. Linking activities between pillars would become a collaborative exercise. The coordination provided currently by PIFS contributes to perceptions of a power imbalance.

Many research participants discussed the need for greater communication and perhaps better planning between agencies. As one interviewee explained:

For example, I'm in Samoa today, I find out last week just before I leave that AusAID are coming through to do a review of the AusAID projects in [my country] and I'm in Samoa and the lady that was here has just left. ${ }^{284}$

That the two key personnel in each agency were in the same country but did not cross paths indicates a severe lack of communication. Another participant also commented on a need for good communication within and across their own government structures:

We need to be heard and it's our responsibility as the head of police or law enforcement to make sure that our leaders understand the problems. They cannot help when they don't know. ${ }^{285}$

Traditionally, police have been the 'poor cousin' in government and as such have received less from government coffers than health and education. ${ }^{286}$

The links between health, education, employment and crime and disorder have been well documented. It is essential for all of these agencies to work together and for all of their ministers to be aware of the links and how they contribute to a safe and peaceful society which itself contributes to economic prosperity.

In 1991 the Pacific Islands Forum Secretariat (PIFS) presented a paper: Regional law Enforcement Co-operation - The Challenge to the South Pacific Chiefs of Police Conference. The report acknowledges law enforcement as a recent focus for PIFS, seemingly instigated by the Commonwealth Secretariat in response to concerns about terrorism and hi-jacking in the region. Issues around legal matters, extraditions, and capacity to respond to such matters were raised. Finding solutions to these problems requires close and regular contact between

\footnotetext{
284 Interview A2.

285 Interview A3.

${ }^{286}$ Conference Secretary "Minutes of the 1st Conference"; Interview A6.
} 
agencies and organisations involved in law enforcement and border security. ${ }^{287}$ While each of the agencies involved in law enforcement and judicial matters have been working on solutions in isolation, the essential collaboration between them has taken seventeen years to come to fruition. As of 2008, the Executive Directors of the PILON, PICP-S, OCO and PIDC meet every two months in Suva at PIFS to discuss law enforcement matters. ${ }^{288}$ A report of the meeting is presented to the FRSC which then has the responsibility of taking pressing matters to the Forum. This process of communication addresses regional cooperation for a number of organisations and ultimately, the Pacific Plan.

\section{Perceptions Of POWER}

Whilst the PIF and PIFS have taken on a leadership role largely driven by Australia and to an only slightly lesser degree New Zealand, there are perceptions of a power mismatch between the two metropolitan states and the Pacific Way. Some research interviewees keenly felt the disadvantage of working and living in developing countries and being reliant on wealthy countries to support them. For example:

[...] Because they are taking the lead, the policy role; because they have more experience and expertise in combating issues at a national level and transnational issues; because of that and including other variables we smaller island countries are a weak attempt on them. Not only from an economical point of view but as well as other variables [...] and in that sense they take more power than us. They decide what they can show us. What they want us to do, in accordance with their political aspect. $[\ldots]^{289}$

Other interviewees talked of a genuine desire by Australia and New Zealand to help the people of the Pacific Islands rather than being politically motivated, and still others were more pragmatic, acknowledging needs-based donations were essential for success:

Donor countries particularly want to sprint things forward. But ultimately aid is going to fail if it is not provided in such a way that the recipient

\footnotetext{
287 Conference Secretary, "Minutes of the 20th South Pacific Chiefs of Police Conference," (New Zealand: SPCPC, 1991).

288 Interview B3.

289 Interview A13.
} 
countries can make use of it and capitalise on it. Otherwise it's just money down the gurgler. ${ }^{290}$

But other respondents saw a conflict for the AFP and NZP. A vested interest in the future of policing in the Pacific through donor and training provider roles does not sit well alongside decision making roles as members of the PICP. A number of respondents saw a solution to this through a more assertive role for the Pacific Islands Chiefs of Police and a more involved role for their Secretariat:

Ownership of policing standards and aid initiatives need to be seized by Pacific Islands' members of PICP to develop their own process, not to be dictated to by donor countries. This requires good practice and ownership which requires strong leadership - it is crucial for the Pacific Islands members to take control of their own processes. The Pacific Islands' chiefs need to lead while other members should sit outside as supporters. PICP-S has a crucial role to play, to be an action body in taking objective coordination of this process. ${ }^{291}$

Advisory roles for AFP and NZP rather than membership would reduce this conflict and return the power of destiny to the Pacific.

\section{LANGUAGE}

Cooperation and collaboration are as much about language as actions. Organisational plans provide an insight into where an organisation sees itself in the present and future and the barriers or pathways to acceptance, discussion and cooperation. For example, the Fourteenth Pacific Islands Forum Communiqué included a section on a 'Single Regional Organisation (iii)', stating that in order for such an organisation [SRO] to be successful it should 'recognise the position of the Forum as the supreme authority on issues of regional concern'. Current Forum literature describes itself as 'the region's premier political and economic policy organisation'. ${ }^{292}$ Whilst the language has been somewhat tempered, there remains an air of superiority. One interviewee was aware of the effects of language on Pacific Island peoples:

\footnotetext{
290 Interview A5.

291 Interview B5.

292 Pacific Islands Forum Secretariat, "About Us," PIFS Website, http://www.forumsec.org.fj/pages.cfm/about-us/? (accessed 25 November, 2008).
} 
It's been my belief, and this has been driven by a government through some need, identified need, then we're probably better to advise softer rather than through a body perhaps like the forum. ${ }^{293}$

\section{THE PACIFIC Way}

The Pacific Community and the Secretariat of the Pacific Community (SPC) has been described by its review team as a 'quiet achiever' that should take more of a leadership role in the region. ${ }^{294}$ The apolitical nature of the Pacific Community, its membership of twenty-two Pacific Island Countries plus four metropolitan states $^{295}$ and its organisational structure and format ensure wide coverage, acceptance and respect of the large majority of all Pacific Island Countries. The SPC literature and philosophy is 'people-centric' where development in three main pillars is a means of improving the life of Pacific Island peoples.

\section{THE TYRANNY OF DISTANCE}

It became apparent during the research interviews that the diversity of the region and time between flights to and out of some countries had a bearing on how much collaboration was undertaken. As one respondent put it:

You can't get off the place. So, not everybody's got a week to spare for a two-day meeting. 296

Such isolation requires careful assessment of the costs and benefits associated with the demands of cooperation. Most regional meetings are run by a chair designated by the meeting's host country and this role rotates to share the burden of cost and time. To take into account the time required to meet in isolated locations more than one conference could be held around the same time as well as cross-agency dialogue, but the gains of holding larger meetings in isolated locations are offset by a shortage in the infrastructure required for such an influx of people. Likewise, when regional meetings are held offsite, the value of additional time away from the workplace over and above that required for one meeting needs to be weighed up against the value of cooperation. Overcoming this type of isolation needs region-wide planning and committed individuals active in pursuing the benefits of cooperation; otherwise, it may be simpler for some very small countries to withdraw from building a regional and global society.

\footnotetext{
293 Interview B2.

294 Secretariat of the Pacific Community (SPC), Corporate Plan (2007-2012). p.14.

295 Australia, France, New Zealand and the United States of America.

${ }^{296}$ Interview A6.
} 


\section{SUMMARY}

Organisations with a range of objectives, but specifically directed at improving the lives of Pacific Island peoples through developing safe, healthy, secure and prosperous societies have been discussed in this chapter. Corporate and action plans reflect the importance of the ocean as the region's premier resource for well-being and wealth alongside issues of the environment, capacity, good governance, regional security and law and order. Regional groups of relevance include the Pacific Community, the Pacific Islands Chiefs of Police and their Secretariat, the Pacific Islands Forum and its Secretariat, the Pacific Islands Law Officers' Network, Oceania Customs Organisation, Pacific Islands Association of Non-government Organisations, Pacific Immigration Directors' Conference, Global Partnership for the Prevention of Armed Conflict, Asia-Pacific Economic Cooperation, ASEAN and ASEAN Regional Forum, and sub-regional bodies.

Australia and New Zealand have a stake in all regional organisations in various roles but there is a difference in the way each country works in the Pacific. Australia has, in the past, looked to New Zealand to support its political moves, particularly immediately following the Second World War in its instigation to establish the South Pacific Commission, and more recently in its endeavour to establish a single regional organisation through the establishment of the South Pacific Forum. ${ }^{297}$ The deliberate removal of the political function, included in the ANZAC Pact but not the establishing documents of the SPC, resulted from the colonial power base of the participating governments and a lack of foresight, along with the refusal, particularly by the US and France, to relinquish the power of colonialism. Had the SPC relinquished this power in 1964 when several amendments were made along with a partial loosening of the colonial reins, and included political development as originally mooted in the ANZAC Pact (1944), there would have been no need for a second regional institution in the form of the South Pacific Forum. And therefore, no drive for a Single Regional Organisation from the SPF and no mention of further ambition to establish such an organisation in the PIF Pacific Plan's update.

Interviewees discussed the need for good communication within their own organisations as well as with other government agencies and across the region and a need for better planning. The need for coordination of regional activities is recognised, but how that should take form is problematic. Australia in particular, and to a lesser extent New Zealand, continue to exert pressure through the PIF

${ }^{297}$ Herr, "Australia, security and the Pacific Islands". 
for the establishment of a three pillar structure for the Pacific in 2010, which would ultimately encompass all regional organisations. Some organisations have co-located themselves with PIFS or with the SPC and this arrangement can work well, particularly if there is no pressure or assumption of ownership or management of these groups by PIFS. There are perceptions that the wealthy countries use the power of the dollar to pursue their own goals in the region, and that this attitude needs to be tempered for just and sustainable development to occur. Attitudes towards and acceptability of cooperative regional policing can be affected by the use of language which can suggest either superiority or inclusion. Discussion with research participants also raised issues concerning the tyranny of distance and isolation. For all members of the Pacific to feel meaningfully involved in such regional arrangements, careful planning through good communication is essential especially when flights are infrequent and infrastructure is minimal.

Whilst coordination and cooperation between agencies, institutions, and civil society are critical in developing the Pacific, more speed can be gathered by gaining true legitimacy from diverse populations, cultures and societies through seeking to truly understand and respect their needs, history, language and culture. Indeed, ways must be found of overcoming obstacles to enhanced regional cooperation through real empowerment of Pacific peoples. Their voices must be heard, respected, and given due weight and perhaps even paramountcy in whatever regional architecture is established. 


\section{CHAPTER FIVE: RECOMMENDATIONS AND CONCLUSIONS}

The Pacific region is vast and populated by only small numbers representing hundreds of cultures across thousands of islands. Policing in this region is complex and arguably an essential element of economic advancement. Policing should be included in all development strategies because just and sustainable economic growth and development cannot occur in unsafe or insecure communities. Policing in PICs is affected by a range of external elements ranging from models of governance and policing left over from colonial days that are inappropriate and expensive to maintain, to the effects of globalisation and regionalism, and to the agenda of wealthy donors intent on rushing change and modernisation or erecting monuments to their generosity. The small populations of PICs have been jolted into a globalising world by such external forces as: the sudden exit of some colonial rulers, prompting Pacific populations and governments to re-establish their own identities; an increasing number of tourists in the region who display their disposable incomes to the vulnerable eyes of the Pacific; increased numbers of migrants taking up residence as a result of politically motivated agreements between states resulting in a greater incidence of organised crime. Along with this explosion of change has come the categorisation of developing countries for the large majority PICs and an opportunity for wealthy countries to parade their international leadership by pouring extensive financial resources into the region under the guise of development.

My research has identified four main issues arising from these elements that affect international policing in the Pacific. The first is a lack of consideration of cultural needs and customs. The second is an asymmetrical balance of power weighted towards Australia and to a lesser degree, New Zealand. The third is the way outsiders engage with local communities in the Pacific. The fourth is aid. All of these are discussed more fully along with recommendations for change that are designed to fully include the voices of the Pacific as creators of their own destiny while also recognising donor countries' security needs.

\section{CONSIDERATION OF CULTURE AND CUSTOM}

The need to develop appropriate cultural models by including local people was first documented in the ANZAC Pact in 1944 and is discussed in this thesis on 
p.52. But according to my interviewees, by far the biggest underlying concern was the metropolitan countries' lack of consideration of cultural needs and customs when working in the Pacific. These are often opposed to western ways of doing things but form the heart of Pacific Island's life and rule of law. Pacific life is centred on familial ties and as such civil society forms an integral part of social control. Interviewees universally agreed there was no going back to precolonial lifestyles and rules, but that any work carried out on their homeland had to be done in a way that took into consideration their customary ways of doing things. Participants saw these as more appropriate, workable, understandable and sustainable than western ways. However, to ensure modifications to models of government and the rule of law reflect such practices, it is essential that decision makers in the Pacific accept the responsibility of making sure their own voices are heard. The following recommendations apply to both those involved specifically in strengthening policing in the Pacific and more generally to efforts at enhancing regional cooperation.

\section{RECOMMENDATIONS}

1. International staff are exposed to 'the heart of the country', learning about the local economy, legal system, customs and institutions (including civil society, non-government agencies and government agencies) so they more fully understand the country's needs before building collegial working relationships with citizens of their host country.

2. International agencies let the host country take the lead in whole-ofgovernment capacity building exercises, and confine themselves to offering support and expert advice on request.

3. Local Pacific staff make their voices heard within their own government and at regional meetings.

\section{THE BALANCE OF POWER}

Since modernity, the peoples of the Pacific Island Countries have been witness to a shift in the locus of power. The preponderance of power has been taken from them, first through colonisation and then decolonisation, then by globalisation and regionalisation, and more recently because of a fear of national and regional insecurity. Although regionalisation suggests a more intimate relationship between partners than the idea of globalisation, the Pacific as a region faces many challenges from much larger players on the global stage. The Pacific regional architecture reflects the importance of the rise of China and Japan as new world powers. However, the focus is on Asia and other large world 
players 298 while none of the nation-states of the Pacific Ocean are identified for economic, community-building, national security, or political consideration. The discourse on building and improving Pacific architecture, ${ }^{299}$ whilst broad in its reach, fails miserably to include the voices of those at its very core. Papua New Guinea is the only member of APEC that is also part of the region discussed in this thesis. This is curious as the twenty-six island countries are positioned in the direct path of east-west and north-south transportation highways. Furthermore, the ocean in which they lie and resources they have ownership over contain a bounty all of those large players vie for. Additionally, the Pacific Islands Forum, a regional body that includes many of the states in its name, also fails, by its own admission, to properly address their cultural needs. In the Pacific the current balance of power is firmly seated with Australia and New Zealand, but this balance is shifting with new and bigger players acting on the Pacific stage.

The first element that contributes to the nature of the unequal relationship is the way political actors employ language. This was seen by discourse in Australian policy and elsewhere and can be compared with that of the Pacific Community to gain an insight into how the balance of power is maintained. The former uses language implying superiority over the region while the latter's language is people centric and inclusive. While Australia maintains the mantle of regional hegemon, the Pacific Community enjoys the loyalty of Pacific peoples. ${ }^{300}$

The second element in maintaining the balance of power is wealth. Australia and New Zealand have provided resources to the Pacific region as a whole for a very long time. They have also supplied financial resources and training to Pacific policing from the late 1970 s through their involvement in the PICP and more recently through more sophisticated bi-lateral agreements. The Chiefs of Police are keenly aware of the asymmetric advantages these donations of time, experience, expertise and finance present.

Interviewees said that Australia and New Zealand work in different ways. Australia appears as the mighty and powerful fistful of dollars, while New Zealand works alongside the people of the Pacific. I acknowledge, as did the interviewees, that both Australia and New Zealand genuinely want to advance development in the Pacific, including policing, but better and more collegial

\footnotetext{
298 Gyngell. "Design Faults: The Asia Pacific's Regional Architecture".

299 Ibid.

${ }^{300}$ Examples are discussed on pp. 16, 17 and 76 of this thesis.
} 
outcomes will result faster by changing to an inclusive approach. No country enjoys being labelled a failing or failed state, and as pointed out in the literature, these labels assume that something is broken. All metropolitan countries must remember and remind themselves that, as developing states, the Pacific Island Countries do not have the benefit of over a hundred years of independence or the resources to bounce onto the world economic stage. Expectations of instant globalisation are unrealistic.

Unequal power breeds resentment and that, in turn, frustrates western ideas of progress which typically want to 'sprint things along'. It must be local partnerships that form the strength and focus of any reform, not the decisions of, or beneficial 'payoffs' for, powerful resource providers.

\section{RECOMMENDATIONS}

4. Australia in particular uses more people centric language, as in Pacific Community documentation. This includes the Australian government, PIF and AFP discourse.

5. Australia and New Zealand both consider the stage of development of Pacific Island Countries and slow their own 'sprint' to a more acceptable 'jog' to be more inclusive of all participants.

\section{METHODS OF ENGAGEMENT}

There are a number of organisations in the Pacific involved in getting things done for and in the region. Pacific governmental architecture in 2009 is hotchpotch and dysfunctional. Australia and New Zealand are engaged in a sibling spat with each emphasising their own successes and ways of doing things as being better than the other. This occurs at PIFS and the PICP where the former says their smaller membership is not important while the latter says their larger membership is important. What is really important for these two actors to grasp is that kinship is the basis of life in the Pacific and therefore the methods of engagement are extremely important to establish acceptability and sustainability. Even though PIF has a smaller membership, and is therefore more limited in its reach than the PICP, there is a place for both organisations. But communication between all regional groups is essential. CROP is a very good effort at regional cooperation and co-ordination, but is hampered in acceptance by the insistence of permanent chairmanship by PIFS.

As discussed in Chapter Three, the PICP and its secretariat, the PICP-S, are beset by similar bickering causing diversions from the work that needs to be 
done on policing in the region. The Chiefs acknowledge their need for outside assistance and are thirsty for knowledge, but the countries capable of providing both of these tools need to recognise the wider picture and their own limitations. For instance, the AFP reportedly represents all Australian police services at the PICP, but again, the language used in their discourse paints a different picture. One example is that while all other members of the PICP express their membership in the name of their country, the AFP expresses its membership in the use of its organisational name. Another example is, when asked for numbers about how many police members the AFP represents at the PICP, I was only given the numbers of AFP staff, not the entire country's numbers. Additionally, the AFP's predominant role is in security and intelligence while the state and territory police are more involved in day-to-day domestic policing which is more akin to the policing methods used and required in Pacific jurisdictions, although, because of the Pacific's positioning in transnational pathways, both skills are needed. While New Zealand provides a domestic view, it is only one view from more advanced police services.

There is a very important place for the PICP and its secretariat as the premier policing organisation for the region. However, a number of issues stand in the way of this happening.

The first is the balance of power, already identified as being weighted towards Australia and New Zealand. During the late 1990s and early 2000s most regional organisations underwent reviews to ensure their structures were strong and appropriate for the future. All of these reviews were undertaken by review teams external to those organisations, with the exception of the PICP which has undergone numerous reviews over its life. Most of the PICP reviews were instigated by the AFP and all were carried out by a review team made up of the AFP, NZP and, sometimes, an additional representative chosen from the remaining members. Again, this indicates that the balance of power is skewed toward the two metropolitan countries. Furthermore, the practice lacks transparency, and is even suggestive of bullying.

The second issue is the Pacific Way. Even though the PICP uses voting as a method of decision-making when agreement can't be reached, the Pacific Way is more powerful. When the strength of the voices is evenly balanced consensus works well, but if two of the twenty-one PICP voices are stronger than the other nineteen, the latter nineteen will defer to the stronger two rather than cause embarrassment or appear ungrateful. This results in the silencing of Pacific voices. 
The third issue, and an important finding of the research, is a conflict of interest by Australia and New Zealand. This conflict is created by their roles as members of the PICP while also being donors to policing initiatives in the region. This impacts on the decision making ability of the rest of the PICP and also in the provision of staff for the secretariat. New Zealand Police provides the Executive Director, his assistant and premises, while the AFP supplies two to three short term project officers sourced from the Pacific. The AFP also provides a project management staffer within the PICP-S who is also expected to carry out the role of Senior Liaison Officer in New Zealand. This position creates a conflict of interest and blurs the purposes of the roles.

\section{RECOMMENDATIONS}

6. The role of chair at CROP rotates among the representatives of the Council with every member taking their turn, including taking responsibility for documenting discussions.

7. The Chiefs of Australian Federal Police and New Zealand Police resign their membership of the PICP, but retain advisory status to the Pacific Islands Chiefs of Police.

8. Advisory positions to the PICP include members of the state and territory police services of Australia, ${ }^{301}$ the AFP, NZP, US Police, and French Police.

9. All Pacific Islands Chiefs of Police accept their responsibilities of leadership and change 'The Pacific Way' from one of deference to the wealthy and powerful, to one of leadership in decision making at the PICP. ${ }^{302}$

10. The PICP and PICP-S are reviewed by an external review team ideally sourced from the widely accepted SPC.

11. The review team should consider:

a. Whether the Pacific Islands Chiefs of Police should become, and maintain a position as, the premier organisation for policing matters in the Pacific.

\footnotetext{
301 Only one additional Australian member should accompany the AFP member to ensure that the loud voices don't drown out the quiet.

302 The Chiefs-only day at conference could be the ideal forum for this while the main conference could consist of advisory presentations and discussion of previously identified issues.
} 
b. Whether the PICP should register as a regional organisation giving it a legal basis.

c. Whether the PICP-S should become an action body for objective coordination of a range of data to properly inform the Chiefs' decisions.

d. Whether the PICP-S should seek staff with expert skills, particularly in the fields of research, assessment and evaluation and the understanding of the cultures and customs of the Pacific.

e. Whether conflicts are created by donor members in providing funds and/or positions which compromise transparency and accountability.

\begin{abstract}
AID
The Pacific Region receives a wealth of funds every year that are largely tagged as resources for 'development', but policing in the region also receives significant donations from a number of countries including Australia, New Zealand, China, Japan, France, and Taiwan. This assistance is given in different guises including the provision of funds, training programmes, buildings, advice, personnel, and other resources with a range of accountability needs. Australia and New Zealand, as significant long-time donors in the region, make stringent monitoring demands on receivers whereas China, Japan and Taiwan have different and less obvious demands for the use of their donations. As discussed in Chapter Three, the benefits of many donated funds return to their country of origin or become unsustainable in the long term. Much of the assistance provided to policing in the Pacific is by way of training programmes and these are often too technically advanced for the police service receiving them and are therefore, also unsustainable. Comments were made by respondents that it was easy to get big items like buildings, cars and advanced training but it was much harder to get the resources they really needed, such as pens, notebooks and other basic necessities.
\end{abstract}

\title{
RECOMMENDATIONS
}

12. Resource needs assessments are undertaken in partnership by PICP-S personnel and in-country police experts.

13. Training needs assessments are undertaken in partnership by PICP-S personnel and in-country staff. 
14. All resources and training needs are compatible with just and sustainable outcomes.

\section{CONCLUSIONS}

In sum, the Pacific is policed by men and women from a range of countries, all dedicated to protecting the safety and security of the people and their territories. I have argued that international actors in this role present their own ideas of western policing models as the answer to future models of policing. However, such policing models often pass over the cultural needs of those they are trying to assist and create a rule of law that reflects western society rather that the communities of the Pacific. I have made recommendations that address this issue including exposing international actors to the culture of the country to gain a full understanding of the country's needs. This understanding is essential to enable local staff to fully engage with international staff and effect reform that is appropriate to their needs. Committing to the people of the land in this way ensures transparency and accountability for international staff. Additionally, my approach to policing in the Pacific offers logical steps and methods of engagement that ensure the voices of the Pacific are heard, respected and acted upon. Furthermore, that Australia and New Zealand hold the balance of power also contributes to the argument that capacity building in the region reflects western policing models and removes the ability from local decision makers and staff to effect their own appropriate change. I have suggested a change in the language used in political and policing literature to address these arguments and return confidence to the Pacific. This imbalance of power has been created by the need to accept a wealth of funds from richer countries manifesting their international status and drawing attention to new international rules concerning human rights. The result is a deluge of assistance across the full range of development. I have recommended that needs assessments be carried out incountry in partnership to ensure resources and training meet the needs of those receiving them. Finally, I have made recommendations to address conflicts of interest in policing the region which will establish the PICP as premier decision makers for policing in the region, supported by a secretariat with expertise in research, assessment and evaluation skills. 
Administrator. "Contributing Nations." Regional Assistance Mission to Solomon Islands, http://www.ramsi.org/node/8 (accessed 09 January, 2009).

Administrator. "Tonga Police Development Programme launched." Government of Tonga, http://www.minfo.gov.to/index.php?option=com_content\&view=article\&i d=197: tonga-police-development-programme-launched (accessed 15 March, 2009).

Andreas, Peter, and Ethan Nadelmann. Policing the Globe: Criminalisation and Crime Control in International Relations. New York: Oxford University Press, 2006.

Andrews, John. "Wanted: New Zealand police officer looking for an overseas adventure." nzherald.co.nz, http://www.nzherald.co.nz/pitcairnislands/news/article.cfm?l_id=433\&objectid=10482163 (accessed 27 March, 2009).

Anthony van Fossen. "The Struggle for Recognition: Diplomatic Competition Between China and Taiwan in Oceania." Journal of Chinese Political Science 12, no. 2 (2007): 125-146.

"The ANZAC Pact ". www.dfat.gov.au/GEO/new_zealand/01-ANZAC.pdf (accessed 29 September, 2008).

Attorney-General's Department. "AFP Training for Overseas Policing." Australian Government: Attorney-General's Department, http://www.ag.gov.au/www/agd/agd.nsf/Page/Publications_Budgets_Bud get2008_MediaReleases_AFPTrainingforOverseasPolicing (accessed 24 February, 2009).

Australian Federal Police. "International Deployment Group: Fact Sheet." edited by Australian Federal Police. Canberra: Australian Federal Police (AFP), 2006.

Australian Federal Police. "International Liaison." Australian Federal Police (AFP), http://www.afp.gov.au/international/liaison.html (accessed 19 January, 2008).

Australian Federal Police. "Pacific Transnational Crime Coordination Centre Opens in Suva." Commonwealth of Australia, http://www.afp.gov.au/media_releases/national/2004/pacific_transnation al_crime_coordination_centre_opens_in_suva.html (accessed 14 January, 2009).

Australian Government, AusAID. "Strengthening the Pacific's Crime Fighting Capabilities." Commonwealth of Australia, http://www.ausaid.gov.au/media/release.cfm?BC=Media\&Id=2925_2989 _8265_171_3189 (accessed 15 March, 2009).

Australian Treaty Series 1948 No. 15. "Agreement Establishing the South Pacific Commission." Australian Government Publishing Service, http://www.austlii.edu.au/au/other/dfat/treaties/1948/15.html (accessed 20 November, 2008).

Bayley, David. "Democratic Policing." In The SAGE Dictionary of POLICING, edited by Alison Wakefield and Jenny Fleming, 80-82. London, Thousand Oaks, New Dehli, Singapore: SAGE Publications Ltd, 2009.

Bayley, David H Changing the Guard: Developing Democratic Police Abroad. New York: Oxford University Press, 2005.

Beijing Organising Committee. "Beijing Olympic Broadcasting." The Beijing Organising Committee for the Games of the XXIX Olympiad (BOCOG), http://en.beijing2008.cn/53/66/column211716653.shtml (accessed 31 December, 2008). 
Bigo, Didier. "Liaison Officers in Europe." In Issues in Transnational Policing, edited by J.W.E. Sheptycki, 67-99. London, New York: Routledge, 2000.

Boswell, B.M. "Policing the Pacific: The Pacific Islands Chiefs of Police 19702008." Wellington: Victoria University of Wellington, 2008.

"A Brief History." http://www.samoa.co.us/history.html (accessed 9 June, 2008).

Brown, M. Anne. "Security and Development: Conflict and Resilience in the Pacific Islands Region." In Security and Development in the Pacific Islands, edited by M Anne Brown, 1-32. Boulder, London: Lynne Rienner Publishers Inc, 2007.

Buchanan, Paul G. "China Steps into Pacific Power Vacuum." Samoa Observer, 17 September 2009.

Chappell, David Q.A. . "The Noumea Accord: Decolonisation without independence in New Caledonia?" Pacific Affairs 72, no. 3 (1999): 19.

Commonwealth of Australia. "Pacific 2020: Challenges and Opportunities for Growth." Canberra: Australian Agency for International Development (AusAID) 2006

Conference Secretary "Minutes of the 1st South Pacific Chiefs of Police Conference." Suva, Fiji Islands: SPCPC, 1970.

Conference Secretary. "Minutes of the 16th South Pacific Chiefs of Police Conference." American Samoa: SPCPC, 1987.

Conference Secretary. "Minutes of the 20th South Pacific Chiefs of Police Conference." New Zealand: SPCPC, 1991.

Conference Secretary. "Minutes of the 22nd South Pacific Chiefs of Police Conference." Papua New Guinea: SPCPC, 1993.

Conference Secretary. "Minutes of the 29th South Pacific Chiefs of Police Conference." New Zealand: SPCPC, 2000.

Cook, Malcolm. "The Pacific: Beyond Post-colonialism and the Pacific Way, A New Era?" Sydney: Lowy Institute for International Policy 2005

Dobell, Graeme. "China and Taiwan in the South Pacific: Diplomatic Chess versus Pacific Political Rugby." Sydney: Lowy Institute for International Policy 2007

Durch, William J., Victoria K. Holt, Caroline R. Earle, and Moira K. Shanahan. "The Brahimi Report and the Future of UN Peace Operations." Washington DC: The Henry L. Stimson Center 2003

Edmondson, Richard. "Island Paradise Like Returning to the 1950s." stuff.co.nz, http://www.stuff.co.nz/print/4817147a6015.html (accessed 15 January, 2009).

"Eminent Person Group has a month to review Pacific Islands Forum Secretariat." Pacific Islands Broadcasting Association, http://www.accessmylibrary.com/coms2/summary_0286-2312121_ITM (accessed 8 January, 2009).

Farrall, Jeremy. "Peacekeeping." In The SAGE Dictionary of POLICING, edited by Alison Wakefield and Jenny Fleming, 221-223. London, Thousand Oaks, New Dehli, Singapore: SAGE Publications Ltd, 2009.

Fraenkel, Jon. The Manipulation of Custom: From Uprising to Intervention in the Solomon Islands. Wellington: Victoria University Press, 2004.

Fraenkel, Jon. "South-West Pacific: Arc of Instability or Matrix of Discontent?" In New Zealand in Globalising World, edited by Ralph Pettman, 119-140. Wellington: Victoria University Press, 2005.

Gibbs, Matthew, "Fact Sheet," April 2007 Suva, Fiji Islands: PIDC Secretariat http://www.pidcsec.org/files/Toolkit/PIDC\%20Fact\%20Sheet\%20April\%2 02007.pdf (accessed 10 November 2008).

Gibson, Joel. "Fiji's police chief reads riot act as military rift grows." The Sydney Morning Herald Website, http://www.smh.com.au/news/world/fijis-policechief-reads-riot-act-as-military-rift-

grows/2006/11/02/1162339989045.html (accessed 15 March, 2009). 
Goldsmith, Andrew. "Transitional Policing." In The SAGE Dictionary of POLICING, edited by Alison Wakefield and Jenny Fleming, 305-307. London, Thousand Oaks, New Dehli, Singapore: SAGE Publications Ltd, 2009.

Goldsmith, Andrew, and J.W.E. Sheptycki. "Introduction." In Crafting Transnational Policing: Police Capacity-Building and Global Policing Reform, edited by Andrew Goldsmith and James Sheptycki, 1-28. Oxford, Portland: Hart Publishing, 2007.

"Govt asks NZ for help on Island." Post-Courier, 20 May 2005.

Gyngell, Allan. "Design Faults: The Asia Pacific's Regional Architecture." Sydney: Lowy Institute for International Policy 2007

Hanson, Fergus. "The Dragon Looks South." Sydney: Lowy Institute for International Policy 2008

"Hawaii History." Hawaiian Roots Website, http://www.hawaiianroots.com/hawaiihistory.htm (accessed 30 December, 2008).

Heaphy, Melanie, "Making a Difference in Our Own Region," July, 20082008 Wellington: NZAID (accessed 11 December 2008).

Heather-Latu, Brenda, "Mending the Nets,"2005 Vanuatu: Pacific Islands Law Officers Network

http://www.pilonsec.org/www/pilon/rwpattach.nsf/PublicbySrc/Mending+ the+Nets.pdf/\$file/Mending+the+Nets.pdf (accessed 30 November 2008).

Hedley, Christopher. "Amendments to the Agreement Establishing the South Pacific Commission." Internet Guide to International Fisheries Law, http://www.intfish.net/igifl/treaties/related/spc.htm (accessed 20 November, 2008).

Henderson, John. "Security in Oceania in the Post 9/11 and Bali Era." In New Zealand in a Globalising World, edited by Ralph Pettman, 73-82.

Wellington: Victoria University Press, 2005.

Herr, Richard. "Australia, Security and the Pacific Islands: From Empire to Commonwealth." The Round Table 95, no. 187 (2006): 705-716.

Herr, Richard. "The Concept of the 'Failed State': A Brobdingnagian View from Lilliput." In New Zealand in a Globalising World, edited by Ralph Pettman, 99-109. Wellington: Victoria University Press, 2005.

Herr, Richard. "The Region and the World: Regional Cooperation and Initiatives, Pacific Community (South Pacific Commission), South Pacific Forum." In The Pacific Islands: an encyclopedia, edited by Brij V. Lal and Kate Fortune, 326-331. Honolulu: University of Hawai'i Press, 2000.

Hettne, Bjorn. "Globalism, Regionalism and Interregionalism." In Globalisation, Development and Human Security, edited by Anthony McGrew and Nana K Poku, 25-46. Cambridge, Malden: Polity Press, 2007.

Howe, K.R. "The Last Frontier." In VAKA MOANA: Voyages of the Ancestors, edited by K.R. Howe, 14-21. Auckland: David Bateman Ltd, 2006.

Huffer, Elise. "Regionalism and Cultural Identity: Putting the Pacific back into the plan." In Globalisation and Governance in the Pacific Islands, edited by Stewart Firth. Canberra: Australian National University (ANU) E Press, 2006.

Hughes, A.V. "Consultative Draft, Strengthening Regional Management: A Review of the Architecture of Regional Co-operation in the Pacific." Suva: Pacific Islands Forum 2005.

http://www.forumsec.org.fj/pages.cfm/documents/other?PageIndex $=1$ (accessed 26 November 2008).

International Service Group. "International Service Group." New Zealand Police, http://www.police.govt.nz/service/overseas/faq.html (accessed 19 January, 2009).

Interpol. "About Interpol." Interpol Website, http://www.interpol.int/public/icpo/default.asp (accessed 28 February, 2009). 
INTRAC, "Improving aid effectiveness: A review of recent initiatives for civil society organisations" n.d. International NGO Training \& Research Centre

Jaffe, Eugene D. Globalisation and Development, The New Global Society. Philadelphia: Chelsea House Publishers, 2006.

Katzenstein, Peter J. A World of Regions: Asia and Europe in the American Imperium. Cornell: Cornell University Press, 2005.

Keal, Paul. "Indigenous Self-Determination and the Legitimacy of Sovereign States." International Politics. The Hague 44, no. Iss. 2/3 (2007): 19.

Kidu, Dame Carol. "Maternal health in PNG- reality, challenges and possible solutions." In Eliminating World Poverty: Global Goals and Regional Progress Symposium. Wellington: Institute of Policy Studies, 2009.

Klein, Naomi. No Logo: no space, no choice, no jobs. London: Flamingo, 2000.

Maclellan, Nic. "The Noumea Accord and Decolonisation in New Caledonia." The Journal of Pacific History 34, no. 3 (1999): 8.

McCall, Grant. "Rapanui (Easter Island)." Fiji Times Ltd, http:www2.hawaii.edu/ ogden/piir/pacific/Rapanui.html (accessed 30 December, 2008).

McDougall, Derek. "Insecurity in oceania: An Australian Perspective." The Round Table 96, no. 391 (2007): 415-427.

McGrew, Anthony. "Introduction." In Globalisation, Development and Human Security, edited by Anthony McGrew and Nana K. Poku, 1-21. Cambridge, Malden: Polity Press, 2007.

McLeod, Abby. "Police Reform in Papua New Guinea." In Security and Development in the Pacific Islands: Social Resilience in Emerging States, edited by M Anne Brown, 73-88. Boulder, London: Lynne Rienner Publishers Inc, 2007.

McLeod, Abby, and Sinclair Dinnen. "Police Building in the Southwest Pacific New Directions in Australian Regional Building." In Crafting International Policing: Police Capacity-Building and Global Policing Reform, edited by Andrew Goldsmith and James Sheptycki, 295-328. Oxford, Portland: Hart Publishing, 2007.

McLeod, Abby, and Juani O'Reilly. "Pacific Policing." In The SAGE Dictionary of POLICING, edited by Alison Wakefield and Jenny Fleming, 213-215. London, Thousand Oaks, New Dehli, Singapore: SAGE Publications Ltd, 2009.

McPhedran, Ian. "Aussie cops to get out of PNG." The Mercury, 14 May 2005.

Nautilus Institute at RMIT. "Pacific Transnational Crime Coordination Centre (PTCCC)." http://gc.nautilus.org/Nautilus/australia/australia-inpacific/pacific-transnational-crime-coordination-centre (accessed 14 November, 2008).

New Zealand Government. "Pacific Strategy 2007-2015." edited by NZAID. Wellington: NZAID, n.d.

New Zealand Police. "Bougainville Community Policing Project." New Zealand Police Website, http://www.police.govt.nz/service/overseas/bougainville.html (accessed 15 December, 2008).

New Zealand Police. "Briefing to the Incoming Minister." Wellington: New Zealand Police 2008

O'Leary, Zina. The Essential Guide to Doing Research. London, Thousand Oaks, New Delhi, Singapore: Sage Publications Ltd, 2004. Reprint, 2007.

Oceania Customs Organisation (OCO). "Oceania Customs Organisation: Fact Sheet." http://www.ocosec.org/assets/oco\%20fact\%20sheet/PDFFact\%20Sheet\%20June\%202006-1.pdf (accessed 8 August, 2008).

Online Editor. "Cook Islands Police Chief Tasker won't renew contract." Pacific Islands News Association, http://www.pina.com.fj/?p=pacnews\&m =read\&o=195285357849a743ae 6e732d85dc70 (accessed 15 March, 2009). 
"Overview." ASEAN Website, http://www.asean.org/328.htm (accessed 29 November, 2008).

Pacific Immigration Directors' Conference Secretariat, "Charter," 30 August 1 September 2005 Fiji Islands: PIDC Secretariat http://www.pidcsec.org/files/Toolkit/PIDC\%20Charter\%20April\%202007. pdf (accessed 30 November 2008).

Pacific Islands Chiefs of Police Secretariat, "5th PICP Women's Advisory Network Conference: Future Directions of Women in Pacific Policing," 1-2 July 2008 Wellington, New Zealand: PICP

Pacific Islands Chiefs of Police Secretariat. "Constitution of Pacific Islands Chiefs of Police." Wellington: Pacific Islands Chiefs of Police, 2005.

Pacific Islands Forum Secretariat, "Corporate Plan 2005-2007: Excelling Together for the People of the Pacific,"2005 Suva, Fiji Islands: Pacific Islands Forum http://www.forumsec.org.fj/_resources/article/files/2005\%202007\%20Corporate\%20Plan.pdf (accessed 29 November 2008).

Pacific Islands Forum Secretariat, "Nineteenth South Pacific Forum," 20-21 September 1988 Nuku'alofa, Tonga: Pacific Islands Forum http://www.forumsec.org.fj/_resources/article/files/1983\%20Communiqu e2.pdf (accessed 27 November 2008).

Pacific Islands Forum Secretariat, "Pacific Island Countries Trade Agreement: Rules of Origin Manual,"2004 Suva, Fiji: Pacific Islands Forum Secretariat http://www.forumsec.org.fj/_resources/article/files/PICTA\%20RoO\%20M anual2.pdf (accessed 29 November 2008).

Pacific Islands Forum Secretariat. "The Pacific Islands Forum and its Secretariat." Pacific Islands Forum Secretariat, http://www.forumsec.org/pages.cfm/about-us/ (accessed 18 August, 2008).

Pacific Islands Forum Secretariat, "Pacific Islands Forum Secretariat Financial Statements for the Year Ended 31 December 2007," 31 December 2007 Suva, Fiji Islands: Pacific Islands Forum Secretariat http://www.forumsec.org.fj/UserFiles/File/PIFS_Audited_Report_2007.pdf (accessed 1 December 2008).

Pacific Islands Forum Secretariat, "Pacific Islands law Officers Meeting (PILOM) Review," January 2007 PILON Secretariat Website: Pacific Islands Law Officers Network (PILON)

http://www.pilonsec.org/www/pilon/rwpattach.nsf/PublicbySrc/Pacific+Isl ands+Law+Officers+Meeting+(PILOM)+Review.pdf/\$file/Pacific+Islands+ Law+Officers+Meeting+(PILOM)+Review.pdf (accessed 16 July 2008).

Pacific Islands Forum Secretariat, "The Pacific Plan: For Strengthening Regional Cooperation and Integration," November 2007 Suva: Fiji Islands: Pacific Islands Forum http://www.forumsec.org.fj/UserFiles/File/Pacific_Plan_Nov_2007_version .pdf (accessed 18 August 2008).

Pacific Islands Forum Secretariat. "Political \& Security." Pacific Islands Forum, http://www.forumsec.org/pages.cfm/security/lawenforcement/?printerfriendly=true (accessed 25 November, 2008).

Pacific Islands Forum Secretariat, "South Pacific Forum," 23-25 February 1972 Canberra: Pacific Islands Forum http://www.forumsec.org.fj/_resources/article/files/1972\%20Communiqu e2.pdf (accessed 27 February 2008).

Pacific Islands Forum Secretariat, "Thirtieth Pacific Islands Forum," 3-5 October 1999 Koror, Republic of Palau: Pacific Islands Forum http://www.forumsec.org.fj/_resources/article/files/1999\%20Communiqu e.pdf (accessed 26 November 2008).

Pacific Islands Forum Secretariat, "Thirty-seventh Pacific Islands Forum," 24-25 October 2006 Nadi, Fiji Islands: Pacific Islands Forum http://www.forumsec.org/_resources/article/files/2006\%20Communique. pdf (accessed 27 November 2008). 
Pacific Islands Law Officers Network, "Home,"2007 PILON Website: PILON http://www.pilonsec.org/www/pilon/pilon.nsf/Page/Home (accessed 30 November 2008).

"Pacific Regional Consultation on the GPPAC Programme." Recommendations resulting from the Conference: "From Reaction to Prevention: Civil Society Forging Partnerships to prevent Violent Conflicts and Build Peace", Pacific Harbour, Fiji Islands, 17-22 April 2005 http://www.gppac.net/uploads/File/Regions/Pacific/Pacific\%20Regional\% 20Action\%20Agenda.pdf (accessed 18 November 2008).

Pacific Regional Policing Initiative (PRPI). "Programme Profile." PRPI Website, http://www.pacific-rpi.com/ (accessed 19 January, 2009).

"Pacific Transnational Crime Network (PTCN)." www.aic.gov.au/Trafficking_Persons_Presentations/Pacific_Transnational_ Crime_Network.pdf - (accessed 7 March, 2009).

Peters, Winston. "Cook Islands Police Service Review." NZ Government Website, http://beehive.govt.nz/release/cook+islands+police+service+review (accessed 15 March, 2009).

PIANGO Secretariat, "Pacific Islands Association of Non-government Organisations Annual Report," 31 December 2006 Suva: PIANGO Secretariat http://www.piango.org/docs/Publications/PIANGO_Annual_Report_2006.p df (accessed 26 November 2008).

PIANGO Secretariat, "PIFS Accreditation,"2007 PIANGO Website: PIANGO Secretariat http://www.piango.org/pifs-accreditation.html (accessed 26 November 2008).

PILON Secretariat, "Pacific Islands law Officers' Network Meeting Outcomes," 610 December 2007 Cook Islands: PILON Secretariat http://www.pilonsec.org/www/pilon/rwpattach.nsf/VAP/(756EDFD270AD7 04EF00C15CF396D6111) 26th+PILON+Meeting+Outcomes.pdf/\$file/26t h+PILON+Meeting+Outcomes.pdf (accessed 30 November 2008).

"Policy Board," n.d. Pago Pago: SPICIN Website http://spicin.com/policy (accessed 1 December 2008).

Radio New Zealand International. "Fiji Police refuse to release shipment of ammunition to army." Radio New Zealand International Website, http://www.rnzi.com/pages/news.php?op=read\&id=27872 (accessed 15 March, 2009).

RAMSI. "RAMSI's Work." Regional Assistance Mission to Solomon Islands Website, http://www.ramsi.org/node/2 (accessed 9 January, 2009).

Ratuva, Steven. "Mara's 'Pacific Way' Legacy: Remembering The Pacific's Dominant Leader." Pacific Magazine, 1 June 2004.

"The Regional Process." GPPAC Website, http://www.gppac.net/page.php?id=1650 (accessed 18 November, 2008).

Reilly, Benjamin, and Kennedy Graham. "Conflict Through Asia and the Pacific: Causes and Trends." In Searching for Peace in Asia Pacific: An Overview of Conflict Preventions and Peacebuilding Activities, edited by Annelies Heijmans, Nicola Simmonds and Hans van de Veen, 9-22. Boulder, Covent Garden: Lynne Reinner Publishers, Inc, 2004.

Rød-Larsen, Terje. "Foreword." In Greater than the Sum of its Parts? Assessing "Whole of Government" Approaches to Fragile States, vii-viii. New York: International Peace Academy, 2007.

"Rule of Law." LexisNexis, http://www.lexisnexis.co.nz/about-us/rule-oflaw/default.aspx (accessed 3 March, 2009).

Secretariat of the Pacific Community (SPC). Corporate Plan (2007-2012). Noumea: Secretariat of the Pacific Community (SPC), 2008.

Secretariat of the Pacific Community (SPC). "The Declaration de Tahiti Nui being The Operational Policies of the Pacific Community." Pacific Community 2000 
Secretariat of the Pacific Community (SPC). "Donors." Secretariat of the Pacific Community (SPC),

http://www.spc.int/corp/index2.php?option=com_content\&task=view\&id $=23 \& p o p=1 \ldots$ (accessed 29 September, 2008).

Secretariat of the Pacific Community (SPC). "History." Secretariat of the Pacific Community, http://www.spc.int/corp/index2.php?option=com_content\&task=view\&id $=24 \&$ pop $=1 \ldots$ (accessed 29 September, 2008).

Secretariat, Pacific Islands Chiefs of Police, "Future Directions of Pacific Policing,"2007 Wellington: Pacific Islands Chiefs of Police Secretariat http://www.picp.org/index.php/Publications/2007Communique (accessed 30 November 2008).

Secretariat, Pacific Islands Forum. "About Us." PIFS Website, http://www.forumsec.org.fj/pages.cfm/about-us/? (accessed 25 November, 2008).

Sheptycki, James. "Introduction." In Issues in Transnational Policing, edited by J.W.E. Sheptycki, 1-20. London, New York: Routledge, 2000.

Sheptycki, James W.E. "Introduction." In Issues in Transnational Policing, edited by James W.E. Sheptycki, 1-20. London, New York: Routledge, 2000.

Skeers, Jake. "Nauru deal cements Australia's Pacific incarceration policy." World Institute for Asian Studies, http://www.asiantribune.com/oldsite/show_article.php?id=1378 (accessed 15 March, 2009).

South Pacific Forum Secretariat, "Declaration by the South Pacific Forum on Law Enforcement Cooperation (Honiara Declaration),"1992 Honiara, Papua New Guinea: South Pacific Forum http://www.cbsi.com.sb/fileadmin/PDF/SIFIU/Honiara-Declaration.pdf (accessed 1 December 2008).

"South Pacific Regional Trade and Economic Co-operation Agreement: A Reference Handbook for Forum Island Country Exporters," 4th Edition 1996 Suva, Fiji:

http://www.customs.gov.au/webdata/resources/files/origin4.pdf (accessed 29 November 2008).

SPC Publications Section. Regional Organisations of the Pacific: Working Together. Noumea: Secretariat of the Pacific Community, 2002.

Tavola, Kaliopate, Makurita Baaro, Lucy Bogari, Lourdes Pangelinan, Adrian Simcock, and Epa Tuioti. "Reforming the Pacific Regional Institutional Framework." Suva: Pacific Islands Forum 2006.

http://www.forumsec.org.fj/_resources/article/files/RIF\%20Study\%20Fin al.pdf (accessed 26 November 2008).

The International Bank for Reconstruction and Development/The World Bank. Atlas of Global Development. Glasgow: Collins, 2007.

The Parliament of the Commonwealth of Australia. "Appendix C: Australia's Overseas Aid Program Budget 2007-2008." In Australia's aid program in the Pacific: Joint Standing Committee on Foreign Affairs, Defence and Trade. Canberra: Commonwealth of Australia 2007.

Ungerer, Carl. "Introduction." In Australian Foreign Policy in the Age of Terror, edited by Carl Ungerer, 1-20. Sydney: University of New South Wales Press Ltd, 2008.

United Nations. "Declaration on the granting of independence to colonial countries and peoples." Official Records of the General Assembly, Fifteenth Session, Supplement No. 2 (A/4494). 1960.

United Nations. "Principles of Democratic Policing." UN Police Magazine, December 2006.

United Nations. "Summary of Contributors of UN Police Personnel: As of 5 December 2006." UN Police Magazine, December 2006.

United Nations. "Summary of Contributors of UN Police Personnel: As of May 2007." UN Police Magazine, June 2007. 
United Nations. "United Nations Peace Operations: A Year in Review 2007." Peace and Security Section of the United Nations Department of Public Information 2007. http://www.un.org/Depts/dpko/dpko/pubs.shtml (accessed 17 January 2009).

van der Goot, Wiepke H.E., and Aldo H.E. Dell'Ariccia. "The European Union in the Pacific: Its role, its relationships, its contribution." In The European Union in the Pacific. Wellington, New Zealand 2008.

Victoria Police, "Commissioner's Conference Concludes," 25 May 2006 Melbourne: Victoria Police Website http://www.police.vic.gov.au/content.asp?Document_ID=6314 (accessed 10 December 2008).

Wainwright, Elsina. "How is RAMSI faring? Progress, challenges, and lessons learned." Australian Strategic Policy Institute (ASPI) 2005

Wainwright, Elsina, Quinton Clements, Mary-Louise O'Callaghan, and Greg Urwin. "Our Failing Neighbour: Australia and the Future of Solomon Islands." Barton: Australian Strategic Policy Institute (ASPI) 2003

Wakefield, Alison, and Eugene McLaughlin. "Transnational Policing." In The SAGE Dictionary of POLICING, edited by Alison Wakefield and Jenny Fleming, 308-310. London, Thousand Oaks, New Dehli, Singapore: SAGE Publications Ltd, 2009.

Weekly Niue News. "Search Continues for Top Cop." Weekly Niue News, http://www.mail-archive.com/weekly-niuenews@lists.electric.gen.nz/msg00107.html (accessed 15 March, 2009).

"The World Factbook." Central Intelligence Agency, https://www.cia.gov/library/publications/the-worldfactbook/geos/zn.html (accessed 8 October, 2008).

Yang, Jian. "China in the South Pacific: A Strategic Threat?": www.asianz.org.nz, 2008.

Zhang, Yongjin. "China and the emerging regional order in the South Pacific." Australian Journal of International Affairs 61, no. 3 (2007): 367-381.

Zhe, Zhu. "Police liaison officers to be sent to Australia." Chinadaily.com, http://www.chinadaily.com.cn/china/2008-12/03/content_7263529.htm (accessed 19 January, 2009). 


\section{APPENDIX ONE: AN APPROACH TO POLICING IN THE PACIFIC}
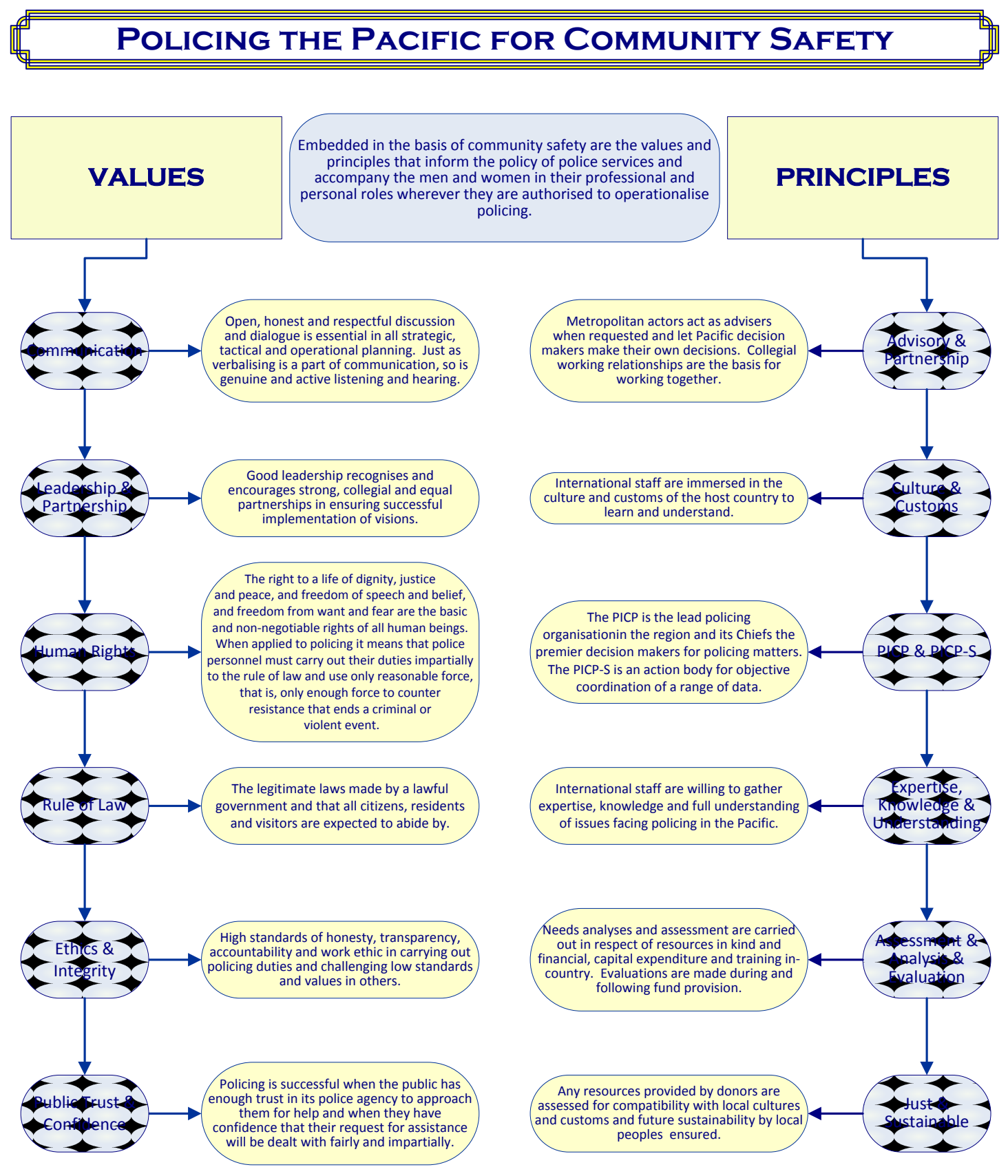

The overarching principles of policing anywhere should be based on clear and agreed values and principles. My approach to international, multinational and transnational policing in the Pacific acknowledges David H. Bayley's concepts of building democratic policing as discussed in Chapter Two, pp.14,16, but shifts the focus from what the already democratic want to achieve, to the needs and approach required from those requesting international assistance. Therefore, my approach incorporates Bayley's principles but is based on values that increase the scope of responsibility for international staff to ensure the needs of Pacific Peoples are met. 


\section{APPENDIX ONE: AN APPROACH TO POLICING IN THE PACIFIC}
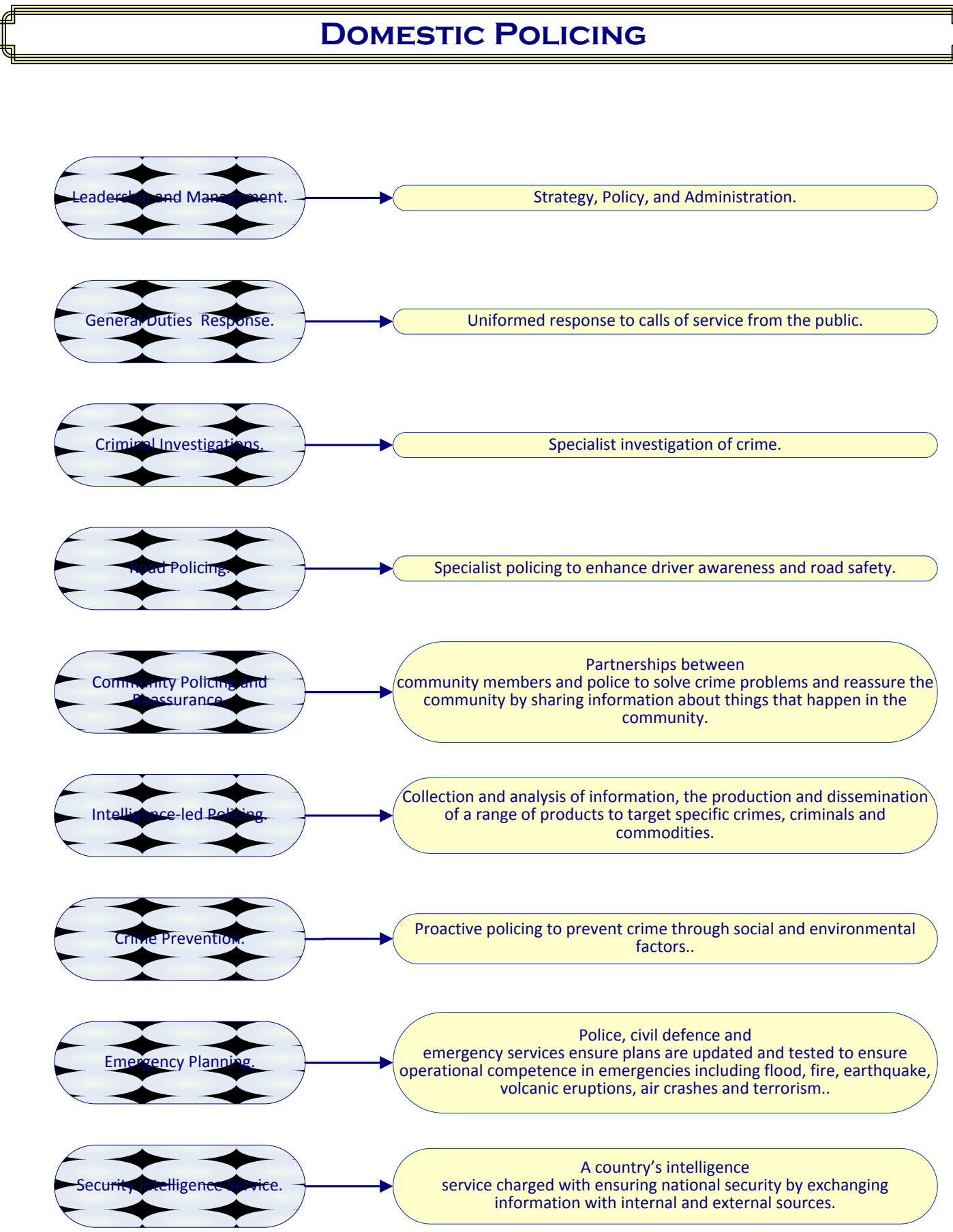


\section{APPENDIX TWO: POPULATIONS \& POLICE}

NUMBERS

Figure 3 - Total Population and Police Numbers by PICP Member Country as at 2008 unless otherwise specified. ${ }^{303}$

\begin{tabular}{|c|c|c|c|c|}
\hline COUNTRY & POPULATION & $\begin{array}{r}\text { GDP } \\
\text { PER } \\
\text { CAPITA } \\
\text { (GDPPC) } \\
\text { IN US \$ }\end{array}$ & $\begin{array}{r}\text { TYPE OF } \\
\text { GOVT }\end{array}$ & $\begin{array}{r}\text { POLICE } \\
\text { NUMBERS }\end{array}$ \\
\hline American Samoa & 57,496 & $\$ 5,800$ & Territory of US & 400 \\
\hline Australia & $20,600,856$ & 37,300 & $\begin{array}{r}\text { Federal } \\
\text { Democracy }\end{array}$ & $\begin{array}{r}56,452 \\
6,036 \\
\text { (Federal police } \\
\text { only) }\end{array}$ \\
\hline Cook Islands & 21,750 & 9,100 & $\begin{array}{r}\text { Self governing } \\
(\mathrm{NZ})\end{array}$ & 120 \\
\hline FSM & 107,665 & 2,300 & $\begin{array}{l}\text { Compact of } \\
\text { Free Assn (US) }\end{array}$ & $\begin{array}{r}392 \\
\text { (Includes } \\
\text { federal and } \\
\text { state police) }\end{array}$ \\
\hline Fiji Islands & 931,741 & 3,900 & $\begin{array}{l}\text { Republic under } \\
\text { military regime }\end{array}$ & (At 2006) 2,640 \\
\hline French Polynesia & 283,019 & 17,500 & $\begin{array}{r}\text { Overseas } \\
\text { Territory of } \\
\text { France }\end{array}$ & * \\
\hline Guam & 175,877 & 15,000 & Territory of US & 293 \\
\hline Kiribati & 110,356 & 3,600 & Republic & 300 \\
\hline $\begin{array}{l}\text { Republic of } \\
\text { Marshall Islands }\end{array}$ & 63,174 & 2,900 & $\begin{array}{l}\text { Compact of } \\
\text { Free Assn (US) }\end{array}$ & 175 \\
\hline Nauru & 13,770 & 5,000 & Republic & 102 \\
\hline New Caledonia & 224,824 & 15,000 & $\begin{array}{r}\text { Overseas } \\
\text { Territory of } \\
\text { France }\end{array}$ & 430 \\
\hline New Zealand & $4,173,460$ & 27,200 & $\begin{array}{r}\text { Parliamentary } \\
\text { Democracy }\end{array}$ & 10,884 \\
\hline
\end{tabular}

303 Pacific Islands Chiefs of Police Secretariat, "5th PICP Women's Advisory Network Conference: Future Directions of Women in Pacific Policing"; "The World Factbook". 


\begin{tabular}{|c|c|c|c|c|}
\hline COUNTRY & POPULATION & $\begin{array}{r}\text { GDP } \\
\text { PER } \\
\text { CAPITA } \\
\text { (GDPPC) } \\
\text { IN US \$ }\end{array}$ & $\begin{array}{r}\text { TYPE OF } \\
\text { GOVT }\end{array}$ & $\begin{array}{r}\text { POLICE } \\
\text { NUMBERS }\end{array}$ \\
\hline Niue & 1,444 & 5,800 & $\begin{array}{r}\text { Self governing } \\
(\mathrm{NZ})\end{array}$ & 16 \\
\hline $\begin{array}{l}\text { C/wealth of Nthn } \\
\text { Marianna Islands }\end{array}$ & 86,616 & 12,500 & $\begin{array}{r}\text { Commonwealth } \\
\text { in union with } \\
\text { US }\end{array}$ & 186 \\
\hline $\begin{array}{l}\text { Papua New } \\
\text { Guinea }\end{array}$ & $5,931,769$ & 2,100 & $\begin{array}{r}\text { Constitutional } \\
\text { Democracy }\end{array}$ & 4,732 \\
\hline Palau & 21,093 & 7,600 & $\begin{array}{r}\text { Compact of } \\
\text { Free Assn (US) }\end{array}$ & 162 \\
\hline Samoa & 217,083 & 5,400 & $\begin{array}{r}\text { Parliamentary } \\
\text { Democracy }\end{array}$ & 457 \\
\hline Solomon Islands & 581,318 & 1,900 & $\begin{array}{r}\text { Parliamentary } \\
\text { Democracy }\end{array}$ & 1,052 \\
\hline Tonga & 119,009 & 5,100 & $\begin{array}{r}\text { Constitutional } \\
\text { Monarchy }\end{array}$ & $\begin{array}{r}\text { (As at 2007) } \\
328\end{array}$ \\
\hline Tuvalu & 12,177 & 1,600 & $\begin{array}{r}\text { Constitutional } \\
\text { Monarchy with } \\
\text { Parliamentary } \\
\text { Democracy }\end{array}$ & 63 \\
\hline Vanuatu & 215,446 & 3,900 & $\begin{array}{r}\text { Parliamentary } \\
\text { Republic }\end{array}$ & 530 \\
\hline TOTAL & $33,949,943$ & 9,071 & & 85,750 \\
\hline $\begin{array}{l}\text { TOTAL LESS } \\
\text { AUSTRALIA }\end{array}$ & $13,349,087$ & 7,660 & & 23,262 \\
\hline $\begin{array}{l}\text { TOTAL LESS } \\
\text { AUSTRALIA AND } \\
\text { NEW ZEALAND }\end{array}$ & $9,175,627$ & 6,631 & & 12,378 \\
\hline
\end{tabular}




\section{APPENDIX THREE: EXTERNAL AID \& GDPPC}

Figure 4 - External States by Country, Population, GDP, Government Type and Aid ${ }^{304}$

\begin{tabular}{|c|c|c|c|c|}
\hline COUNTRY & POPULATION & $\begin{array}{r}\text { GDP PER } \\
\text { CAPITA } \\
\text { (GDPPC) } \\
\text { IN US \$ }\end{array}$ & TYPE OF GOVT & $\begin{array}{r}\text { AID TO } \\
\text { THE } \\
\text { PACIFIC }\end{array}$ \\
\hline Australia & $20,600,856$ & 37,300 & $\begin{array}{r}\text { Federal } \\
\text { Democracy }\end{array}$ & $\begin{array}{r}\text { A } \$ 872.5 \\
\text { million } \\
(2007- \\
2008)^{305} \\
\text { Plus A } \$ 80.1 \\
\text { million for } \\
\text { policing } \\
(2009)^{306}\end{array}$ \\
\hline China & $1,338,612,968$ & 6,500 & Communist State & $\begin{array}{r}\text { Est } \\
\text { US } \$ 100- \\
350 \\
\text { million }^{307}\end{array}$ \\
\hline $\begin{array}{l}\text { European } \\
\text { Union }\end{array}$ & $491,582,852$ & $\begin{array}{r}34,100 \\
(7-78,000)\end{array}$ & $\begin{array}{r}\text { Hybrid } \\
\text { intergovernmental } \\
\text { and supranational }\end{array}$ & $\begin{array}{r}€ 392 \\
\text { million } \\
(2007)^{308}\end{array}$ \\
\hline France & $64,057,792$ & 32,600 & Republic & Unknown \\
\hline Japan & $127,078,679$ & 34,500 & $\begin{array}{r}\text { Parliament with } \\
\text { Constitutional } \\
\text { Monarchy }\end{array}$ & $\begin{array}{r}\text { US } \$ 415 \\
\text { million } \\
(2007- \\
2009)^{309}\end{array}$ \\
\hline $\begin{array}{l}\text { New } \\
\text { Zealand }\end{array}$ & $4,173,460$ & 27,200 & $\begin{array}{l}\text { Parliamentary } \\
\text { Democracy }\end{array}$ & $\begin{array}{r}\mathrm{NZ} \$ 205.5 \\
\text { million }\end{array}$ \\
\hline
\end{tabular}

304 "The World Factbook,"

305 The Parliament of the Commonwealth of Australia, "Appendix C: Australia's Overseas Aid Program Budget 2007-2008," in Australia's aid program in the Pacific: Joint Standing Committee on Foreign Affairs, Defence and Trade (Canberra: Commonwealth of Australia 2007).

306 Attorney-General's Department, "AFP Training for Overseas Policing," Australian Government: Attorney-General's Department, http://www.ag.gov.au/www/agd/agd.nsf/Page/Publications_Budgets_Budget2008_MediaReleases_AF PTrainingforOverseasPolicing (accessed 24 February, 2009).

307 Zhang, "China and the emerging regional order in the South Pacific."

308 Wiepke H.E. van der Goot and Aldo H.E. Dell'Ariccia, "The European Union in the Pacific: Its role, its relationships, its contribution," in The European Union in the Pacific (Wellington, New Zealand 2008).

${ }^{309}$ Zhang, "China and the emerging regional order in the South Pacific." 


\begin{tabular}{|c|c|c|c|c|}
\hline COUNTRY & POPULATION & $\begin{array}{r}\text { GDP PER } \\
\text { CAPITA } \\
\text { (GDPPC) } \\
\text { IN US \$ }\end{array}$ & TYPE OF GOVT & $\begin{array}{r}\text { AID TO } \\
\text { THE } \\
\text { PACIFIC }\end{array}$ \\
\hline & & & & $\begin{array}{r}(2007- \\
2008)^{310}\end{array}$ \\
\hline Taiwan & $22,974,347$ & 31,500 & $\begin{array}{l}\text { Multi-party } \\
\text { Democracy }\end{array}$ & $\begin{array}{r}\text { Unknown } \\
\text { (in decline } \\
\text { as One } \\
\text { China } \\
\text { policy } \\
\text { becomes } \\
\text { effective) }\end{array}$ \\
\hline
\end{tabular}

310 Melanie Heaphy, "Making a Difference in Our Own Region," July, 20082008 Wellington: NZAID (accessed 11 December 2008). 


\section{APPENDIX FOUR: INTERVIEW SCHEDULE}

You have been involved in matters of policing in the Pacific and have gained a good understanding of how the region works. Would you consider the following questions and discuss them with me?

1. What organisation are you with and what is your role within that organisation?

2. What is your understanding of the driving force that brought together the Chiefs of Fiji, Tonga, the British Solomon Islands (now Solomon Islands), New Hebrides (now Vanuatu), Gilbert \& Ellice Islands (Kiribati \& Tuvalu), and Nauru for the first Chiefs of Police Conference in $1970 ?$

The PICP grew significantly from just seven members in 1970 to twenty-eight in 1992 (this number included the Australian state police services) and back to twenty-one in 2001.

3. In your opinion, has this regional focus on policing in the Pacific through the Conference been successful and/or useful? In what way?

Along with a growth in membership of the PICP there has also been growth in donations to Pacific Island Countries from the foreign affairs departments in Australia and New Zealand, and also from larger Pacific Rim Countries such as China, Taiwan, the US and also the European Union.

4. Are there significant differences in the expectations between PICP member and non-member donor countries? If so, how do these differences impact on policing in the region?

There are a number of regional government and non-government organisations working in law enforcement throughout the Pacific.

5. In your opinion, how well do these groups work together in providing services in the area?

6. Is there a need to strengthen relationships between NGOs and other groupings?

PICP member countries are extremely diverse, in population size, culture and economic basis.

7. How do different perceptions of power across the region impact on policing standards? What if anything could or should be done about this?

8. In your opinion what is the most important factor impacting on policing in your country? And neighbourhood? And region?

Most Pacific Island Countries' government infrastructures are based on the systems of previous colonial powers.

9. Since decolonisation have these structures been changed in any way to reflect the culture and traditions of your country? How?

10. If so, have previous colonial influences had a beneficial impact on policing in your country? Region?

11. What is your vision for policing in the Pacific? 


\section{APPENDIX FIVE: CONSENT FORM}

Research Project:

Researcher:

"POLICING THE PACIFIC: MULTINATIONAL ARRANGEMENTS"

Bronwin M BOSWELL

Tel: +6444638027

Tel: +640275762200

Email: Bronwin.Boswell@vuw.ac.nz

I, [print name] consent to participate in the research project titled "Policing the Pacific: Multinational Arrangements" The purpose of the research has been explained to me, and I have been given the opportunity to ask questions about the research and received satisfactory answers.

I permit the researcher to digitally record my interview as part of this project.

I understand that I have a choice about whether information gathered from me in the course of this research can be attributed to me by name and/or other identifying information; or, that I prefer that my name and any other identifying information remain confidential. In the case that I do wish this information to remain confidential I understand that neither my name nor any other identifying information will be used or published.

I understand that Victoria University Wellington (VUW) Human Ethics Committee and New Zealand Police have approved this research.

I understand that if I have any complaints or concerns about this research I can contact:

\begin{tabular}{|l|l|}
\hline Dr Allison Kirkman & Dr Ray Goldstein \\
\hline $\begin{array}{l}\text { Chair - Human Ethics Committee Victoria } \\
\text { University Wellington (VUW) - Kelburn Campus }\end{array}$ & $\begin{array}{l}\text { Senior Lecturer - Political Science \& International } \\
\text { Relations (VUW) - Kelburn Campus }\end{array}$ \\
\hline & Supervisor for Researcher \\
\hline Phone: 044635676 & Phone: 04 4635796 \\
\hline Email: Allison.Kirkman@vuw.ac.nz & Email: Ray.Goldstein@vuw.ac.nz \\
\hline
\end{tabular}

Signed by

Name (Printed)

Date

My name and any other identifying information are to remain confidential 